\title{
المعايير التربوية والفنية لتصميـم وإنتاج المتتوى التدريبي ببيئة الواقع المعزز
}

\author{
أ.د / خالا مصطفى محمد مالك \\ أ. د / ايمان صلاح الاين صالح \\ أستاذ تكنولوجيا التعليم \\ أستاذ تكنولوجيا التعليم ووكيل كلية التربية للدراسات \\ كلية التربية - جامعة حلوان \\ العليا والبحوث جامعة حلوان
}

\author{
سلامة عبدالعظيم محمد عبدالمجيد \\ أخصائى أول أ تكنولوجيا التعليم ورئيس قسم التطوير التكنولوبي \\ - إدارة نخل التعليمية- شمال سيناء
}

المستخلص

سعى هذا البحث إلى إعداد قائمة المعايير التربوية والفنية لتصميم وانتاج المحتوى

التدربيى ببيئة الواقع المعزز· وقد استخدم الباحثون منهج البحث الوصفى التحليلى لبحوث

تكنولوجيا التعليم فى عرض البحوث ودراستها وتحليلها لاستخلاص المعايير، قام الباحث باشتقاق قائمة مقترحة مبدئياً لمعايير لتصميم وإنتاج المحتوى التدربيى ببيئة الواقع المعزز ، ثم عرضها على السادة المحكمين عددهم (9) (19) من متخصصى المناهج وطرق التدريس وتكنولوجيا التعليم، وتوصل إلى قائمة المعايير النهائية التى يمكن استخدامها فى تصميم محتوى تذربي بيئة الواقع المعزز •

الكلمات المفتاحية: الواقع المعزز، المحتوى التدريبي ، معايير تصميم بيئة الواقع المعزز

\section{Abstract}

This research sought to prepare a list of educational and technical standards for the design and production of training content in the augmented reality environment. The researchers used the descriptive analytical research methodology for educational technology research to present research, study and analyze it to extract the criteria. The researcher derived a preliminary proposed list of criteria for designing and producing training content in the augmented reality environment, then presented it to the (19) arbitrators who specialize in curricula, teaching methods and education technology. It reached a list of the final criteria that can be used in designing training content in the augmented reality environment.

Keywords: Augmented Reality, Training content, Augmented Reality environment design standards. 
يواجه العالم اليوم في القرن الحادي والعشرين مجموعة من التحولات والتحديات السريعة

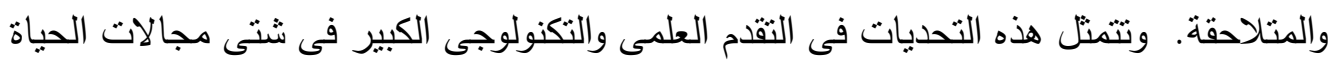

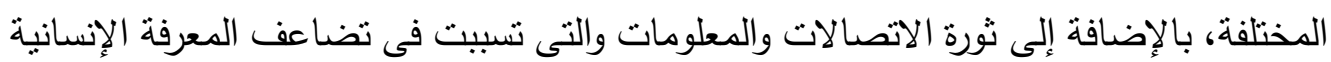

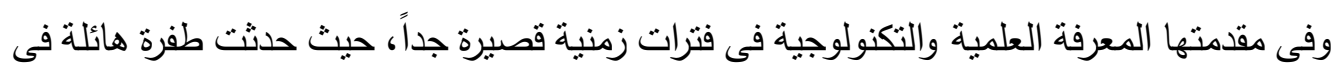
مجال تكنولوجيا الأقمار الصناعية، والوسائط المتعددة، وشبكة الانترنت. وقد أظهرت الثورة اللاسلكية والصناعية والتطور التقني الحديث واقعا جديدا له القدرة على النواصل من خلال شبكة الانترنت؛ وهو تقنية الواقع المعزز (Augmented Reality) الذي بدأ

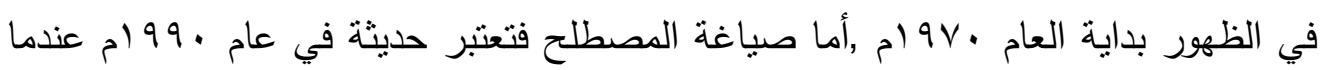

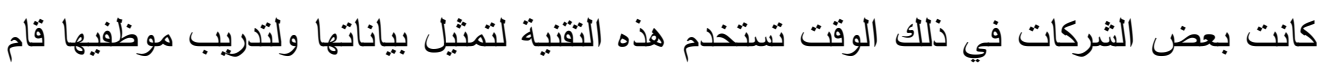
باحث في شركة بوينغ بإطلاق مصطلح " الواقع المعزز "على شاشتة عرض رقمية كانت نرشد التش

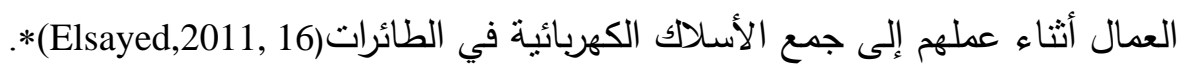
وتعتبر تكنولوجيا الواقع المعزز (Augmented Reality) من المفاهيم المعاصرة والهامة

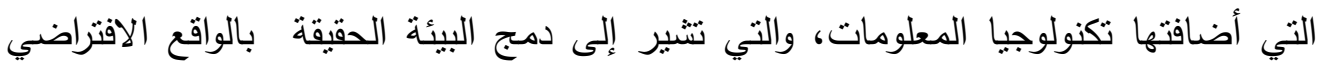

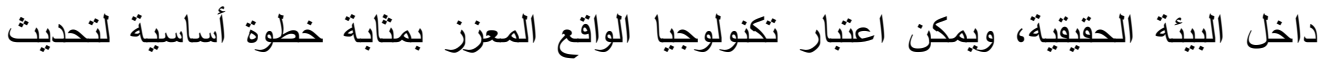

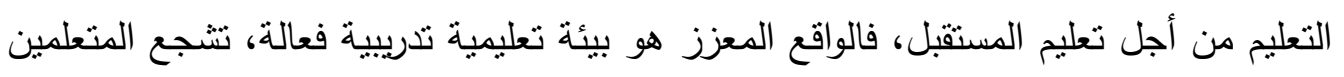
والمتدربين على التساؤل حول الحقائق العلمية والمفاهيم الواقعية والتخيلية.

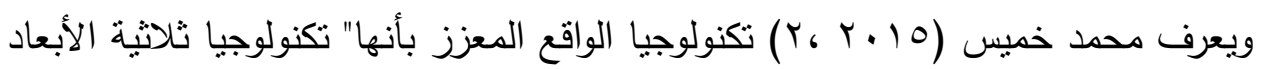

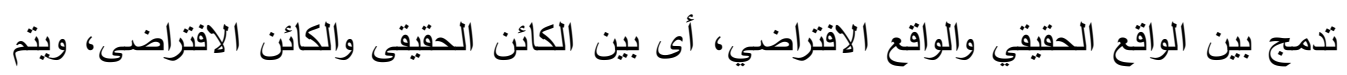

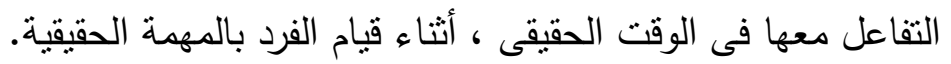

ويعرفه كل من يوين ويايونياجوجنسون( Yuen, Yaoyuneyong \& Johnson,2011, 120 ) بأنه " شكل من أثنكال التقنية التى تعزز العالم الحقبقى من خلال المحتوى الذى ينتجه الحاسب

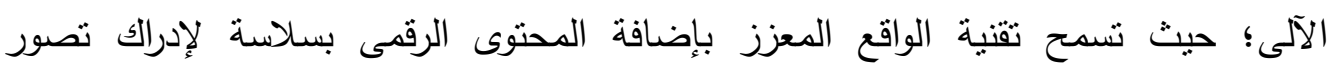

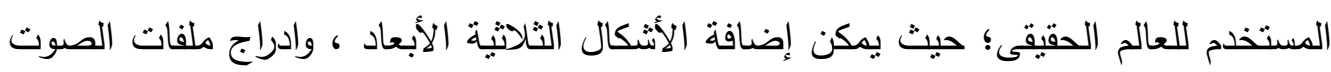

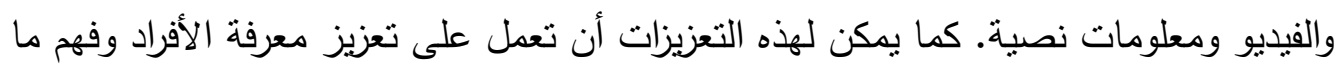
يجرى من حولهم". 


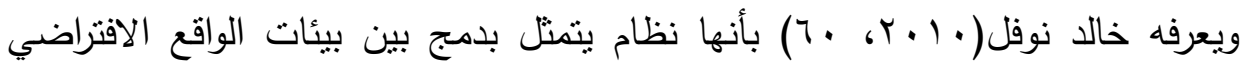

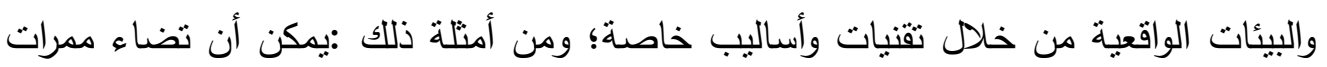
الهبوط أمام الطائرات في المطارات الحقيقية، أو أن يرى الجراحون معلومات افتراضية أثناء إجرا ء الجراحة فعلياً نوضح له الأماكن التي يجب استثئصالها بالفعل.

ويتضح من هذه التعريفات فكرة الواقع المعزز Augmented Reality وهى عبارة عن بيئة تعلم تجمع بين العالم الحقيقى والعالم الافتراضى الذى يضم رسوماً وصوراً بانورامية ثلاثية

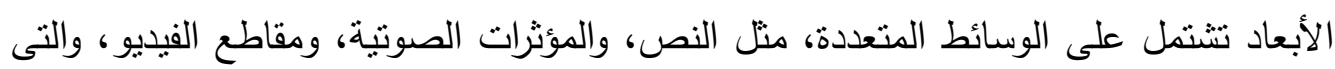

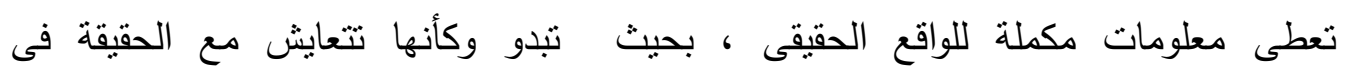
نفس المكان.

فالواقع المعزز يختلف تمامًا عن الواقع الافتراضى وهذا ما أكده كل من( احمد سالم،

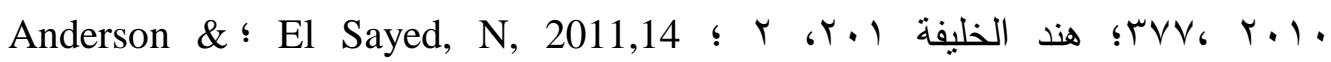
Y Liarokapis, 2014, 2

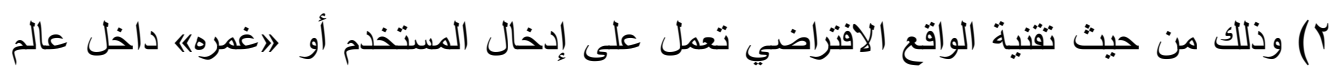
افتراضي آخر عبر أداة تلبس على الرأس أو نظارة معينة، وتعزله عن العالم الخارجي، بينما

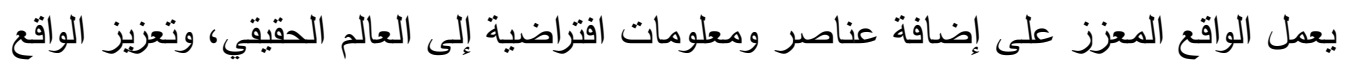
عبر نظارة مخصصة.

حيث جاء الواقع المعزز تطويرا للواقع الافتراضى؛ يأخذ شكل المحتوى؛ ويتطلب برامج

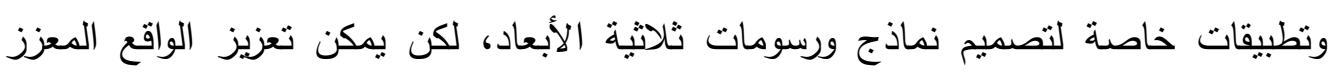

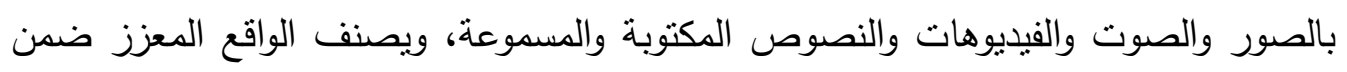
بيئات التعلم الافتراضية.

ويؤكد ديننج وآخرون (Denning, T., et al. 2014) أن تقنية الواقع المعزز تعتبر من أكثر تطبيقات التعلم الافتراضية من الناحية الاجرائية. حيث يهدف إلى تكرار البيئة الحقيقية

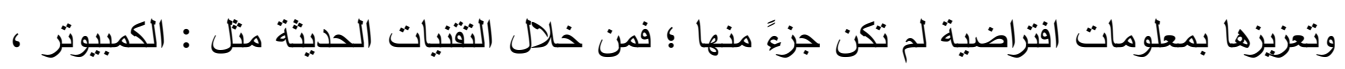
والأجهزة اللوحية، والهواتف الذكية حيث يتم تعزيز المشهد الحقيقى بمعارف إثرائية افتراضية. 
كما أكدت عديد من الدراسات منها تشانج وآخرون(Chiang, T, et al.2014؛

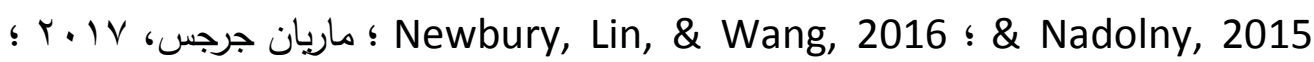

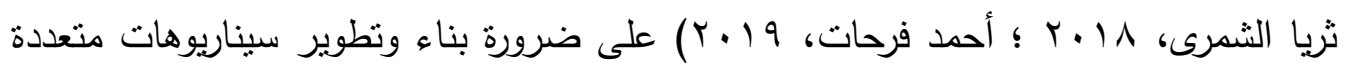
لتوظيف تكنولوجيا الواقع المعزز فى التعليم والتعلم، والتى يمكن أن تعمل على تحسين

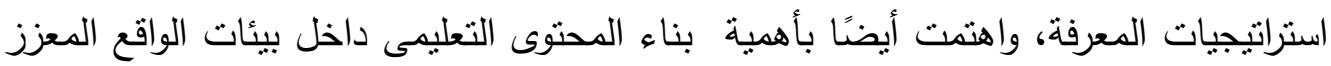

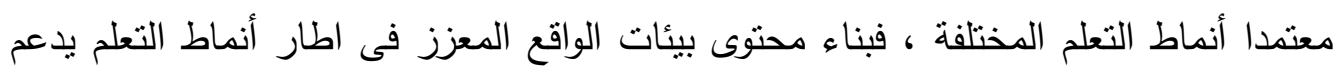
عملية تدريب المعلمين داخل بيئة التعلم الإكترونى.

ويعد تقديم المحتوى التدريبى أيضا أحد المتغيرات الأساسية فى تصميم وتطوير البرامج، ولما لبيئات الواقع المعزز عبر الهواتف الذكية من أهمية في التدريب، يحاول البحث الحالي تحديد قائمة المعايير التربوية والفنية اللازمة لإعداد محتوى تدريبى بييئة الواقع المعزز .

\section{مشكلة البحث}

نلاحظ فى الأونة الأخيرة حدوث قفزات هائلة في التكنولوجيا حتى أنها تبدو غير ممكنة إلا في عالم الخيال العلمي ومن هذه التكنولوجيا تقنية الواقع المعزز (Augmented Reality) حيث لا يمكن لأحد أن يتوقع أن تكون نظارة جوجل الذكية ظاهرة منتشرة في ثقافة المستقبل

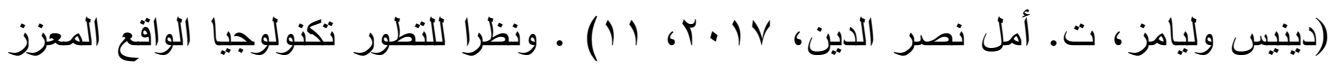

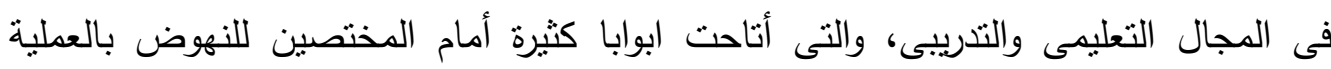

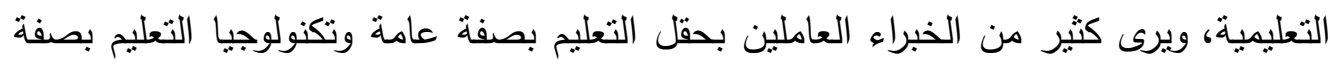

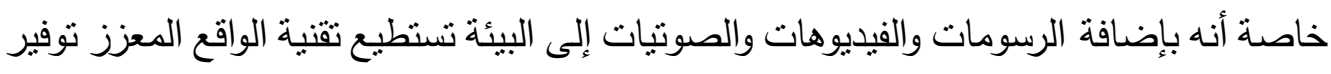

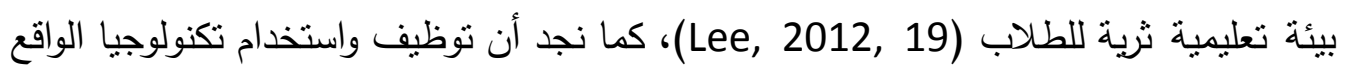
المعزز القائم على التعلم النقال فى العملية التعليمية فى تزايد مستمر وأنه يمكن أن يكون فعالا

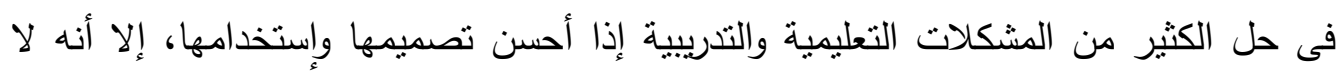

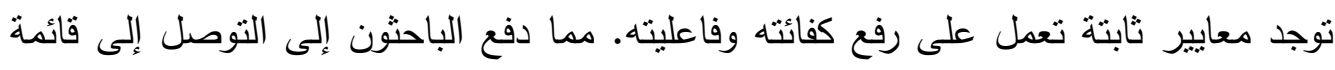
من المعايير التربوية والفنية لتصميم محتوى بيئة الواقع المعزز القائم على التعلم النقال. أوصت العديد من المؤتمرات الداعمة للمشكلة ومن هذه المؤتمرات : المؤتمر الدولى

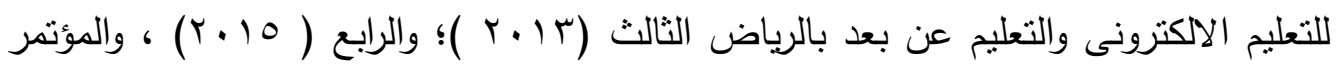

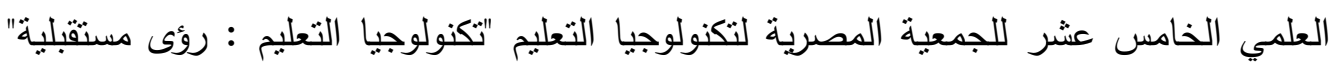


(10 • (Y)، والمؤتمر العلمي لكلية الدراسات العليا للتربية جامعة القاهرة بالتعاون مع الجمعية

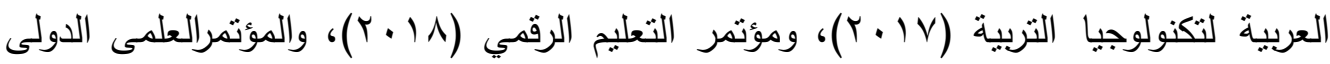

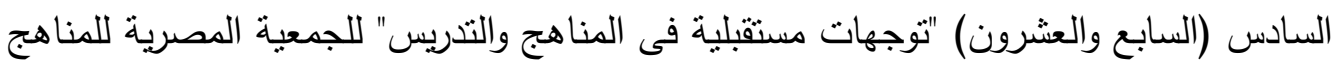
وطرق التدريس (9 (ب))، وقد أوصت هذه المؤتمرات بضرورة اعداد وتدريب اعضاء هيئة

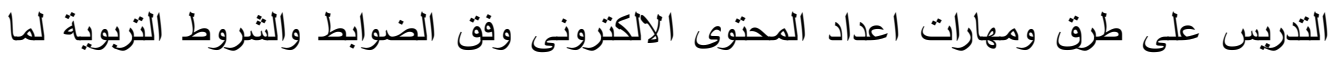
يضمن جودة التعليم.وبضرورة تطوير وتصميم بيئات تعلم الكترونية تفاعلية وتوظيفها بما

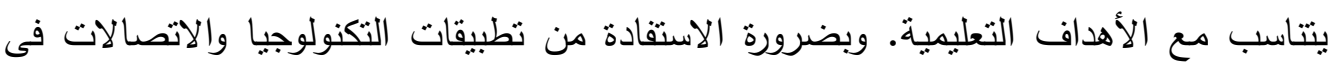
تحسين جودة العملية التعليمية. ولا شك أن تقنية الواقع المُعزز من المستحدثات التقنية في الوقت الحالي التي تساعد على التى تطوير العملية التعليمية واكتساب المعرفة بصورة أسرع من خلال إنتاج مقطع صوتي أو أو فيديو وربطه بنص أو صورة بطريقة توضح المفهوم الأساسي وتساعد على ترتيب الأفكار وسرعة التعلم

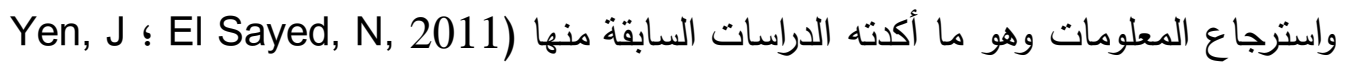
Y. I Wang, S, 2014 ؛ Hou, et al. 2013 ؛ \& Tsai, C, 2013

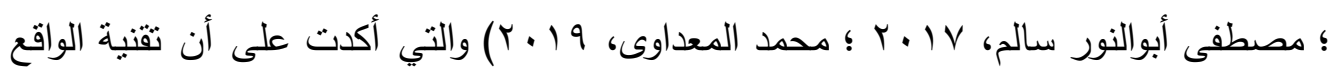

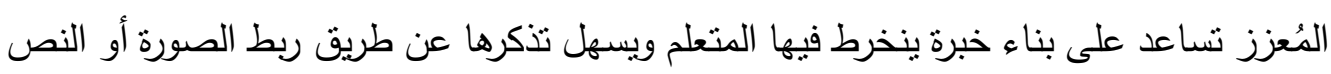

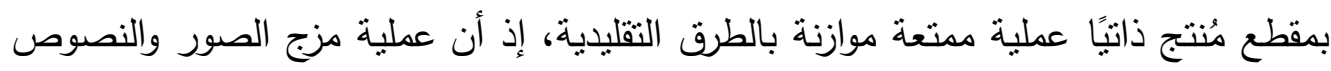

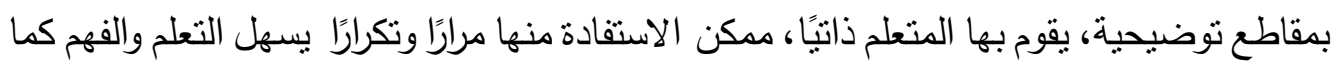

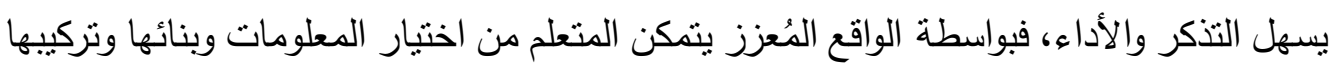

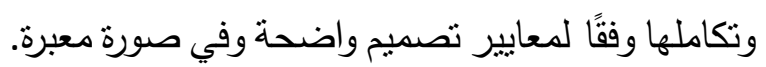

وعلى الرغم من الأهمية الكبرى لتوظيف تقنية الواقع المُعزز في العملية التعليمية بمختلف جوانبها، إلى أن الباحثين لاحظوا ندرة الدراسات التي تتاولت نوظيف تصميم الواقع المُعزز كثقنية لخدمة الأهداف والمواقف التدريبية بناء على معايير مُعتمدة، وأن تصميم وإنتاج المحتوى التنريبي

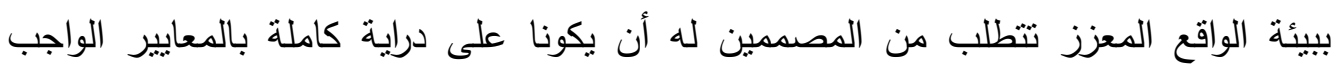

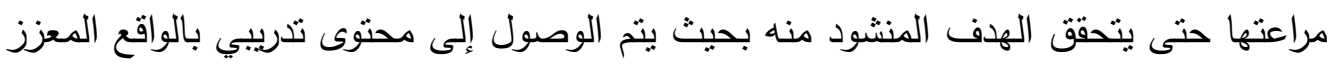

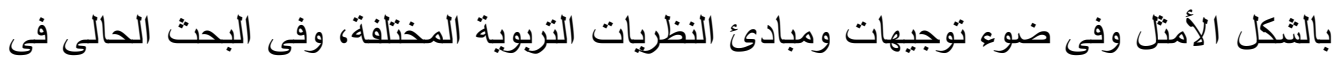
صدد محاولة تقصى المعايير التربوية والفنية اللازمة لتصميم محتوى تدريبي بيئة الواقع المعزز يحقق الهدف المنشود منه بفاعلية. 
ويحاول البحث الحالى الاجابة على السؤال الرئيس التالي: ما المعايير التريوية والفنية

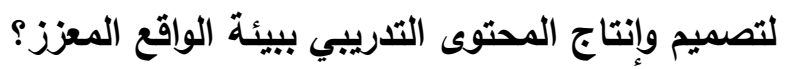

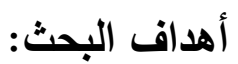

يهدف البحث الحالى إلى تحديد المعايير التربوية والفنية لتصميم وإنتاج المحتوى التدريبي بييئة الواقع المعزز بما يؤدي إلي رفع كفاءة بيئات الواقع المعزز وزيادة فاعليته عند تصميم وبناء البرامج التدريبية التربوية.

\section{أهمية البحث تبرز أهمية هذا البحث في: البحث}

التوصل الى قائمة معايير تصميم وبناء المحتوى التدريبي، والتي يمكن الاعتماد عليها عند بناء وتصميم بيئات الواقع المعزز .

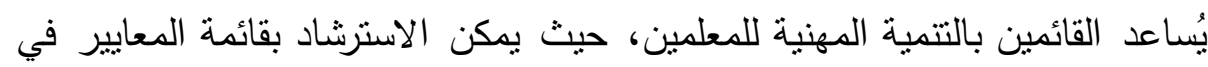

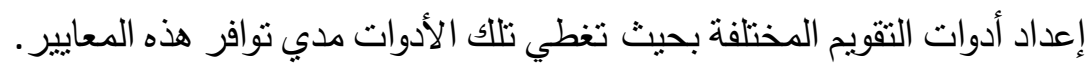

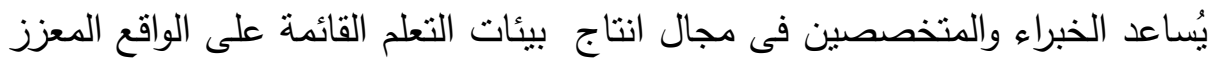

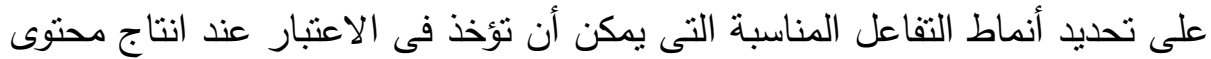

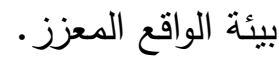

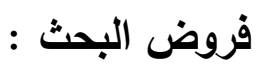
يفترض البحث الحالى أنه بالإمكان تحديد معايير تربوية وفنية حديثة وشاملة لإنتاج محتوى تدريبي بييئة الواقع المعزز . حدود البحث : اقتصر هذا البحث الحالي على استخلاص المعايير التربوية والفنية اللازمة لانتاج المحتوى التدرييي ببيئة الواقع المعزز من الادبيات والدراسات والبحوث والمعايير العالمية

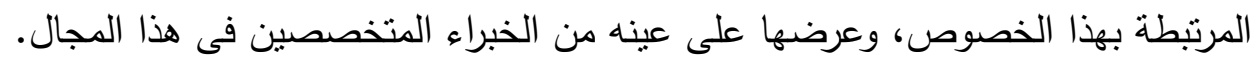

$$
\text { منهج البحث : }
$$

يتبع البحث الحالى المنهج الوصفى، وذللك لتحليل الكتابات فى الإطار النظرى والدراسات

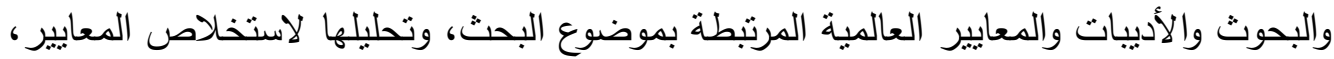

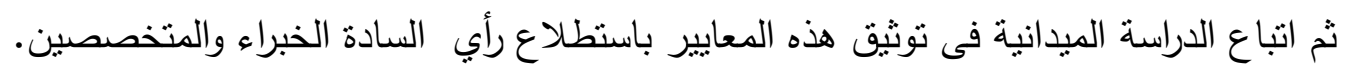
أدوات البحث : قائمة المعايير التربوية والفنية لانتاج بيئات الواقع لمعزز التدريبية (إعداد الباحث) 


\section{اتبع الباحث الخطوات التالية:}

أولاً: دراسة وتحليل الأدبيات والدراسات السابقة التى تتاولت معايير تصميم بيئات التعلم النقال بصفة عامة ومحتوى بيئة الواقع المعزز خاصة.

ثانيًا : إعداد قائمة بمعايير تصميم المحتوى التدريبى بييئة الواقع المعزز عن طريق: ( ) تجميع المعايير المستخلصة وتصنيفها منطقياً، ووضع المؤشرات الخاصة بكل معيار . r) إعداد الصيغة المبدئية لقائمة المعايير وعرضها على السادة المحكمين فى صورة استطلاع رأى. r) تعديل هذه الصيغة المبدئية ، في ضوء آراء المحكمين وملاحظاتهم ومقترحاتهم. ء) إعداد الصورة النهائية لقائمة المعايير الخاصة بتصميم المحتوى التدريبى بييئة الواقع المعزز ثالثًا : : عرض نتائج البحث. رابعًا : التوصيات والمقترحات. مصطلحات البحث :

"المعايير"هي مجموعة من الإجراءات التي يهدف تبنيها وتتفيذها إلى تحقيق أقصي درجة من

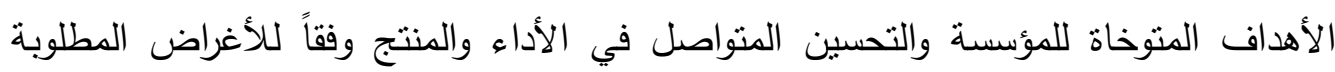
والمصفوفات المنشودة بأفضل طرق وأقل جه وتكلفة ممكنين (حسن حسين البيلاوي وآخرون،

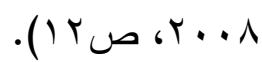
وتعرف إجرائياً في البحث الحالى: بأنها"مجموعة من العبارات أو الجمل التي يستتد إليها

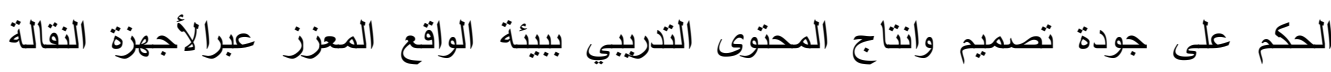
(اللوحية أو هواتف ذكية)".

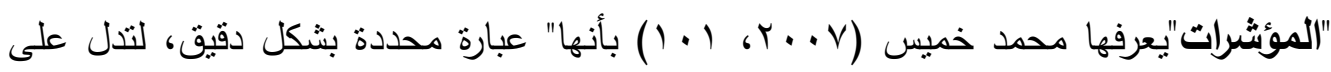
إلى مدى يتوفر المعيار فى هذا الثئي". وتعرف إجرائياً في البحث الحالى: بأنها" مجموعة من العبارات التى نصف بدقة أكثر

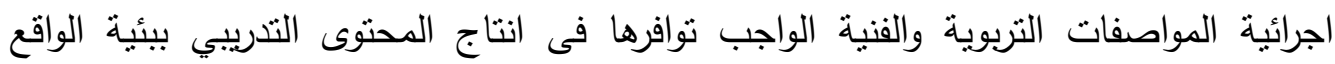
المعزز لتحقيق المعايير وفقًا للمجال الذى تتنمى إليه". "الواقع المعزز"يعرفه كل من يوين ويايونياج وجنسون () \&uen,Yaoyuneyong (Johnson,2011, 120 
المحتوى الذى ينتجه الحاسب الآلى ؛ حيث تسمح ثقنية الواقع المعزز بإضافة المحتوى الرقمى

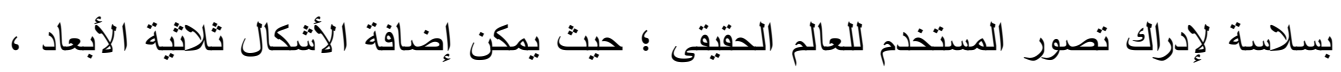

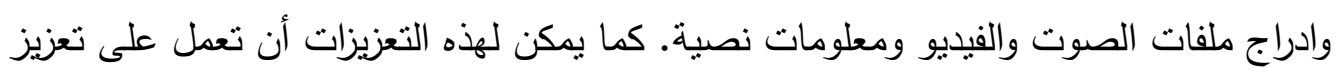
معرفة الأفراد وفهم ما يجرى من حولهم". ويعرف إجرائياً في البحث الحالى: بأنه "دمج العالم الحقيقى بالعالم الافتراضى بواسطة

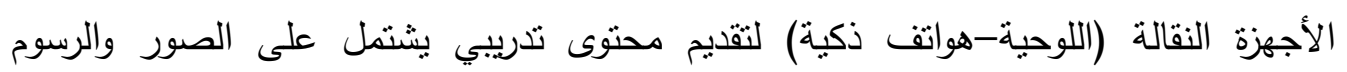
والفيديو الثلاثية الأبعاد مع ادراج ملفات صوت ومعلومات نصية، والتى تعطى معلومات مكلة

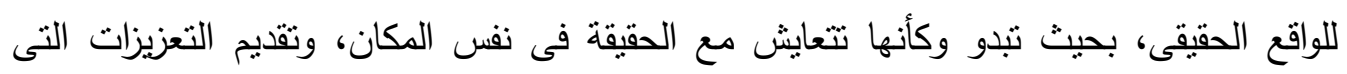
تعمل على تعزيز معرفة المتدربين وتتمية مهاراتهم ورفع كفائته".

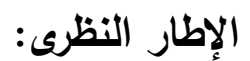

يعتمد الإطار النظري للبحث الحالي على ثلاث محاور رئيسية، حيث يتتاول المحور

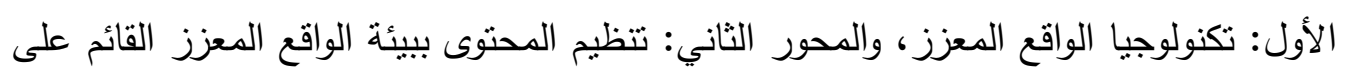
التعلم المتتقل، ثم المحور الثالث: يتتاول معايير تصميم المحتوى ببيئة الواقع المعزز القائمة

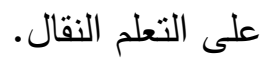

المحور الأول : تكنولوجيا الواقع المعزز:

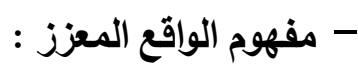

هناك عدة أساليب لتدريب المعلمون وتدريبهم فيما يحتاجونه من معلومات ومهارات، وتتشمل

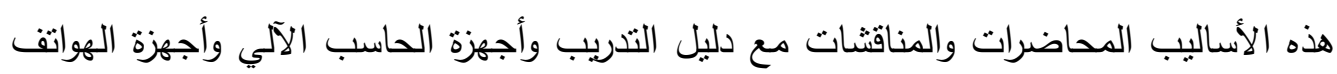

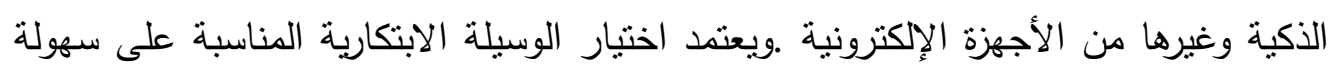
وصول المستخدم إلى التقنيات المختلفة وقوة البنية التحتية، وفي عصر بتميز بالنطور السريع، ولئل

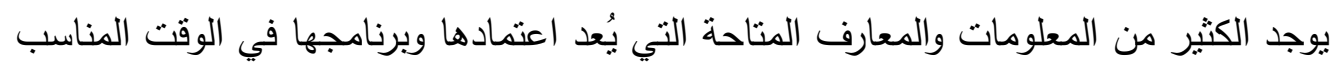

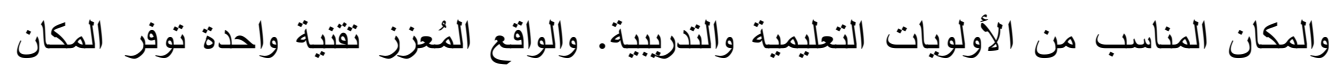
والتوقيت المناسبين للحصول على هذه المعلومات والمعارف (Lee, 2012).

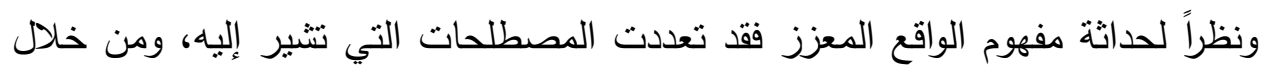

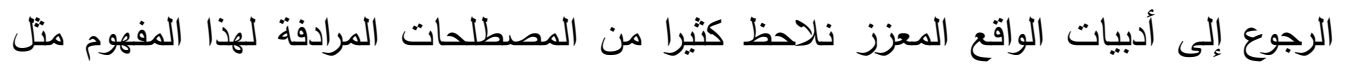

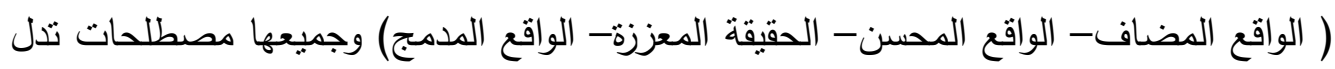


على الواقع المعزز، والسبب في اختلاف الألفاظ طبيعة الترجمة لمصطلح الواقع المعزز باللغة الإنجليزية(Augmented Reality)، وسنعرض فيما يلي أبرز التعريفات لمفهوم الواقع المعزز : ويعرف دونيليفي وديدي (Dunleavy\&Dede,2006,7) الواقع المعزز بأنه:" مصطلح يصف التقنية التي تسمح بمزج واقعي منزامن لمحتوى رقمي من البرمجيات والكائنات الحاسوبية باتهية

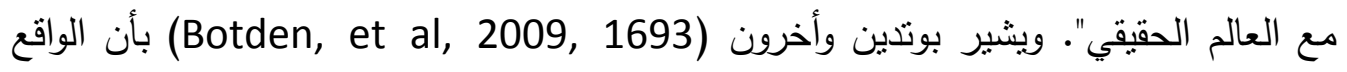

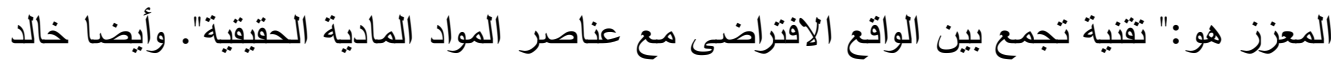

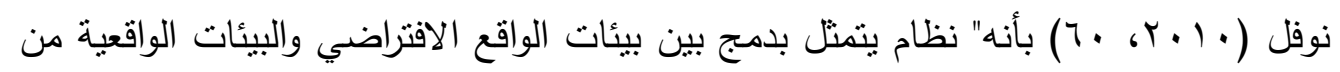

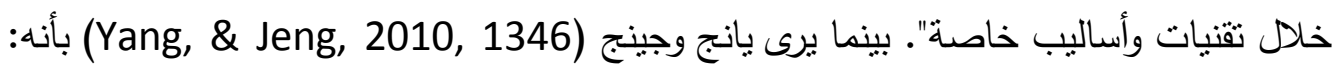

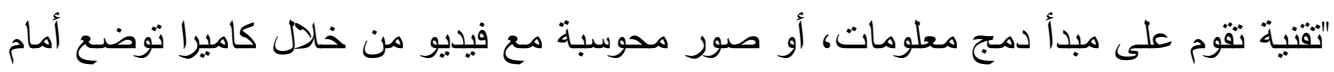

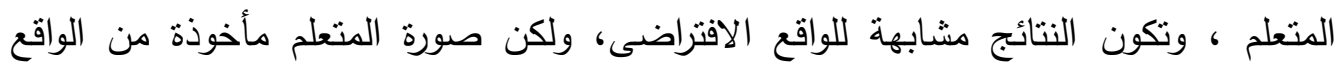
الحقيقى". وعرفه لارسن وأخرون (Larsen,et al,2011, 41) بأنه: "إضافة بيانات رقمية منافية وتركيبها وتصويرها واستخدام طرق رقمية للواقع الحقيقي للبيئة المحيطة بالإنسان، ومن منظور

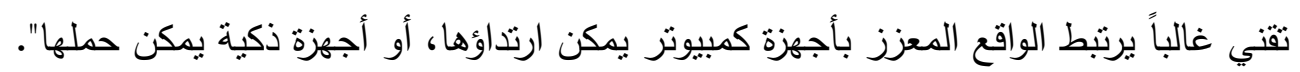
ويرى غلوكنر وآخرون (Glockner, et al, 2014, 3) أنها توسع في الواقع الحقيقي من خلال إضافة طبقات من معلومات مولدة باستخدام الحاسب الالى الى البيئة الحقيقية، وهذه

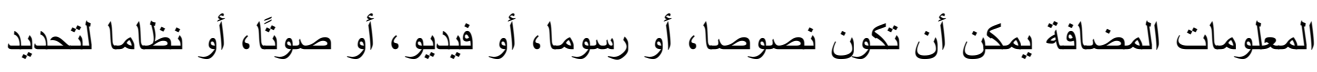

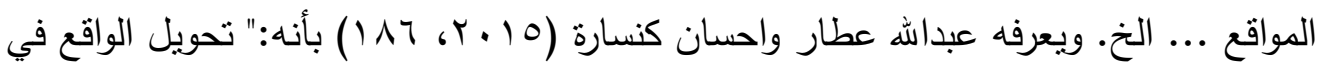
العالم الحقيقي إلى بيانات رقمية وتركيبها وتصويرها باستخدام طرق عرض رقدية تعكس الواقع

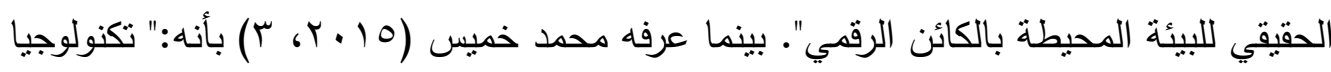
ثلاثية الأبعاد تدمج بين الواقع الحقيقى والواقع الافتراضى، أى بين الكائن الحقيقى والكائن

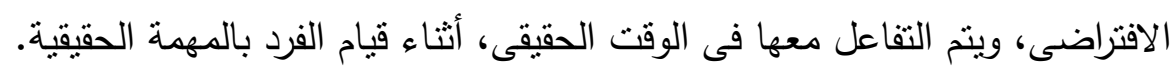

ونستخلص من هذه التعريفات أن الواقع المعزز : تقتية تسمح بمزج واقعي منزامن لمحتوى رقمي. • تقنية تفاعلية تستخدم الأجهزة السلكية والاسلكية. استخدام طرق رقمية للواقع الحقيقي للبيئة المحيطة بالإنسان. يرتبط الواقع المعزز بأجزة الكمبيوتر أو أجهزة ذكية يمكن حملها. 
المحتوى الرقمى للاقع الحقيقى عبارة عن (صور افتراضية - مقاطع فيديو - رسوم تفاعلية ثلاثية الأبعاد).

يعرض المحتوى الرقمى على شاثات الأجزة الذكية والهواتف النقالة. يدمج بين الواقع الحقيقى والواقع الافتراضى فى الوقت نفسه لتحفيق هدف معين.

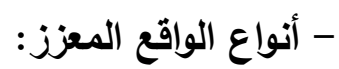

نوجد عدة أنواع للواقع المعزز تتاولتها بعض اللأدبيات والدراسات السابقة ومنها (Dunleavy, \& Dede, 2014, 4)؛ (Scheinerman, 2009, 9)

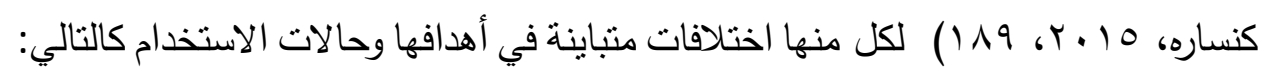
- الواقع المُعزز المعتمد على العلامات (Marker Based Augmented Reality) وتستتد البرامج التي تقوم على هذا النوع غالبًا على التكنولوجيا مفتوحة المصدر وتستخدم كاميرا وعلامة بصرية لتحديد المركز والتوجه ومجموعة من نظام الاحداثيات الكروية .

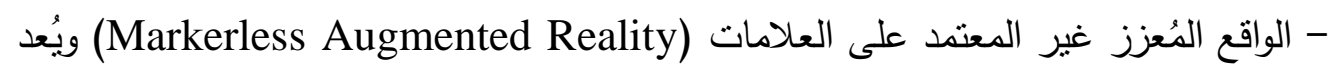
حاليًا من أفضل تكنولوجيا التتبع، إذ يقوم بتتفيذ مجموعة من التتبعات النشطة والتي تتعرف

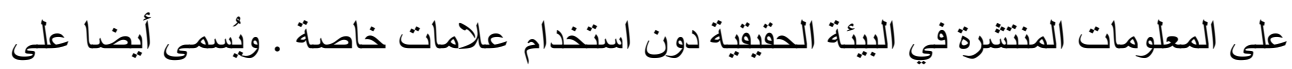
أساس الموقع، القائم على الموقف، ويستخدم نظام تحديد المواقع، البوصلة الرقمية، عداد السرعة، أو التسارع الذي هو جزء لا يتجزأ في الجهاز لتوفير البيانات استتادًا إلى موقعك، مثل التل

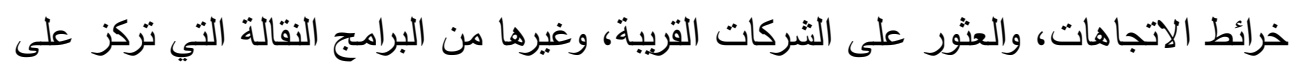

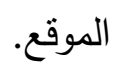
- الاسقاط القائم على الواقع المُعزز (Projection Based Augmented Reality) وهو : أكثر أنواع الواقع المعزز شيوعا، ويعتمد على استخدام الصور الاصطناعية كإسقاطها على

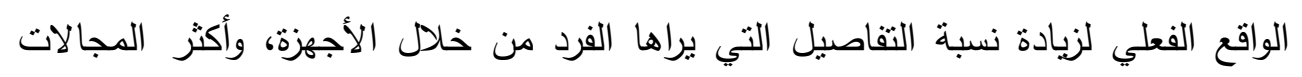

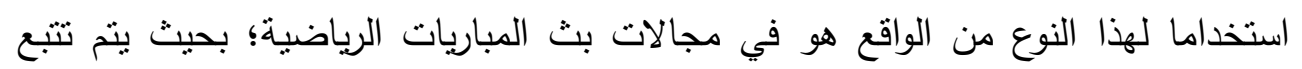

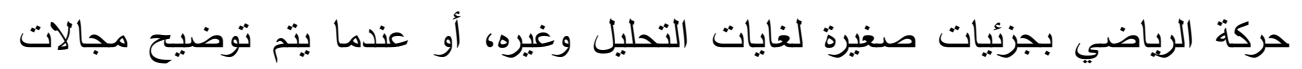

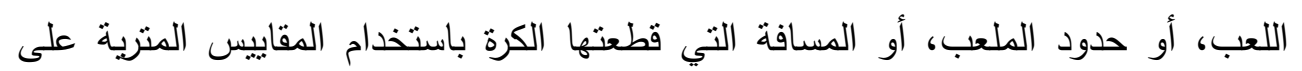

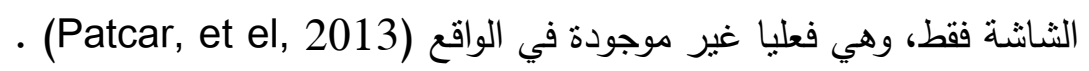
- المخطط (Outline): المخطط هو طريقة دمج بين الواقع المعزز والواقع الافتراضي، وهو

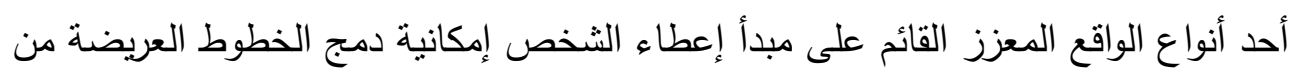


جسمه، أو أي جزء مختار من جسمه مع جسم آخر افتراضي، مما يعطي الفرصة للتعامل،

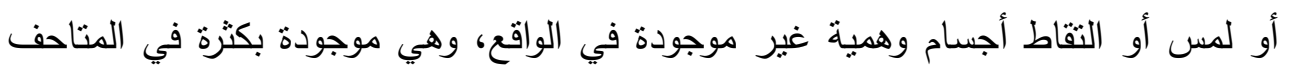

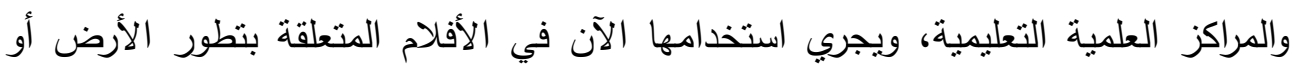
الحقب الزمنية القديمة؛ بحيث ينم دمج مخلوقات منقرضة أو أسطورية مع وجود الإنسان الفعلي(Vincent, et al, 2013).

\section{- الفرق بين الواقع المعزز والواقع الإفتراضي:}

الواقع الافتراضي هو واقع اصطناعي Artificial ثلاثي الأبعاد مولد بالكمبيوتر ، يشيرإلى

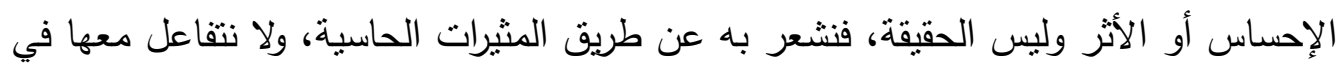

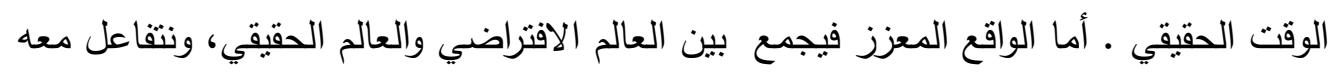

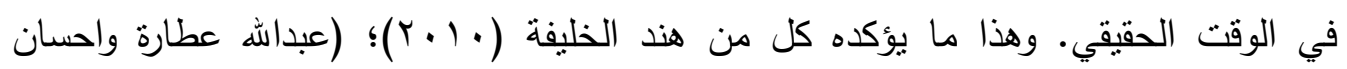

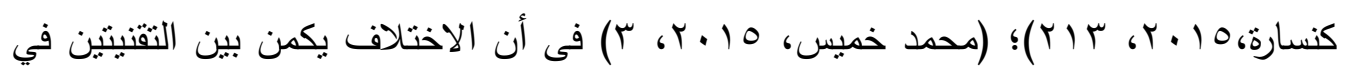

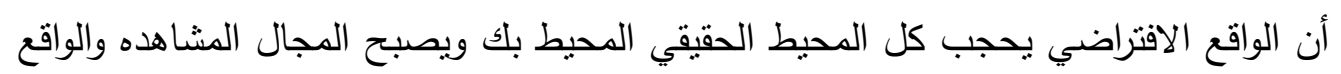
الافتراضي فقط وذللك من خلال النظارات (جهاز العرض ) ، فالجهاز يزود المستخدم بصور

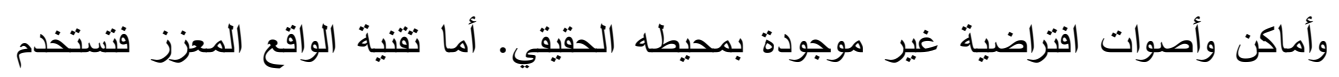

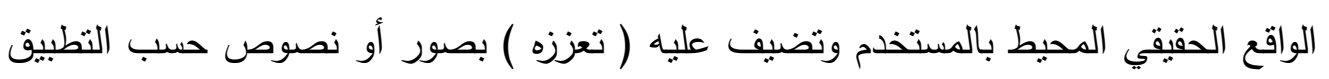
المستخدمة لأجله التقنية.

\section{ويمكن تصنيف اتجاهات برامج الواقع المُعزز على النحو التالي، (Yuen,2011):}

التعلم القائم على الاستكثاف (Discovery-based Learning) وهو: تعلم يتم فيه

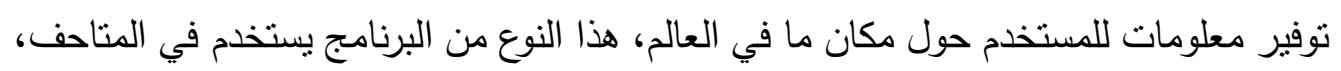
وفي التعليم الفلكي، وفي الأماكن التاريخية.

نمذجة الكائنات (Objects Modeling) وهو: تعلم يسمح للطلاب بتصميم الكائنات

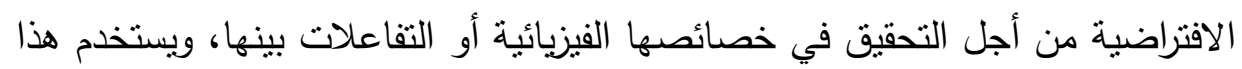

$$
\text { النوع من البرامج أيضا في التعليم المعماري. }
$$

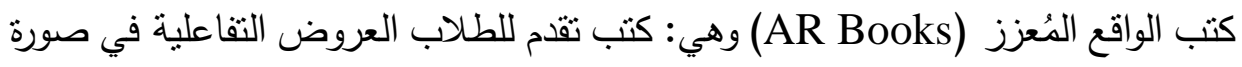

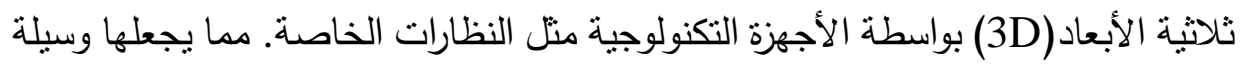
تعليمية مناسبة لجميع المراحل الدراسية والعمرية. 
• التدريب على المهارات (Skills Training) ويتم فيه ندريب المستخدمين على مهارات

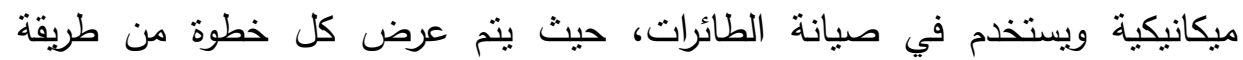

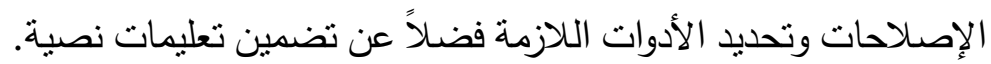

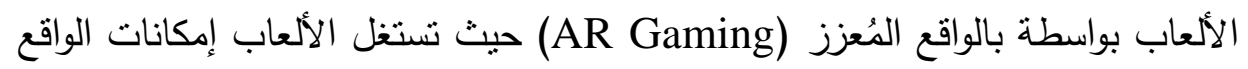
المُعزز لزيادة تفاعل الطلاب مع المحتوى في البيئات التعليمية.

وقد أثنتت كثثر من الأدبيات منها(Ivanova\&Ivanov,2011,178-179)؛ ( ) و Diegmann, ) (Anderson, \& Liarokapis,2014,2)؛(Wang, 2012)؛(2012, 19 Schmidt-Kraepelin, Eynden \& Basten, 2015

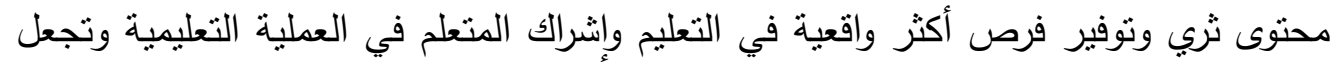

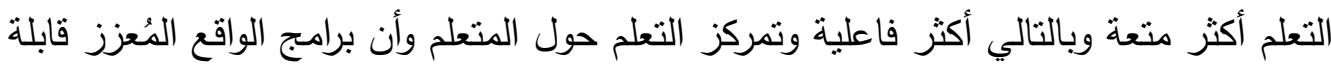
للاستخدام في البيئات التعليمية وأكدت فاعليته في زيادة الدافعية للتعلم وتوصلت إلى مدئل ميزات الواقع المُعزز وفوائده في العملية التعليمية كالتالي:

(Increased Motivation) زيادة الدافعية ل جذب الانتباه (Increased Attention). (Increased Concentration) زيادة التركيز

زيادة الرضا (Increased Satisfaction) زيادة

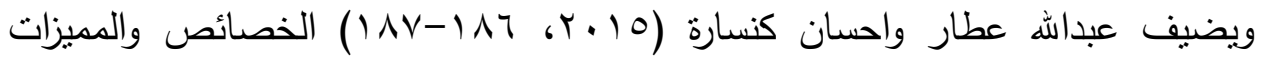

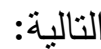
1 - نتفيذ التقنية من خلال حلول بسيطة، مثل جهاز كمبيوتر محمول أو جهاز هاتف محمول. r - الجمع بين أثنياء حقبقية وافتراضية. r - ربط مجالات مختلفة مع بعضها البعض، مثل : التعليم والترفية، اختبار المنتج المناسب قبل

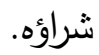

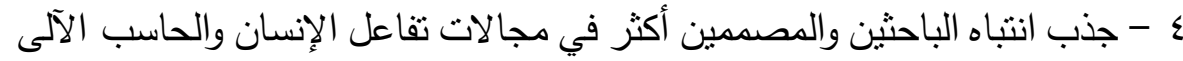

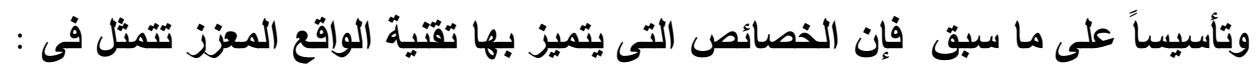

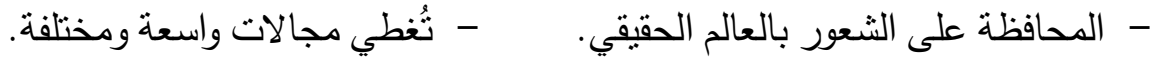

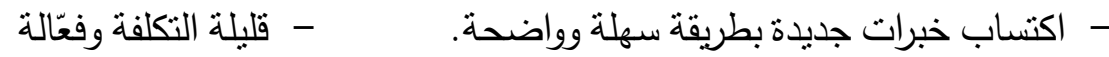
- فهم أكثر للحقائق والأشياء المحسوسة والعلاقات. 
ويتضح من خصائص الواقع المعزز أنها تخدم العملية التعليمية فى جميع جوانبها، مما يجعل الواقع المعزز هو الأفضل فى المستقبل، مما يدفع الى توظيف تقنية الواقع المعزز

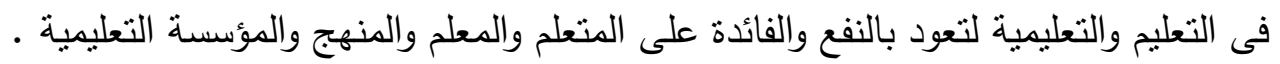

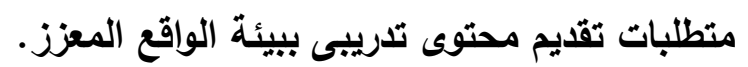

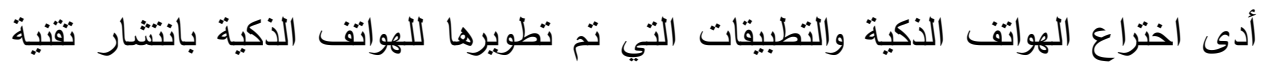
الواقع المعزز) (AR ) مما سمح للمستخدم لعرض العالم من خلال كاميرات هواتفهم النقالة

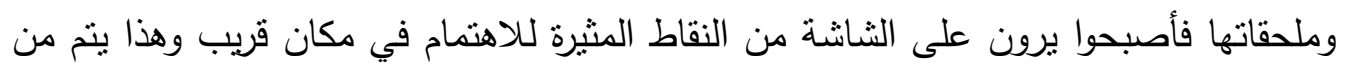

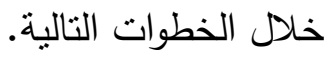
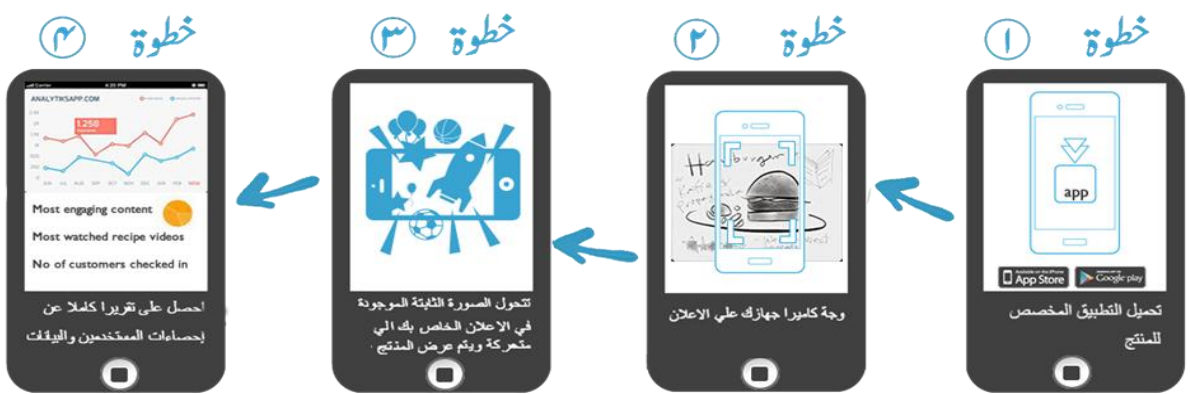

شكل (1) خطوات استخدام الهاتف فى الواقع المعزز

" الخطوة الأولى : تحميل التطبيق المناسب من خلا المتجر مثل تطبيق اورزما (HP Reval) الخطوة الثانية : يتم توجيه كاميرا الهاتف الى العلامة (صورة / رمز).

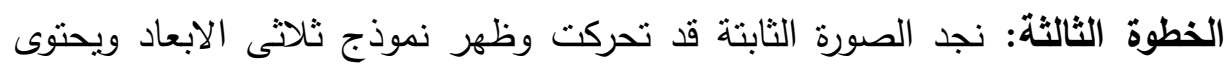
على معلومات اضافية اخرى على شاشة الهاتف.

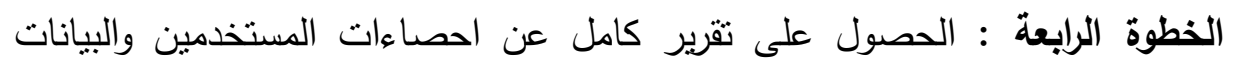

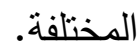
وفي كل المجالات التعليمية أو التدريبية بشكل عام وفي مجال تكنولوجيا التعليم تحديدًا،

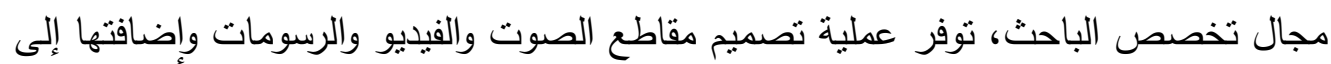

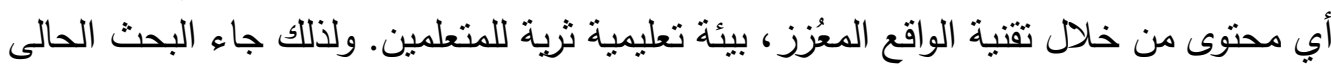

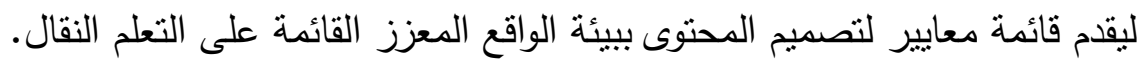
المحور الثانى : تنظيم المحتوى ببيئة الواقع المعزز القائم على التعلم المتنقل.

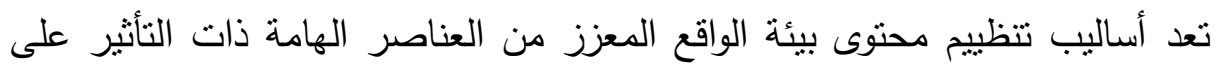

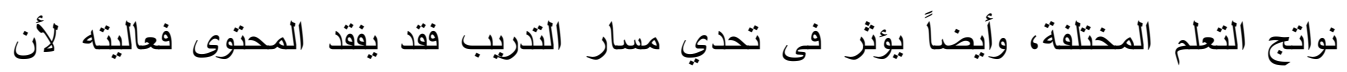


تتظيمه أو أسلوب تقديمه وعرضه هما اللذان يجعلان التدريب صعباً، وفى هذا البحث يقدم

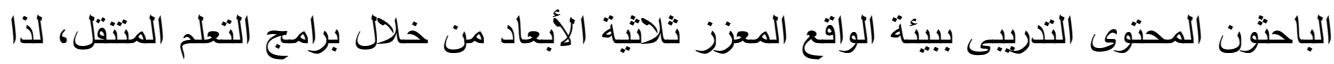

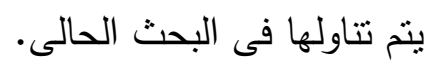

- أهمية تنظيم محتوى بيئة الواقع المعزز القائمة على برامج التدريب المتنقل:

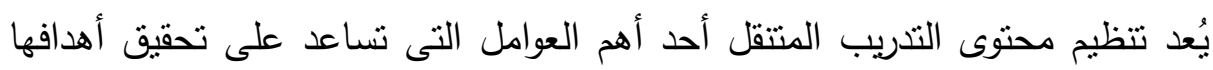

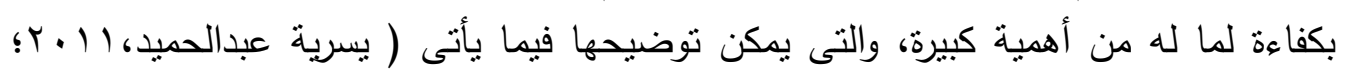

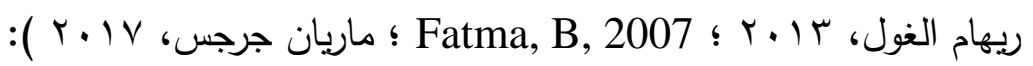

م يتم تتظيم المحتوى وفق نظريات التعليم والتعلم مما يساعد فى تحسين العملية التعليمية. م يحقق التتظيم الجيد للمحتوى مستوى منقدم من التفاعل سواء كان تفاعل اجتماعى أو شخصى. O يساعد تتظيم المحتوى على تتظيم المعرفه لدى المتعلم، وينعكس ذلك على تذكر هذه

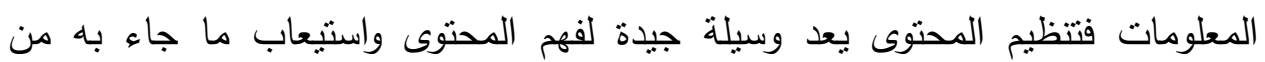
معلومات. م بساعد على اكتساب الخبرات المتتوعة وبقاء أثر التعلم لفترات طويلة حيث يعد نتظيم

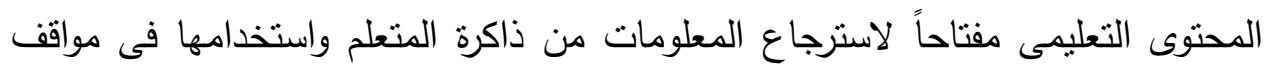
الحياة المختلفة.

م يحقق تتظيم المحتوى اختصار فى الوقت، وتوفير الجهد، وتحسين جودة التعليم.

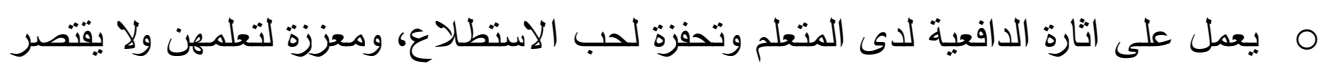
النفع على المتعلم فقط، بل يشمل جميع المشتركين فى تحقيق الأهداف التعليمية.

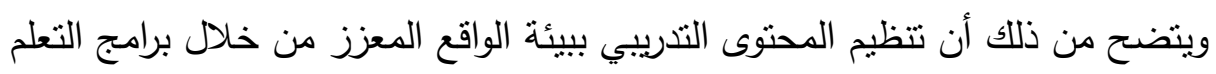
المنتقل من أهم المعايير قابليتها للاستخدام. - أساليب تنظيم محتوى بيئة الواقع المعزز القائمة على التعلم المتنقل:

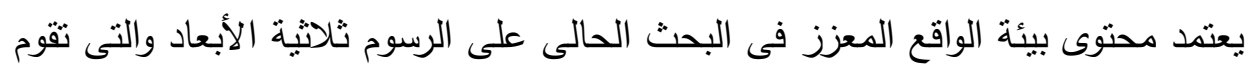
بدور أساسى فى عملية التعلم، حيث تعد الرسوم ثلاثية الأبعاد التعليمية (التدريبية) من الوسائل التئل

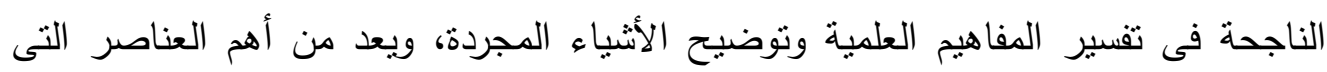
تؤثر فى إعدادها وتصميهما طرق عرض هذه النماذج داخل البيئة التدريبية بالواقع المعزز فهناك طرق عدة لعرضها، منها: أ) أنماط عرض عاد لمرضها، منها: المحتوى بناءً على خصائص المتعلمين. ب) أنماط العرض في ضوء نظريات التعليم والتعلم: 
أ) أنماط العرض بناءاً على خصائص المتعلمين: تتعدد أساليب تتظيم محتوى برامج التعلم المتتقل والتى يمكن من خلالها مراعاة خصائص

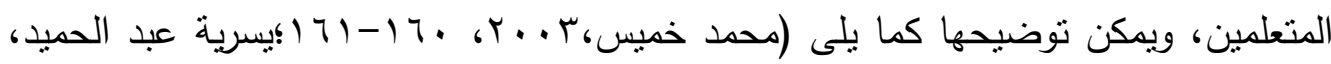

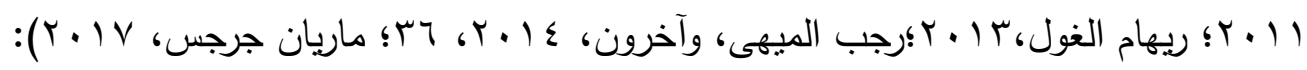
الأسلوب الخطى ذى المسار الدائرى: يعد هذا الأسلوب من أبسط اساليب تتظيم المحتوى

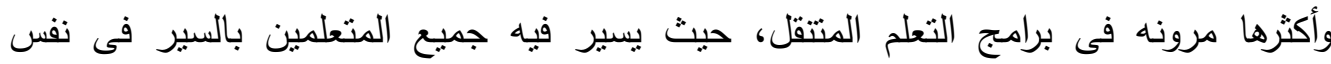

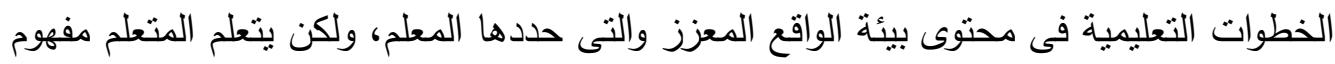
ما فلابد من المرور بكل الاجراءات التى يقررها البرنامج وفى نفس الترتيب للمعلومات والأمتلة والمهام، ويمكنه البدء من نقطة والعودة لها مرة أخرى.

ويتميز هذا الأسلوب بعدة مزايا منها: أنه فعال عندما تكون مستويات المتعلمين متجانسة، ويتسم بالبساطة فهو أقل تعقيدا من الأساليب الأخرى، والقدرة على التحكم التام فى جميع التهابه

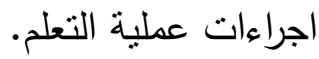

الأسلوب المتفرع (الثبكى): ويقصد بالتفرع داخل البرنامج قدرة المتعلم على التقام للأمام او الرجوع للخلف والذهاب لأى نقطة فى البرنامج، حيث أنه يعتمد على قدرة البرنامج على تقديم تعليم فردى، ويستخدم هذا الأسلوب فى اتاحة الفرصة للمتعلم لدراسة موضوع معين دون المرور لئه بموضوعات أخرى.

الأسلوب المنطقى: ويعتمد على مجموعة من المبادئ مثل: الانتقال من المعلوم إلى المجهول

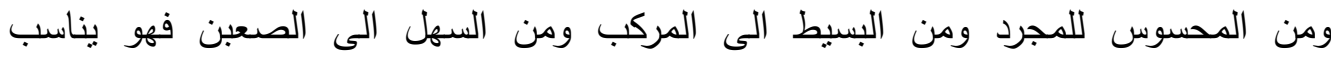

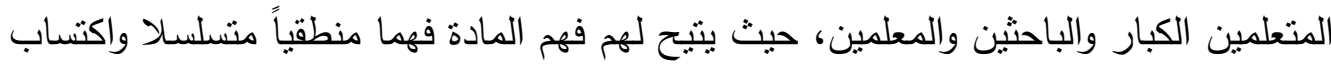

$$
\text { كمية كبيرة من المعلومات والمعارف. }
$$

الأسلوب السيكولوجى: يعتمد على مرعاة خصائص المتعلمين وميولهم وطرائق تعملهم أى

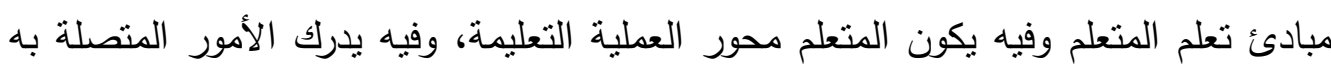

$$
\text { مباشرة، وهذا الأسلوب يناسب صغئ وفيه يكار السن. }
$$

الأسلوب الهرمى التسلسلى: التتظيم الهرمى لبنية المحتوى يعتمد على التدرج فى تتظيم بنية

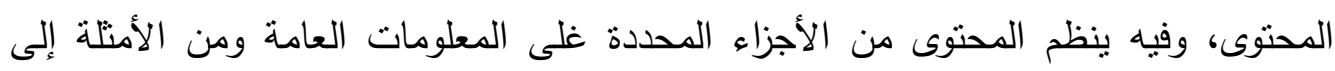
الكليات، فيتعلم المتعلم منطلبات التعلم السابقة لكل مهمة تعليمية جديدة وتعلم المهارات الدنياء قبل المهارات فى أعلى الهرم، ويستند نمط التتظيم الهرمى إلى نموذج (جانيه) والذى يفترض ان انعانه 
كل محتوى تعليمى أو كل جزء منه له بنية هرمية تشمل قيمتها أكثر الموضوعات أو الأجزاء

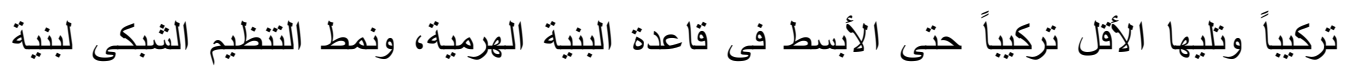
المحتوى يعتمد على ترتيب الأجزاء للمحتوى بحيث يرتبط اى جزء فى الاحتوى بأجزاء أخرى

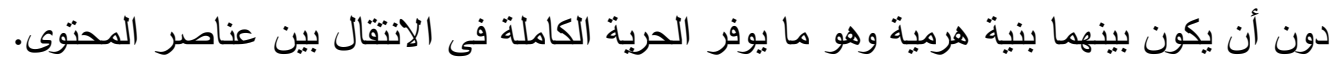

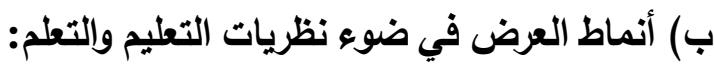
- النظرية السلوكية: أدرك علماء النفس السلوكيون أهمية التعلم بالواقع المعزز من خلال ما يتم ملاحظته وتقديمه من مفاهيم وتطبيقات حول النموذج السلوكي الذي بمكن أن يعدل أو بطور

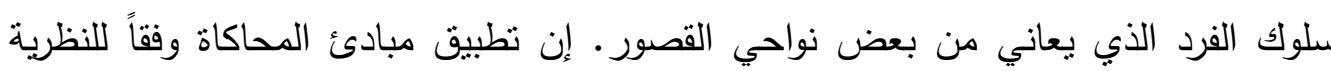

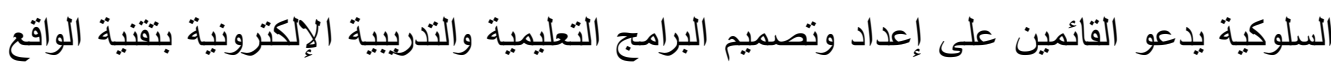

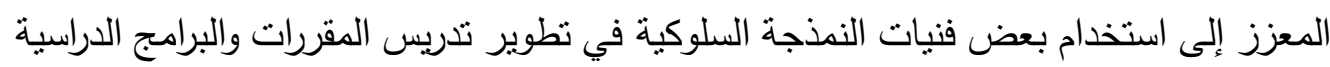

والبرامج العلاجية (Dabbagh, 2005). وتأسيساً على ما سبق فإن توظيف محتوى بيئة الواقع المعزز يعتمد على النظرية

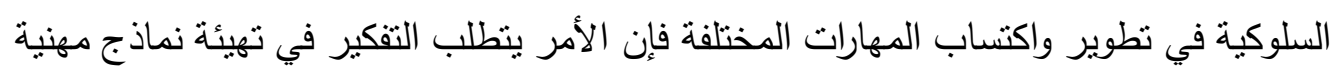
تربط واقع تدريس هذه المهارات بواقع العمل الفعلي أو الحقيقي من خلال الواقع المعزز والتتلمذ بند

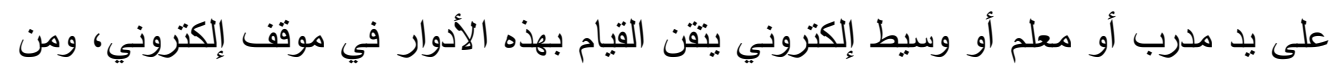
خلال تتبع المتعلم بممارسة للدور المتوقع منه ممارسته بعد الإعداد أو التدريب. - النظرية المعرفية: وضع جيروم برونر (Jerome Bruner ) عالم النفس الأمريكي نظرية

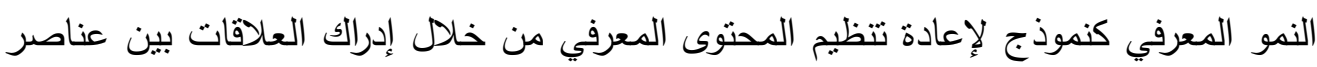
الموضوع، فالتعلم عند برونر هو التعلم الذي يحدث عند تقديم جزء مبسط من المحتوى التعليمي للطلاب، ثم يقوم المتعلم بتنظيمه أو اكتثاف العلاقات بين المعلومات (Takaya, 2008, 1-19).

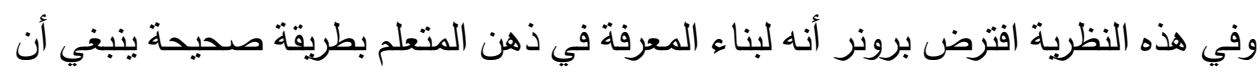

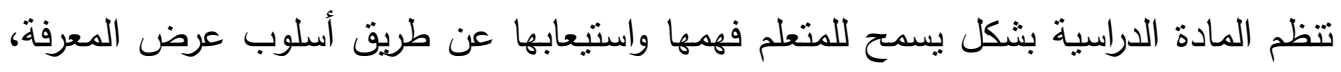

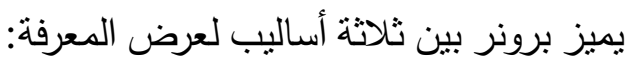

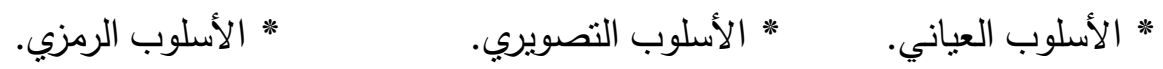

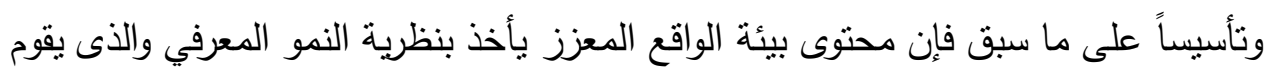

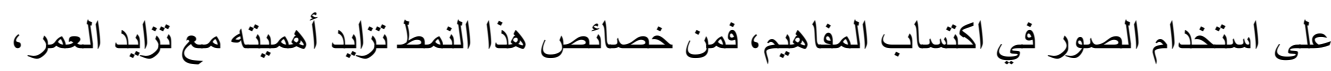
حيث الحاجة إلى تعلم المفاهيم والمبادئ التي لا يسهل تقديم نماذج تطبيقية لها مثل اكتشاف 
أعطال بعض الأجهزة، وصيانتها، والتركيب الداخلى لبعض المستحدثات وغبرها، وتدريس هذه

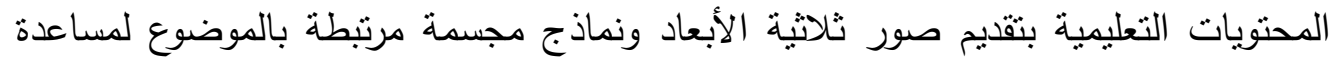
المتعلمين على تكوين صور ذهنية لما يراد تعلمه.

- النظرية البنائية: توضح النظرية البنائية خمس شروط شبنه مؤكدة للنهوض بلهنه بالعملية التعليمية

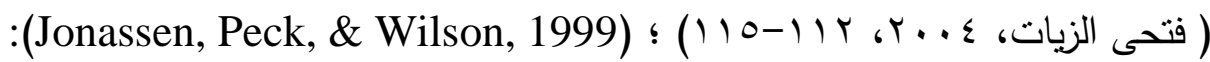
أن تكون العملية التعليمية راسخة داخل البيئة المعنية. أن يتم إجراء مباحثات اجتماعية لاستكمال الخبرات التعليمية. توفير رؤى متعددة للعرض التقديمي. إعطاء فرص تعليمية قوية وإتاحة الفرصة للتوجيه الذاتي.

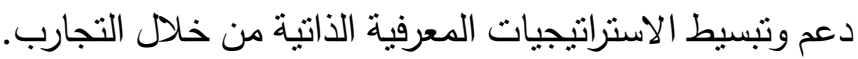
وتأسيساً على ما سبق وبما أن الواقع المعزز أداة معرفية ومنهجية تربوية، فإنها وبصفة هبطة

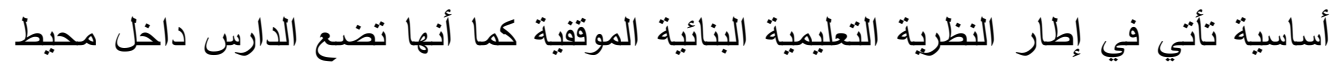
اجتماعي مادي عالمي حقيقي وفي الوقت ذاته تقوم بإرشاده وبتسهيل عملية المشاركة والعمليات

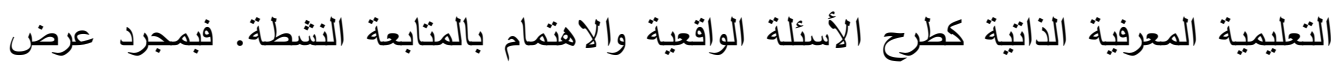
المحتوى بييئة الواقع المعزز يتيح بناء المفاهيم من خلال الأنشطة الثخصية والملاحظة، ضدن بالهن بيئات تفاعلية غنية، والذي بدوره يؤدي إلى تعلم أفضل، فمن مبادئ النظرية البنائية أن المتعلم

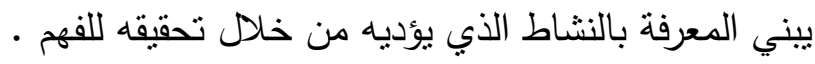
- نظرية معالجة المعلومات البصرية: لقد دعمت نظرية معالجة المعلومات البصرية نظرية داطية برونر في النمو المعرفي، حيث تتشير هذه النظرية إلى أن العمليات الأساسية التي تجري داخل

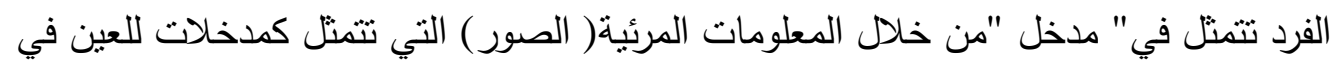
شكل أجزاء، حيث يقوم الفرد" بمعالجة "هذه المدخلات وتتظيمها في نموذج مرئي كلي يشمل الأجزاء ودمجه بالخبرة السابقة للوصول إلى" مخرج " في ضوئه يقوم الفرد بالاستجابة (زاهر

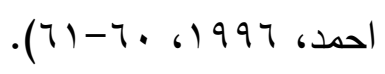

وتأسيساً على ما سبق فإن البحث الحالى يأخذ بنظرية معالجة المعلومات البصرية فى

إعداد محتوى بيئة الواقع المعزز بالرسوم ثلاثثية الأبعاد للأسباب التالية: اهتمام النظرية بمقدار الصور البصرية التي يستطيع الفرد استيعابها. ارتكاز النظرية على قدرة الفرد على استخدام الصور المرئية في إصلاح الأخطاء. 
الإثارة إلى أن المتعلم يمتلك نظاماً خاصاً لمعالجة الصور المرئية. والإثارة إلى دخول المعلومات البصرية للعين في أجزاء ويقوم الفرد بتتظيمها في نموذج مرنئي يشمل هذه الأجزاء. وبذلك تعد نظرية معالجة المعلومات البصرية أحد النظريات التي تدعم عرض محتوى

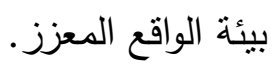
- نظرية أوزابل للتعلم ذي المعنى: وضع أوزابل نظرية التعلم ذو المعنى كنموذج لتتظيم المحتوى في شكل هرمي متدرج تكون فيها العموميات في القمة والخصوصيات في القاعدة، وقد اقترح

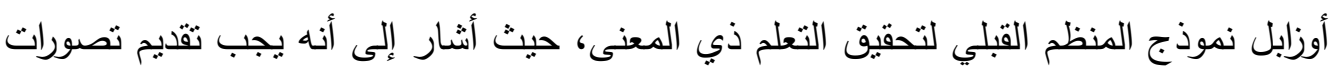

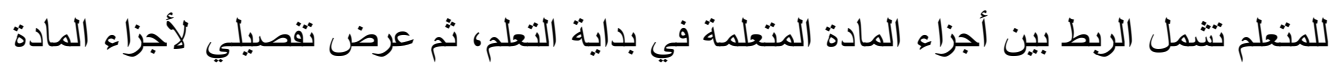
المتعلمة، وأن التعلم بطريقة التلقي يساعد على ربط المادة الجديدة بالبنية المعرفية القائمة(زاهر لاهرة

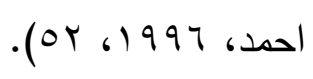

وقد عرف" أوزابل "المنظمات القبلية على أنها" ما يزود به الطلاب من مقدمة أو مادة

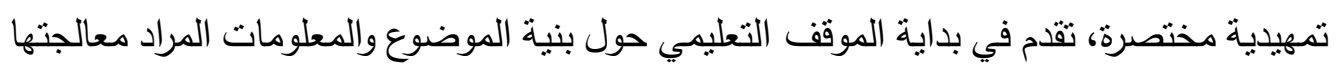

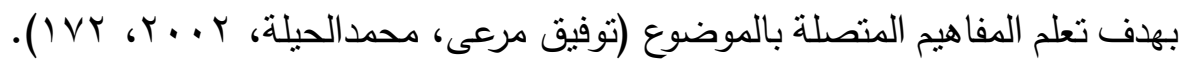

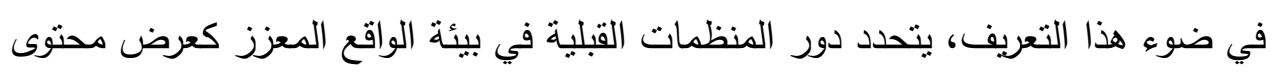
تعليمي يقدم كلياً في بداية التعلم يليه العرض الجزئي. - نظرية الجشطالت: وضع" ماكس فريتمر "نظرية الجشطالت وانضم إليه" كوهلرو كوفكا "في لهيه تأسيس هذه النظرية ,كنموذج للتعلم بالاستبصار والذي يتبنى فكرة أن التعلم يتكون بالإدراك فئك

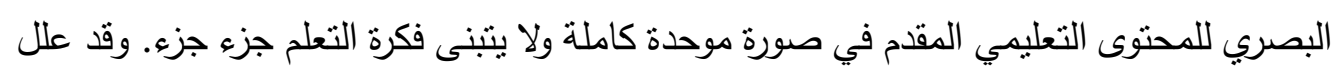

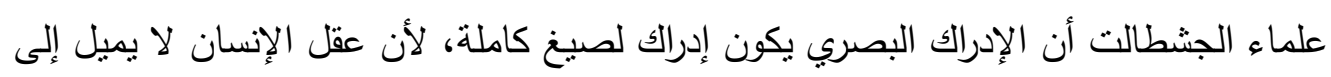

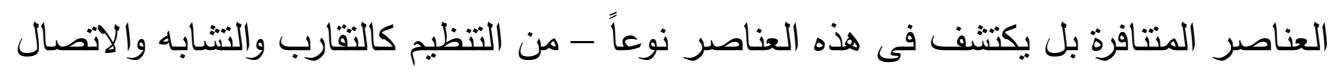
بين عناصر المحتوى العلمي ,كقواعد لكيفية تجميع أجزاء العناصر البصرية(اسماعيل شوقى، . ( 2 r.... ونظراً لتأكيد نظرية الجشطالت على العرض الكلى للعناصر البصرية، فإن بيئة الواقع المعزز قد اهتمت بتوضيح والربط بين أجزاء عرض المحتوى التدريبي المقدم. 
المحور الثالث : معايير تصميم المحتوى ببيئة الواقع المعزز القائمة على التعلم النقال. تُعد قضية "جودة المحتوى" من القضايا التي نالت اهتماماً من التربوبين منذ الثمانينيات من القرن العشرين، وتعني الجودة الخلو من الأخطاء (Zero Defect) أو أنها ملائمة الهدف

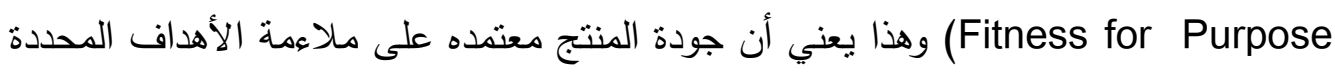

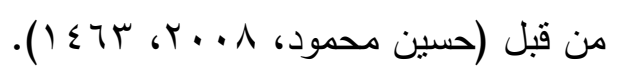
وقد أدت المتغيرات الاقتصادية والسياسية والاجتماعية والتتموية في عصر ثورة المعرفة

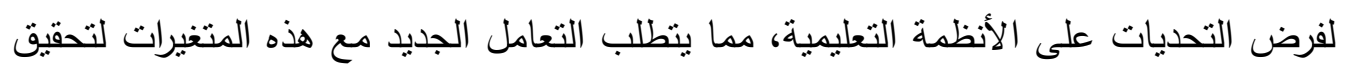

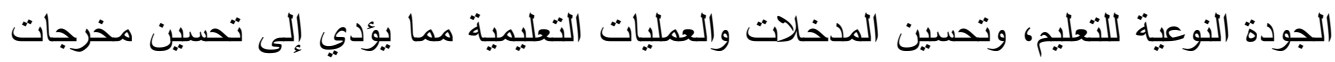

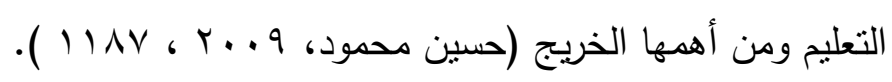

وتحاول المؤسسات التعليمية تحقيق الجودة للمنتج التعليمي، الذي يقدم الموصفات الجيدة التي تضمن حسن مستواه و فعاليته وقدرته على المنافسة في الأسواق العالمية.(أحلام حسن،

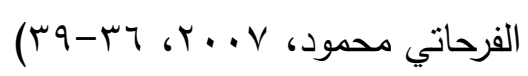

ولبناء بيئات الواقع المعزز لابد من نوافر مجموعة من المعايير التربوية والفنية تجعلها بيئة جيدة البناء، وتنساعد في إتمام التعلم بشكل متكامل.

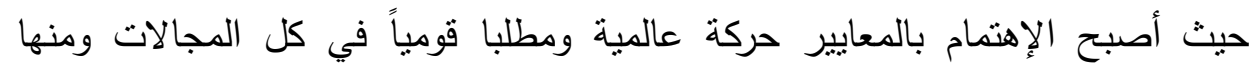
التعليم، فعلى المستوى العالمي تقوم منظمة المعايير الدولية (المنظمة الدولية للتوحيد القياسي" فئي" International Standardization Organization "ISO بالأداءات والعمليات والمنتجات (9004-9000 ISO) ) وهي معايير عامة لم توضع لمنتجات أو خدمات معينة، ولكنها تصلح للتطبيق على أي منتجات أو خدمات ومنها التعليمية (محمد خميس، فوزية أبا الخيل، ع . . Y) معاييرسكورم (SCORM) وهي مجموعة من المعايير والمواصفات تهدف إلى إنشاء محتوى تعليمي يمكن تبادله والوصول إليه بشكل مستمر يمكن إعادة استخدامه في سياقات متتوعة .وهي معايير فنية وهي: أنساء

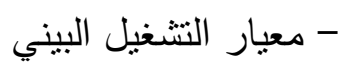

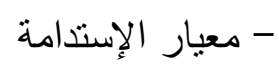

- معيار إعادة الاستخدام

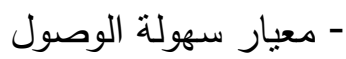

كما قامت (World Wide Web Consortium, 2006) بإعداد وثثية حول أفضل الممارسات الخاصة بالويب النقال ووضعتها فى الاصدار الأول (Mobile Web Best Practices 1.0) والذى ساعى 
اشتمل على (• (7) ممارسة مقسمة على (0) محاور وهم: السلوك العام ، الابحار والوصلات، تخطيط الصفحة والمحتوى، تعريف الصفحة، ومساهمات ادخال المستخدم.

وفى مصر قامت وزارة التربية والتعليم بإعداد المعايير القومية للتعليم، حيث قامت لجنة متخصصة فى المناهج وتواتج التعلم بإعداد وثيقة المنهج، حيث تضدنت ونئ مستويات معيارية لكل

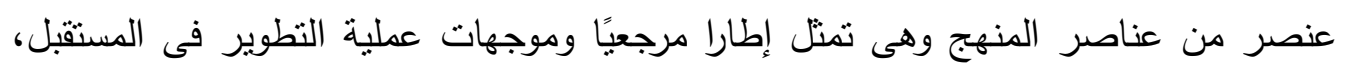

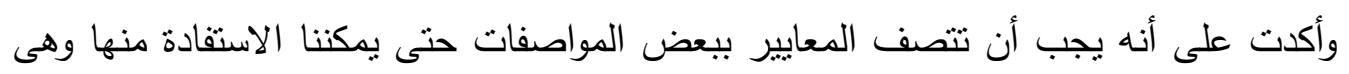

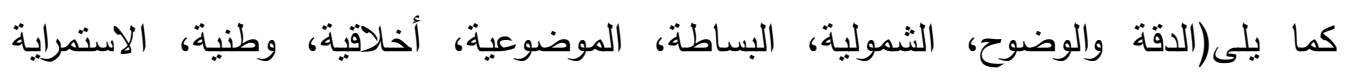

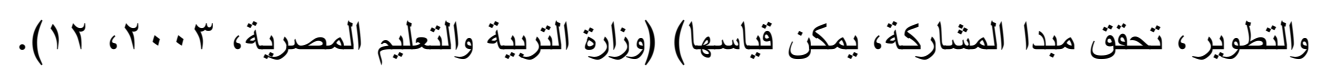

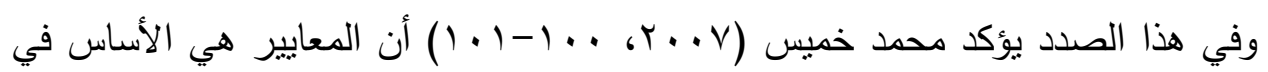

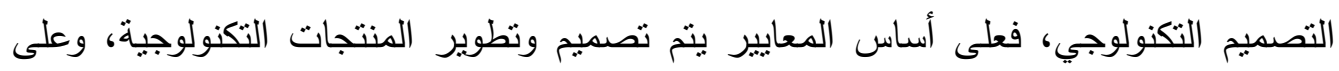

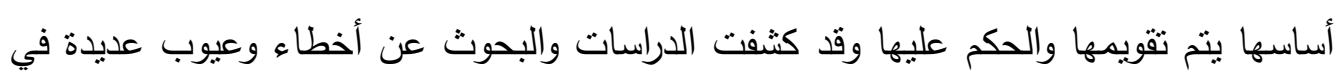

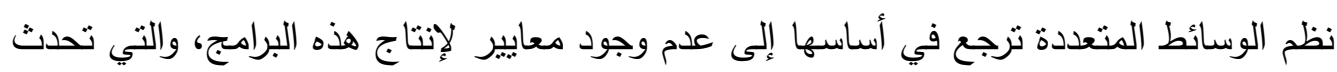

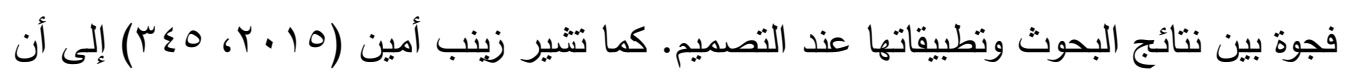

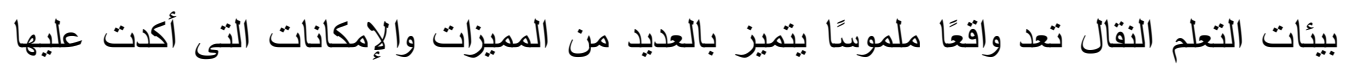

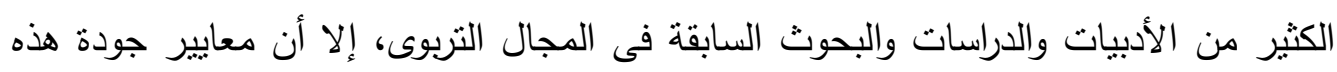

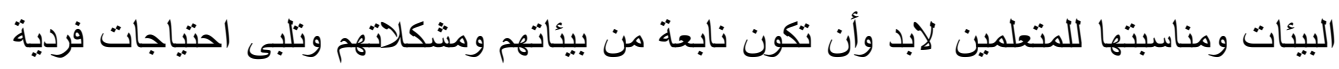
يجب أن تكون مصممة وفة معايير محددة. وأوصت دراسة فريح (Fraih, 2009) على لئل

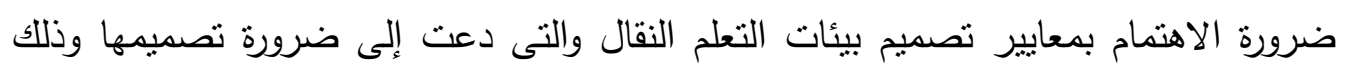

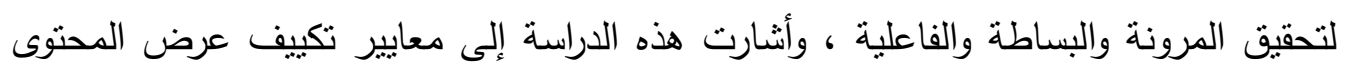

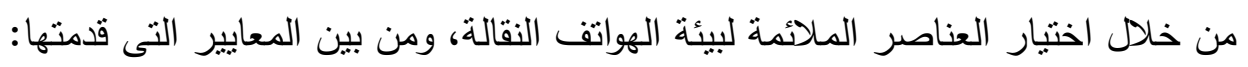

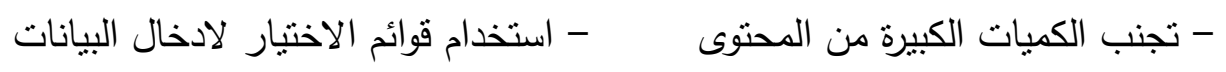

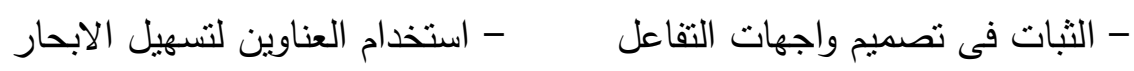
- استخدام الكلمات القصيرة. قام ( Nikolaou\& Economides, 2008 ) بتحديد ثلاث مجالات رئيسية يمكن الاسترشاد بها لتقويم واختيار الأجزة الأجزة النقالة ، وهى : المجال الأول: القابلية للاستخدام

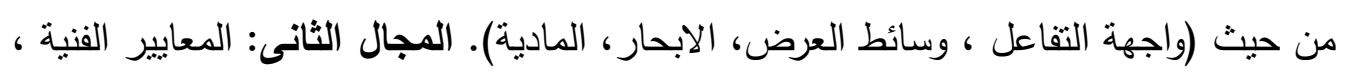

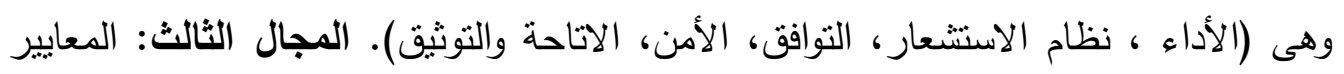


الوظيفية وهى (الاتصالات ، المعلومات والمعرفة، الادارة والتنظيم، التسلية والترفيه). وحددت

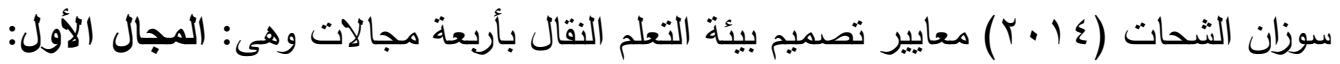

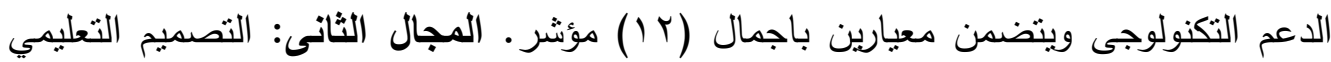

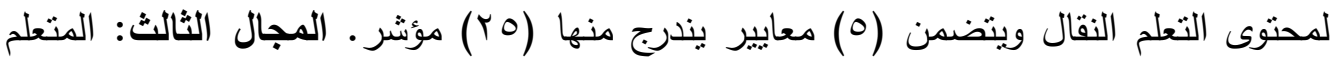

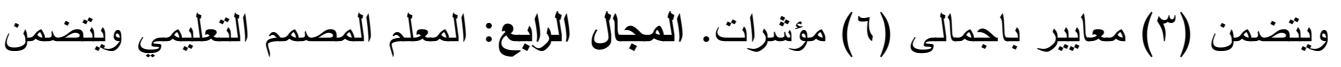

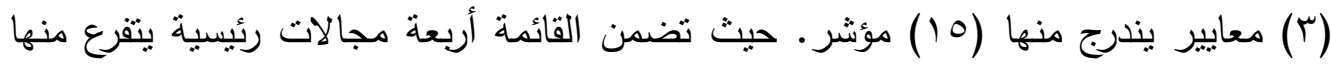

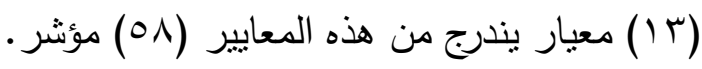

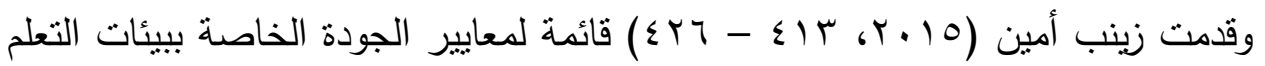

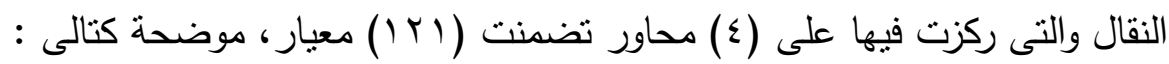
المحور الأول : أدوات المتعلم ويضم (0؛ ) معيار ، ويهتم هذا المحور بمواصفات أدوات التسليم ، ومواصفات وسائط التخزين التى يمكن توظيفها مع أدوات التسليم. المحور الثانى:

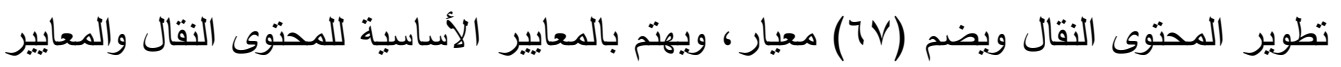

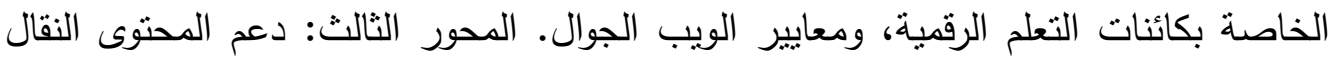

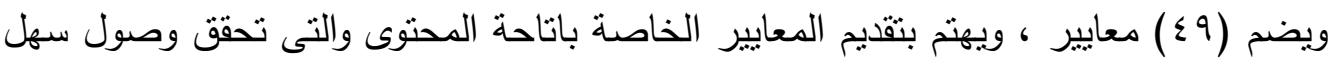

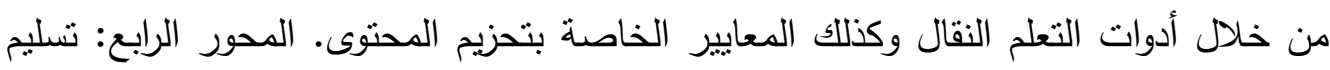
المحتوى النقال ويضم (ع) معايير ، ويهنم بالخدمات التى يقدمها الويب إلى التعلم النقال.

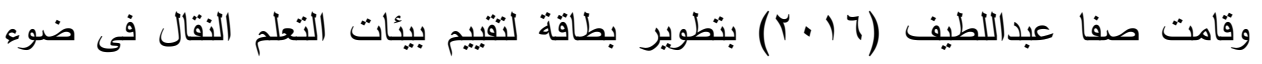

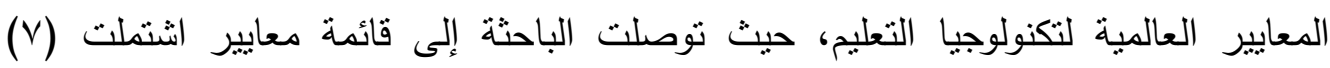
محاور رئيسية ، يتفرع منها (T) (I) معيار أساسى لتصميم بيئة التعلم النقال تحتوى بإجمالى

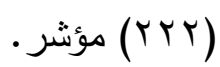

حيث يعتمد الواقع المعزز على بيئة أساسية وهى العالم الحقيقى وبيئة فرعية وهى العالم

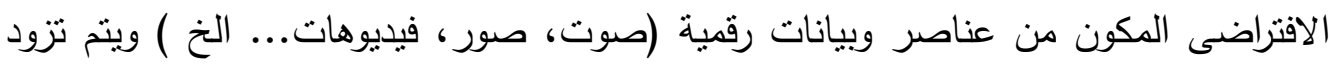

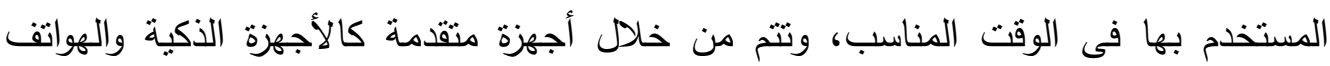

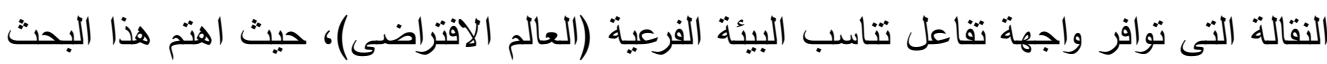

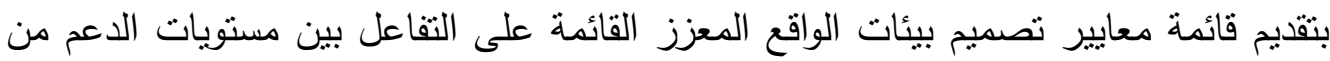
خلال التعلم النقال. 
حيث تتاولت بعض الدراسات والبحوث معايير تصميم بيئات التعلم القائمة على الواقع المعززمنها : دراسة (Markina, T \& Salalm, S, 2011, 183) والتى قدمت معايير تصميم الواقع المعزز لأغراض النعليم وهى: - تقديم الصورة الكلية وتحديد كل جزء وشرح وظائفها.

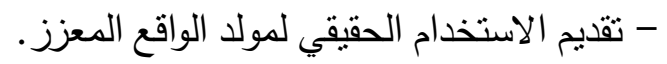
- توفير الرسوم المتحركة والتي تعمل مرارا وتكرارا.

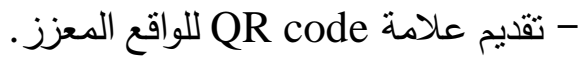

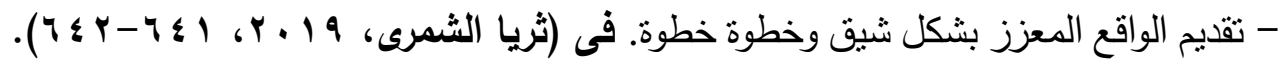

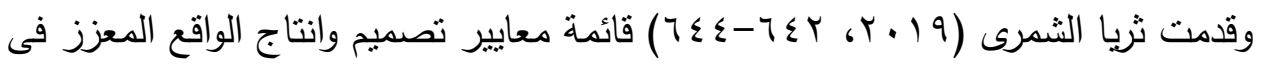
بيئة الهاتف المحمول، والتى تكونت من مجالين، هما: المجال الأول : تصميم الواقع المعزز

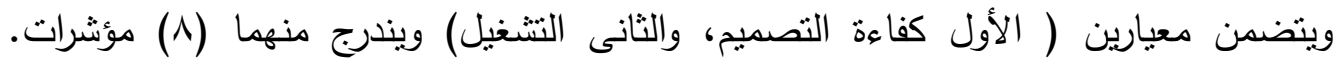

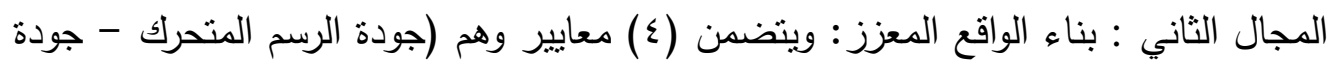

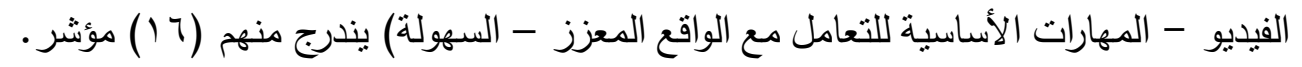

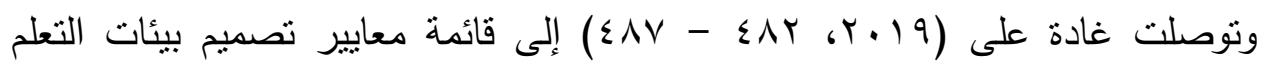

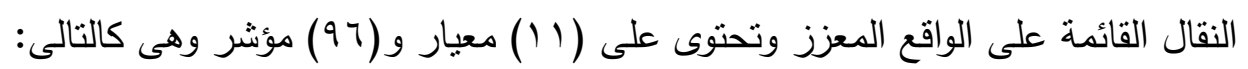

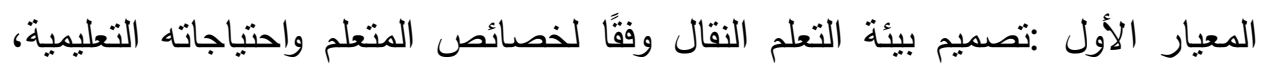

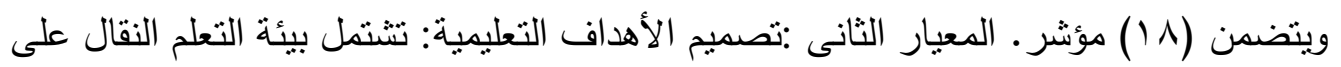

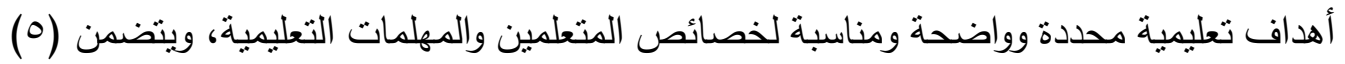

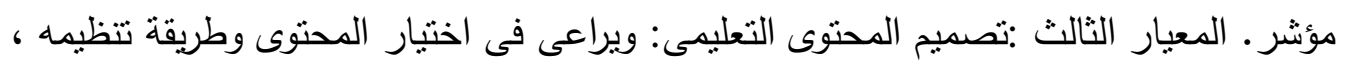

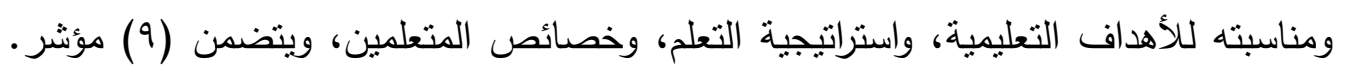

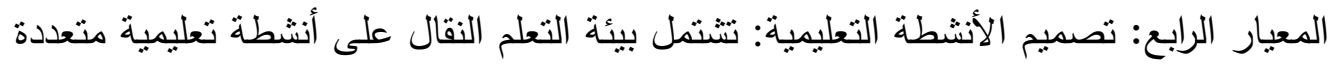

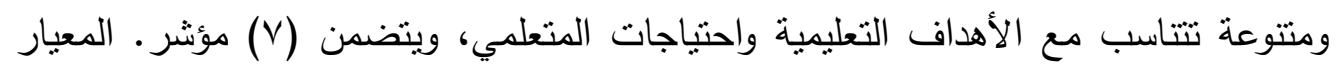

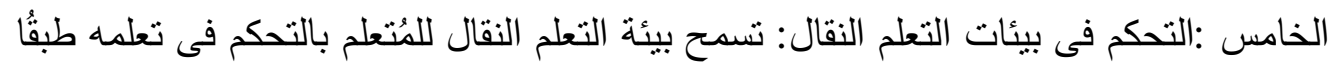
لاحتباجاته واستعداداته، ويتضمن (0) مؤشر • المعيار السادس :التغذية الراجعة: تقديم تغذية لفئة

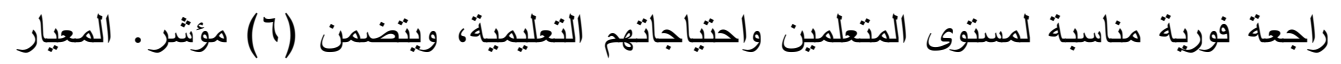
السابع :المساعدة والتوجيه: تتنمل بيئة التعلم النقال على أساليب مساعدة وتوجية مناسبة ولئة لاحتياجات المتعلمين، ويتضمن (7) مؤشر . المعيار الثامن : القابلية للاستخدام : تتميز بيئة التهائة

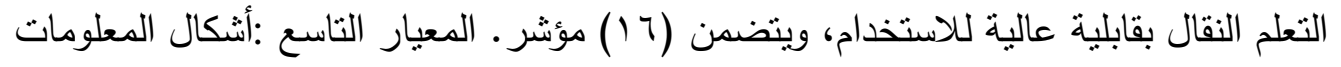

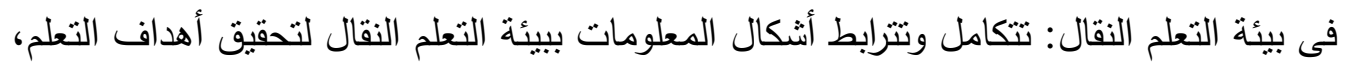


وتتناسب مع خصائص المتعلمين، ويتضمن (9) مؤشر . المعيار العاشر : تصميم بيئة التعلم

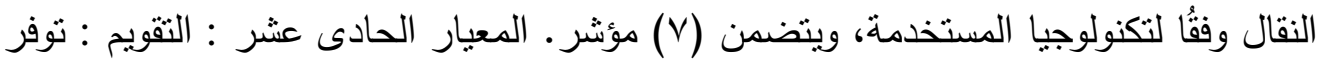

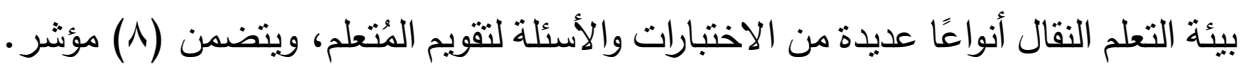
وبناءا على ما سبق يرى الباحثّن أن معايير تصميم محتوى بيئات الواقع المعزز القائم

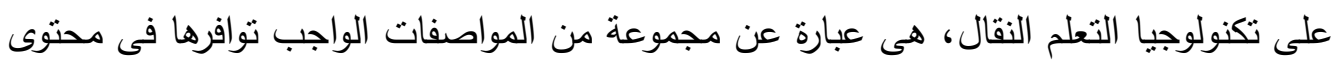
بيئة الواقع المعزز القائم على الهواتف الذكية لضمان نجاحها وتصميمها وتطويرها، لكى تصبح أداة يسترشد بها فى إنتاجها والمحافظة على استمراريتها. ولذلك استفاد الباحثون من العرض السابق فى إعداد قائمة المعايير التربوية والفنية لتصميم وانتاج المحتوى التدريبى ببيئة الواقع المعزز القائم على التدريب النقال.

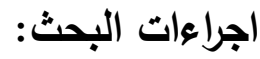
تم إعداد قائمة بالمعايير التربوية والفنية لتصميم وإنتاج المحتوى التدريبى ببيئة الواقع المعزز ، من خلال المرور بالمراحل التالية: بالئل

المرحلة الأولى: تحديد الهذف العام من بناء قائمة المعايير:

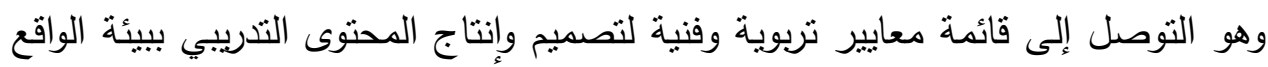
المعزز واستخدامها بالثكل الأمثل فى البرامج التدريبية. المرحلة الثانية: تحديد مصادر اشتقاق قائمة المعايير

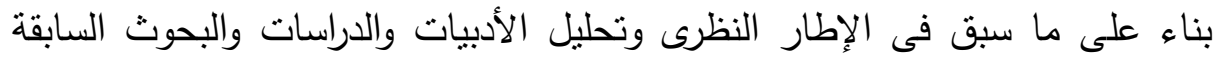

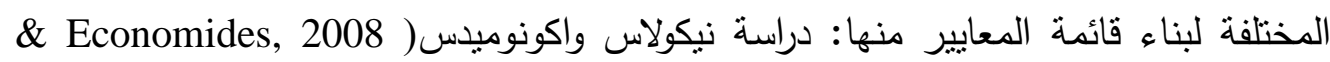
(Nikolaou

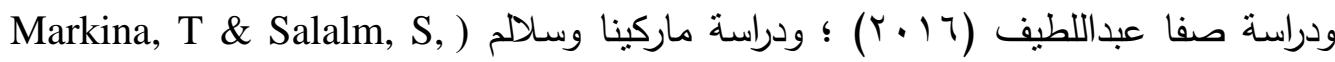
2011, 183$) ؛$

المرحلة الثالثة: إعداد قائمة مبئية للمعايير: قام الباحثون بإعداد تصور مبئي لقائمة المعايير كبنود ومؤشرات، وتضمن مبائبه هذا

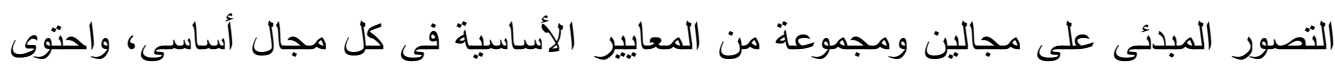

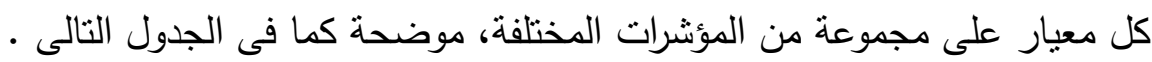


جدول ( ) نصور مبدئى لقائمة المعايير

\begin{tabular}{|c|c|c|c|}
\hline النسبة المئوية & عدد المؤشرات & عدد المعايير & المجال \\
\hline$\% \leq r, 11$ & 07 & 0 & المعايير التربوية \\
\hline$\% \circ \vee, \wedge q$ & $V V$ & V & المعايير الفنية \\
\hline$\% 1 \ldots$ & זrו & IT & الاجمالى \\
\hline
\end{tabular}

المرحلة الرابعة: عرض قائمة المعايير على الخبراء والمتخصصين:

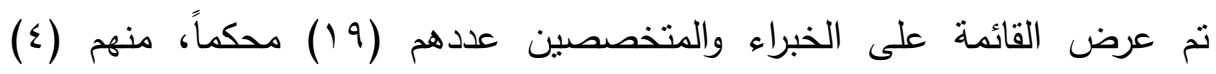
تخصص مناهج وطرق تدريس، و(0 10) تخصص تكنولوجيا التعليم.

المرحلة الخامسة: حساب صدق استبانة تحديد المعايير (صدق المحكمين):

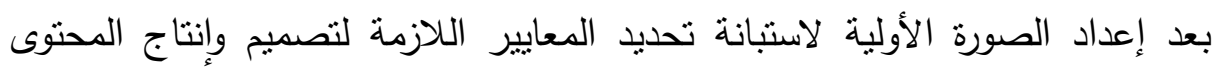

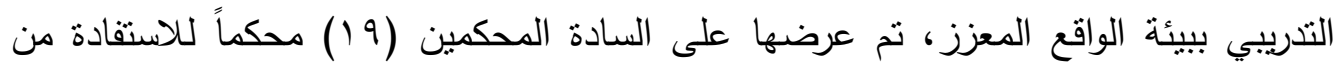

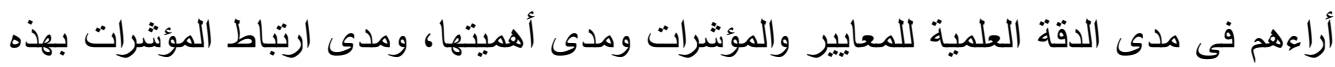

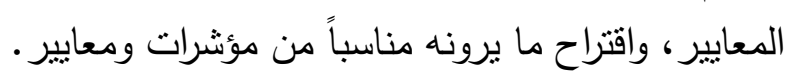

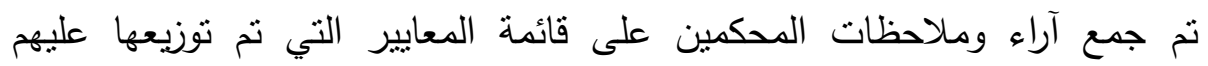
لضبطها وإبداء الرأي في النقاط التالية:

تحديد مدى أهمية المعيار ومؤشراته (مهم جدا - مهر - غير مهم ).

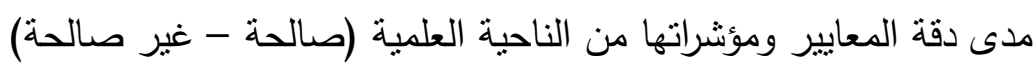

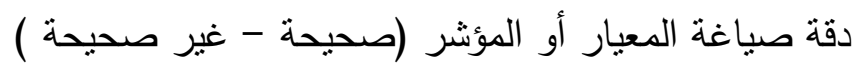
مدى الصحة اللغوية للمعايير والمؤشرات. إضافة أو تعديل أو حذف بعض المغ المعايير والمؤشرات. مدى صلاحية المعايير والمؤشرات للتطبيق.

المرحلة السادسة: المعالجة الاحصائية:

- - تم رصد استجابات المحكمين حول أهمية كل مؤشر ، ومدى ارتباط كل مؤشر بالمعيار الرئيسى، ثم ارتباطها بالمجال الأساسى الذئى تنتمى إليه.

- تم إعطاء الاستجابة (مهم جدا) ثلاث درجات ، وإعطاء استجابة (مهم) درجتين، وأعطيت للاستجابة (غير مهم) درجة واحدة.

- - تم حساب التكررات والنسب المئوية والمتوسطات لاتفاق آراء الخبراء فى بنود استطلاع الرأي ونم حساب الوزن النسبى لكل معيار ومؤشر باستخدام المعادلة التالية: 


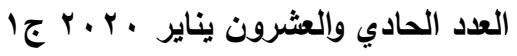

(مجموع التكرارات × التقدير النسبى لـها)

التقدير النسبى الأعلى × عدد العينة

الوزن النسبى للبند

وبوضح الجدول الآتى النسبة المئوبة لاتفاق السادة المُحَكِمين على المجال الأول:

المعايير التربوية؛ ولكل معيار من المعايير على حده بعد إجراء المعالجة الإحصائية.

جدول (Y) نسب اتفاق المحكمين على المجال الأول المعايير التريوية لانتاج المحتوى التريبي بيئة الواقع

\begin{tabular}{|c|c|c|c|c|c|c|c|}
\hline \multicolumn{8}{|c|}{ 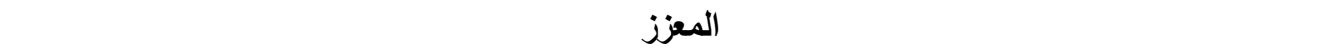 } \\
\hline \multirow[t]{2}{*}{ ملاحظات } & \multirow[b]{2}{*}{ 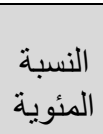 } & \multirow[b]{2}{*}{ 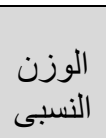 } & \multicolumn{3}{|c|}{ الأهميـــــة } & \multirow[b]{2}{*}{ المعـــــــــير } & \\
\hline & & & 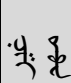 & 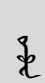 & 串 & & \\
\hline & $1 \ldots$ & 1 & . & . & 19 & لمعيار الأول: وضوح الأهداف التعليمية للمحتوى & \\
\hline وتُعْدل & $97 . \leqslant 9$ & .970 & - & r & iv & أن تكون أهداف محتوى بيئة الو اقع المعزز محددة ودقيقة. & 1 \\
\hline تُقبل & $1 \ldots$ & 1 & . & . & 19 & أن يتتاسب الأهداف التدرييية طبيعة التدريب. & r \\
\hline وتُعْلَ & $9 \wedge . Y_{0}$ & $.9 \wedge r$ & - & 1 & 11 & أن تصاغ الأهداف صياغة سلوكية سليمة . & $r$ \\
\hline وتُعُعبل & $9 \leq . \vee \leq$ & $.9 \leq V$ & 1 & 1 & iv & 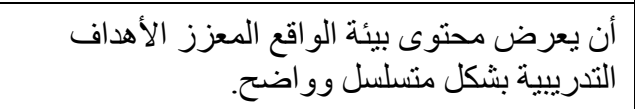 & $\varepsilon$ \\
\hline وتُعْدل & $9 \leq . \vee \leq$ & $.9 \leq V$ & - & 1 & 11 & 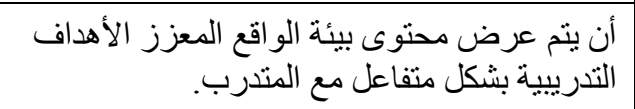 & 0 \\
\hline 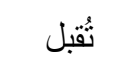 & $1 \cdots$ & 1 & · & $\cdot$ & 19 & أن يشمل الهذف التدريبي نتاج تعلم واحد من نو اتج التدريب. & 7 \\
\hline تُحذف & סر. & $\cdot . \varepsilon \cdot \varepsilon$ & 17 & $r$ & 1 & أن تصف الأهداف سلوك المتدرب وليس سلوك المعز & $V$ \\
\hline تُقْبل & $1 \ldots$ & 1 & . & . & 19 & أن يتضمن الهدف نتائج التدريب وليس أنشطة التنريب. & $\wedge$ \\
\hline و تُعْدل & $q \wedge . \varphi_{0}$ & $.9 \wedge r$ & . & 1 & 11 & 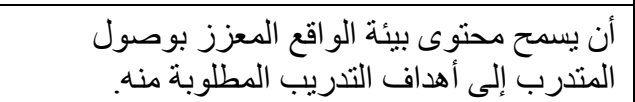 & 9 \\
\hline و تُعْدل & $q \leq . \vee \leq$ & $.9 \leqslant V$ & 1 & 1 & IV & 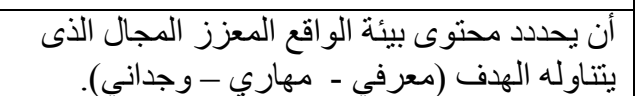 & 1. \\
\hline و تُعْدل & $q \leq . \vee \leq$ & $.9 \leqslant V$ & . & . & 11 & 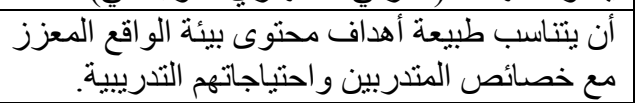 & 11 \\
\hline 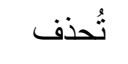 & ro. 9 & .101 & 11 & 1 & • & أن تكون الأهداف ذات أهمية وقيمة تربوية للمتدرب. & ir \\
\hline تُحذف & $\leq 0.71$ &.$\leqslant 07$ & $1 \varepsilon$ & r & r & أن تكون الأهداف المحتوى التدريبى ببيئة الو اقع & $1 \pi$ \\
\hline
\end{tabular}




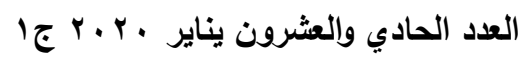

المجلة العلمية لكلية التربية النوعية

\begin{tabular}{|c|c|c|c|c|c|c|c|}
\hline \multirow[t]{2}{*}{ ملاحظات } & \multirow[b]{2}{*}{ 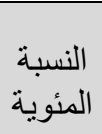 } & \multirow[b]{2}{*}{ 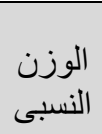 } & \multicolumn{3}{|c|}{ الأهمبـــــة } & \multirow[b]{2}{*}{ المعـــــــــير } & \\
\hline & & & 果里 & s & 21 & & \\
\hline \multirow[t]{2}{*}{ تُحذف } & $\varepsilon Y .11$ & $\cdot \sum Y_{1}$ & 10 & $r$ & 1 & 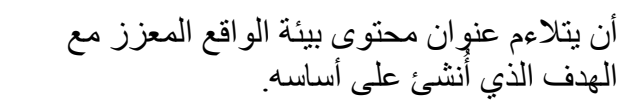 & $1 \varepsilon$ \\
\hline & $1 \ldots$ & 1 & • & · & 19 & معيار الثانى: تتظيم المحتوى التدريبي ببيئة الواقع & \\
\hline تُقبل & $1 \ldots$ & 1 & • & - & 19 & 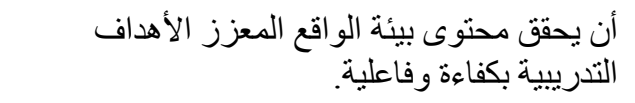 & 10 \\
\hline وتُعْلَ & 91. Yo & $.9 \wedge r$ & • & 1 & 11 & 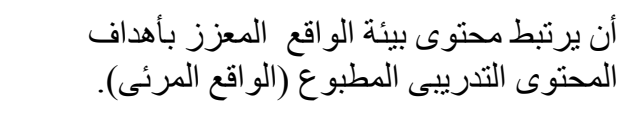 & 17 \\
\hline وتُعندل & $9 \leq . V \leq$ & $\cdot .9 \leqslant V$ & 1 & 1 & iv & أنت يتو افق محتوى بيئة الو اقع المعزز خصائص & IV \\
\hline وتُعبل & q1.Y & .914 & r & 1 & 17 & أن يُحدد محتوى بيئة الواقع المعزز المنطلبات & 11 \\
\hline تُقُبل & $1 \ldots$ & 1 & . & $\cdot$ & 19 & أن يُر اعى محتوى بيئة الو اقع المعزز الفروق بين الفتربين. & 19 \\
\hline وتُعْدل & 94.91 & .94. & 1 & $r$ & 17 & 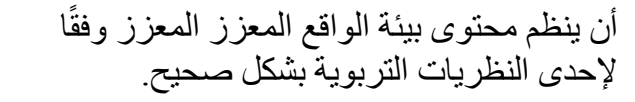 & $r$. \\
\hline تُقبل & $1 \ldots$ & 1 & . & · & 19 & 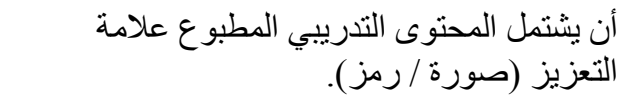 & YI \\
\hline تُقبل & $1 \ldots$ & 1 & • & · & 19 & 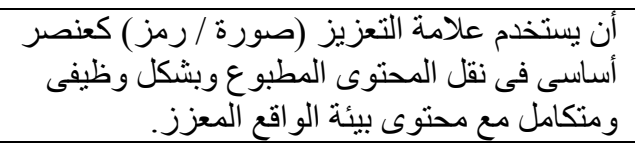 & Yr \\
\hline وتُعْلَ & $97 . \leqslant 9$ & .970 & . & $r$ & IV & 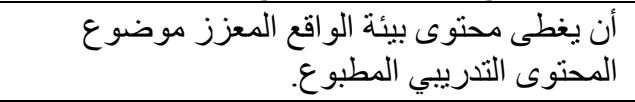 & r \\
\hline تُقبل & $1 \ldots$ & 1 & . & • & 19 & أن يكون اللغويةتوى التدريبى المطبوع سليمًا من & $r \varepsilon$ \\
\hline تُقبل & $1 \ldots$ & 1 & • & · & 19 & 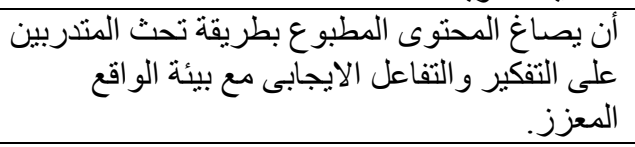 & ro \\
\hline وتُعْلَ & 91. Yo & $.9 \wedge r$ & . & 1 & 11 & 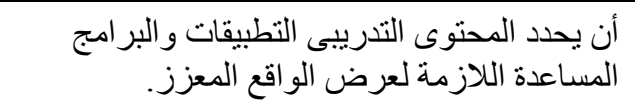 & $r 7$ \\
\hline وتُُعبل & $9 \leq . \vee \leqslant$ & $\cdot .9 \leqslant V$ & 1 & 1 & iv & 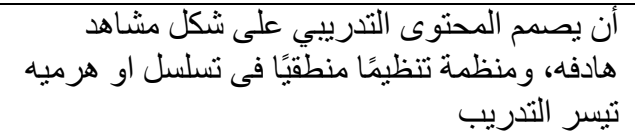 & $r V$ \\
\hline تُقبل & $1 \ldots$ & 1 & - & $\cdot$ & 19 & عنصر التدريز المحتوى التدريبى بالمعلومات التي يقدمها & $\uparrow \wedge$ \\
\hline
\end{tabular}




\begin{tabular}{|c|c|c|c|c|c|c|c|}
\hline \multirow[t]{2}{*}{ ملاحظات } & \multirow{2}{*}{ 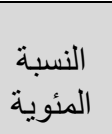 } & \multirow{2}{*}{ 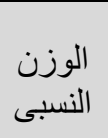 } & \multicolumn{3}{|c|}{ الأهميــــة } & \multirow[b]{2}{*}{ المعـــــــيير } & \\
\hline & & & 羊: $q$ & \& & \& & & \\
\hline \multirow[t]{2}{*}{ تُحذف } & $\varepsilon V . r V$ & $\cdot \leq V \leq$ & W & $\varepsilon$ & r & 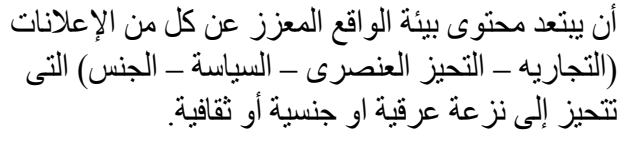 & $r q$ \\
\hline & $9 \leqslant . \vee \leq$ & $\cdot .9 \leqslant V$ & 1 & 1 & IV & \multicolumn{2}{|l|}{ المعيار الثالث: توافر الأنشطة التدرييية: } \\
\hline وتُُعبل & $91 . Y_{0}$ & $.9 \wedge r$ & - & 1 & 11 & 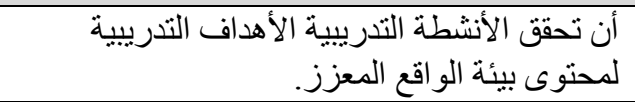 & r. \\
\hline تُقبل & $1 \ldots$ & 1 & - & · & 19 & كل مهمة تدريبية. أنتويعة التدريبية الداعمة للمحتوى بعد & ו \\
\hline تُقُبل & $1 \ldots$ & 1 & - & · & 19 & وأن تتدرج الأنشطة التدريبية من السهل إلى الصعب، المجرد. & rt \\
\hline و تُُعبدل & $97 . \leqslant 9$ & .970 & 1 & $\cdot$ & 11 & 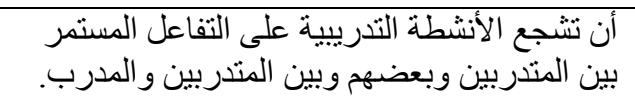 & אז \\
\hline تُقبل & $1 \ldots$ & 1 & • & · & 19 & للنتأيتناسب الأنشطة التدريبية مع المستوى الأكاديمي & re \\
\hline وتُُْبل & $9 \leq . \vee \leq$ & $\cdot .9 \leq V$ & 1 & 1 & IV & للمندربين. أنى الأنشطة التدريبية الفروق الفردية & ro \\
\hline تُقبل & $1 \ldots$ & 1 & • & · & 19 & 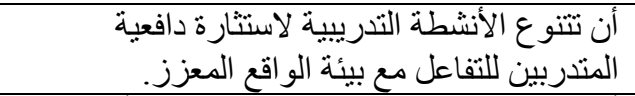 & דr \\
\hline وتُُعبل & $97 . \leqslant 9$ & .970 & • & r & IV & 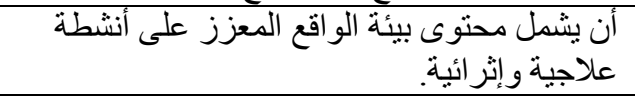 & rV \\
\hline تُقبل & $1 \ldots$ & 1 & • & - & 19 & مهار أن تنى الأنشطة التدريبية ببيئة الواقع المعزز & rᄉ \\
\hline تُقبل & $1 \ldots$ & 1 & • & $\cdot$ & 19 & للمندربين تعلمه. ألنشة التدريبية للواقع المعزز بما سبق & rq \\
\hline تُقبل & $1 \ldots$ & 1 & . & . & 19 & أن يحدد وقت زمنى لممارسة الأنشطة التدريبية. & $\varepsilon$. \\
\hline وتُعْدل & $91 . \mathrm{ro}_{0}$ & $\cdot . \wedge r$ & • & 1 & 11 & تز أن يناح حل الأنشطة التنريبية بطريقة نز امنية و غير & 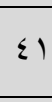 \\
\hline & $94.9 \wedge$ & $\cdot 9 r \cdot$ & 1 & r & 17 & الر الر ابع: اثارة الدافعية : & 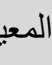 \\
\hline تُقبل & $1 \ldots$ & 1 & . & - & 19 & للمعلئومات طرق إثارة للمتدرب محتوى بيئة الو اقع المعزز & $\varepsilon r$ \\
\hline وتُعْل & $9 \leq . \vee \leq$ & $\cdot .9 \leq V$ & 1 & 1 & iv & مختلفة من المحاكاة. محتئة الو اقع المعزز على أنواع & $\varepsilon r$ \\
\hline وتُقُعل & $9 \wedge$. Yo & $\cdot . \wedge r$ & • & 1 & 11 & أن يعرض محتوى بيئة الو اقع المعزز مسنوى تقلم المندرب. & $\varepsilon \varepsilon$ \\
\hline تُقُبل & $1 \ldots$ & 1 & • & . & 19 & أن يعرض لتحفيز المتدرى بيئة الو اقع المعزز عبار الاستمرار. & $\leqslant 0$ \\
\hline وتُعْدل & 94.91 & $\cdot .9 r \cdot$ & 1 & r & 17 & أنخاطب الصنوي محتوى بيئة الو اقع المعزز على أسلوب & $\leqslant 7$ \\
\hline
\end{tabular}




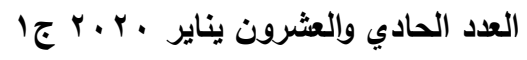

المجلة العلمية لكلية التربية النوعية

\begin{tabular}{|c|c|c|c|c|c|c|c|}
\hline \multirow[t]{2}{*}{ ملاحظات } & \multirow[b]{2}{*}{ 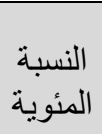 } & \multirow[b]{2}{*}{ 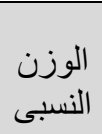 } & \multicolumn{3}{|c|}{ الأهميــــة } & \multirow[b]{2}{*}{ المعــــــــير } & \\
\hline & & & 电事 & \& & da & & \\
\hline \multirow[t]{2}{*}{ تُقْبل } & $1 \cdots$ & 1 & - & · & 19 & 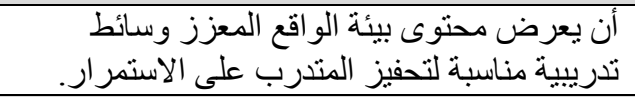 & $\varepsilon V$ \\
\hline & $97 . \leqslant 9$ & .970 & - & r & iv & \multicolumn{2}{|l|}{ المعيار الخامس: التغذية الراجعة : } \\
\hline تُقُبل & $1 \cdots$ & 1 & - & - & 19 & 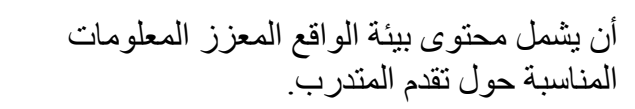 & $\varepsilon \wedge$ \\
\hline تُقُبل & $1 \cdots$ & 1 & . & · & 19 & جزء من أجز اء الثحتوى التدريبى على تقويم تكوينى لكل & $\leqslant 9$ \\
\hline تُقُبل & $1 \cdots$ & 1 & • & $\cdot$ & 19 & أن يشمل المحتوى التدريبى على تقويم نهائى للتأكد & 0. \\
\hline وتُعْدل & $9 \Lambda . Y_{0}$ & $.9 \wedge r$ & . & 1 & 11 & أن يتميز التقويم داخل المحتوى التدرييى بالتفاعلية. & 01 \\
\hline و وتُعْبل & $97 . \leqslant 9$ & .970 & . & $r$ & 18 & أن يُر اعي الصياغة العلمية و اللغوية الصحيحة للأسئلة . & or \\
\hline تُقُبل & $1 \cdots$ & 1 & . & . & 19 & أن أنو الفق عرض بيانات التغذية الراجعة مع بيئة & or \\
\hline تُقُبل & $1 \cdots$ & 1 & . & · & 19 & أن يقدم التغذية الراجعة خلال التدريب بييئة الو اقع & $0 \leqslant$ \\
\hline تُقبل & $1 \cdots$ & 1 & . & · & 19 & 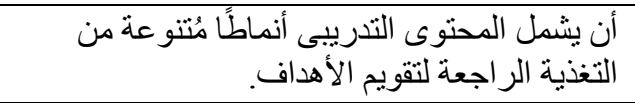 & 00 \\
\hline وتُعْل & $9 \Lambda . Y_{0}$ & $.9 \wedge r$ & • & 1 & 11 & لأن يحناتوي بيئة الو اقع المعززئة علي تغذية راجعة لكل & 07 \\
\hline تُقبل & $1 \ldots$ & 1 & . & · & 19 & 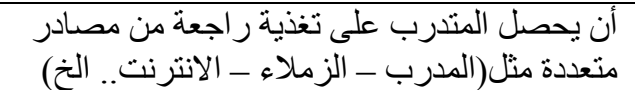 & ov \\
\hline & $97 . \leqslant 9$ & .970 & . & $r$ & 18 & ط نسبة اتفاق السادة المحكمين على المجال الأول & 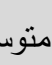 \\
\hline
\end{tabular}

يتضح من الجدول السابق أن النسبة المئوية لاتفاق المحكمين حول أهمية كل مؤشر

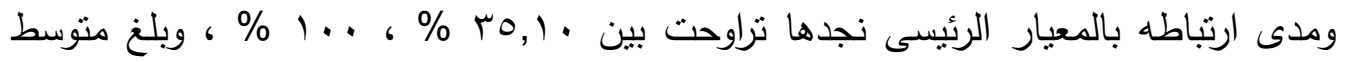

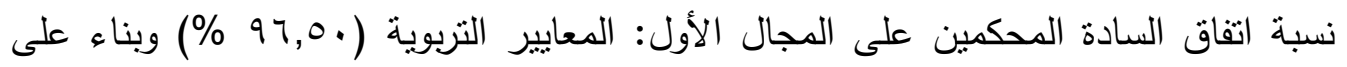
ـ. ذللك تم استبعاد مجموعة من المؤشرات التى تقل نسبة اتفاق السادة المحكمين عليها عن \% واجراء التعديلات اللازمة على قائمة المجال الأول: المعايير التربوية.

ويوضـح الجدول التالى النسبة المئوبة لاتفاق السادة المُحَكِين على المجال الثانى: المعايير الفنية؛ ولكل معيار من المعايير على حده بعد إجراء المعالجة الإحصائية. 
جدول (r) نسب اتفاق المحكمين على المجال الثانى المعايير الفنية لانتاج المحتوى التدريبي ببيئة

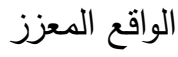

\begin{tabular}{|c|c|c|c|c|c|c|c|}
\hline \multirow{2}{*}{ ملاحظات } & \multirow{2}{*}{ 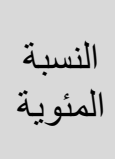 } & \multirow{2}{*}{ 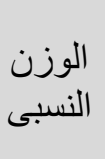 } & \multicolumn{3}{|c|}{ الأهمبـــــة } & \multirow{2}{*}{ المعـــــــــــيـر } & \multirow[b]{2}{*}{ ? } \\
\hline & & & -q. & $\dot{q}$ & $£ \underline{1}$ & & \\
\hline & $9 \wedge . Y_{0}$ & $.9 \wedge r$ & - & 1 & 11 & المعيار الأول : تصميم المحتوى المطبوع (الو اقع & \\
\hline تُقُبل & $1 \cdots$ & 1 & . & • & 19 & غلاف خلفِي المحتوى المطبوع علي غلاف أمامي و & 1 \\
\hline وتُُعبل & $9 r .91$ & $\cdot 94 \cdot$ & 1 & r & 17 & 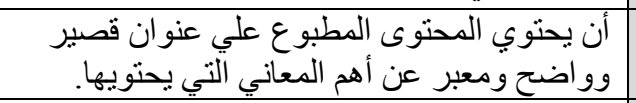 & $r$ \\
\hline 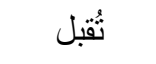 & $1 \cdots$ & 1 & - & • & 19 & أن يكون الغلاف مناسبًا للفئة المستهدفة من المتدريب. & r \\
\hline تُقُبل & $1 \cdots$ & 1 & - & • & 19 & أن يشمل المحتوى المطبوع علي صفحه للعنوان. & $\varepsilon$ \\
\hline تُقُبل & $1 \cdots$ & 1 & - & $\cdot$ & 19 & 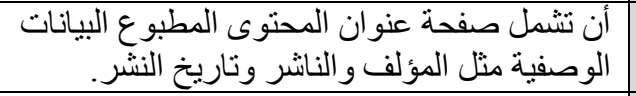 & 0 \\
\hline وتُعْلَ & $9 \Lambda . Y_{0}$ & $\cdot .9 \wedge r$ & - & 1 & 11 & ألن يثنمل المحتوى المطبوع على قائمة محتويات & 7 \\
\hline وتُعْدل & 94.91 & $\cdot .94$. & 1 & r & 17 & 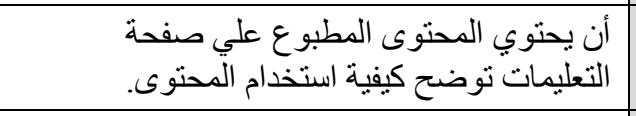 & $V$ \\
\hline تُقُبل & $1 \cdots$ & 1 & - & • & 19 & أنكويني و التقويم النهائي . & $\wedge$ \\
\hline تُقُبل & $1 \cdots$ & 1 & - & • & 19 & أن يتميز شكل صفحات المحتوى المطبو ع بالثبات & 9 \\
\hline تُقُبل & $1 \cdots$ & 1 & $\cdot$ & • & 19 & أن يُرقم صفحات المحتوى التدريبى المطبوع. & 1. \\
\hline تُقُبل & $1 \cdots$ & 1 & - & • & 19 & يكون النص واعى ضبط هو امش المحتوى المطبوع بحيث & 11 \\
\hline وتُعْلَ & $97 . \leqslant 9$ & .970 & - & r & iv & 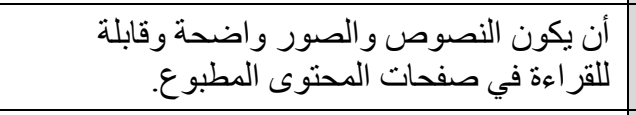 & IT \\
\hline تُقبل & $1 \cdots$ & 1 & - & $\cdot$ & 19 & 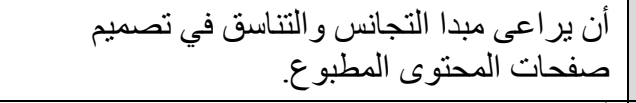 & 14 \\
\hline وتُعْدل & $9 \wedge . Y_{0}$ & $.9 \wedge r$ & - & 1 & 11 & 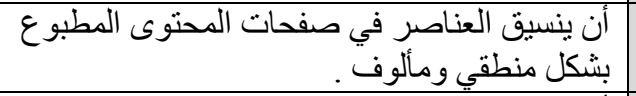 & $1 \varepsilon$ \\
\hline وتُعْدل & $91 . \mathrm{r}$ & $.91 \mathrm{r}$ & r & 1 & 17 & 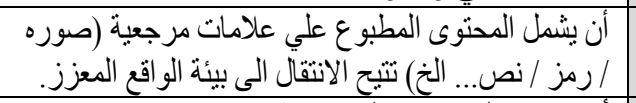 & 10 \\
\hline وتُعْل & $9 \wedge . Y_{0}$ & $\cdot 9 \wedge r$ & • & 1 & 11 & 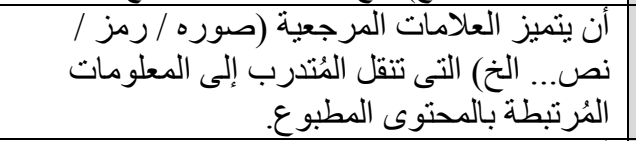 & 17 \\
\hline تُقبِل & $1 \cdots$ & 1 & . & • & 19 & و أن يحتوى المحتوى المطبوع على وسائل الاتصال & IV \\
\hline
\end{tabular}




\begin{tabular}{|c|c|c|c|c|c|c|c|}
\hline \multirow{2}{*}{ ملاحظات } & \multirow{2}{*}{ المئوية } & \multirow{2}{*}{ 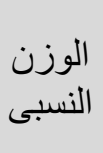 } & \multicolumn{3}{|c|}{ الأهمبــــة } & \multirow{2}{*}{ المعـــــــــيـر } & \multirow[b]{2}{*}{ r } \\
\hline & & & q. & 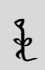 & 承 & & \\
\hline تُحذف & $\varepsilon Y .11$ & $\cdot . \leqslant Y$ & 17 & 1 & r & أن يحتوى المحتوى المطبوع على قدر أقل من النصوص . & 11 \\
\hline تُحذف & $\varepsilon r .11$ & 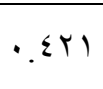 & 10 & r & 1 & 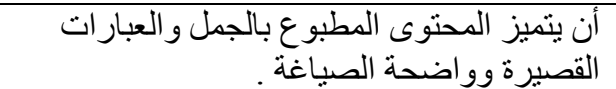 & 19 \\
\hline وتُُعبل & $9 \leq . \vee \leq$ & $\cdot .9 \leq V$ & . & 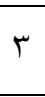 & 17 & 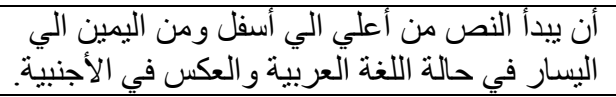 & r. \\
\hline تُحذف & $\varepsilon \cdot{ }^{0}$ & $\cdot \varepsilon \cdot \varepsilon$ & 17 & r & 1 & و وعلامات النغت لغة صحيحة من حيث القو اعد و الاملاء & YI \\
\hline & $97 . \leqslant 9$ & .970 & - & r & iv & \multicolumn{2}{|l|}{ المعيار الثانى: تصميم المحتوى المعزز (الواقع المعزز): } \\
\hline تُقُبل & $1 \cdots$ & 1 & . & . & 19 & مرتبطة بأهداف التدريب. المعزز على وسائط متعددة & Yr \\
\hline تُقُبل & $1 \cdots$ & 1 & . & • & 19 & 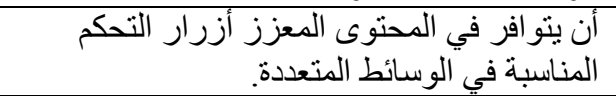 & Tr \\
\hline تُقُبل & $1 \cdots$ & 1 & . & . & 19 & أن يتناسب تصميم المعزي من حيث الوضو التدريبية مع تصميم & $r \varepsilon$ \\
\hline تُقُبل & $1 \ldots$ & 1 & . & . & 19 & 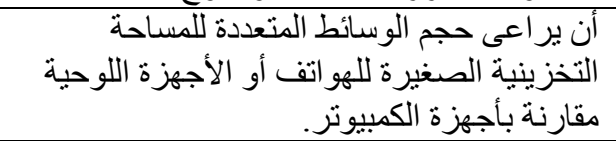 & ro \\
\hline وتُقُعبل & $97 . \leqslant 9$ & .970 & . & r & iv & (أن تكون لغة المحتوى المعزز صحيحة من الإملاء وقيثة : الصياغة). & $r 7$ \\
\hline تُقَبل & $1 \cdots$ & 1 & . & . & 19 & أن يكون المحتوى المعزز مناسبًا للمتدربين المستهوفين. & rV \\
\hline وتُُعْلَل & $97 . \leqslant 9$ & .970 & 1 & r & 17 & أن أن يتميز المحتوى المعزز بالبساطة والدقة و التناسق & $r \wedge$ \\
\hline تُقُبل & $1 \cdots$ & 1 & . & . & 19 & أن ير اعى تحقيق التوازن بين عناصر المحتوى & rq \\
\hline تُقُبل & $1 \cdots$ & 1 & . & . & 19 & أن يتجنب المحتوى المعزز كترة الاز التفاصيل بالوسائط & r. \\
\hline وتُعْلَل & $97 . \leqslant 9$ & .970 & - & $r$ & iv & أندرييية المر اد تعلمها. المعزز مناسبًا لطبيعة المهمات & M \\
\hline تُقُبل & $1 \cdots$ & 1 & . & . & 19 & أنش يتلائم تصميلم المحتوى المعزية & Tr \\
\hline & $97 . \leqslant 9$ & .970 & . & $r$ & IV & عيار الثالث: جودة الرسوم المتحركة فى المحتوى & \\
\hline وتُعُعدل & $97 . \leqslant 9$ & $\because .970$ & . & $r$ & IV & وأن يكون الرسم المتحرك و واضح وبسيط مع مر اعاة النسبة & r \\
\hline تُقُبل & $1 \cdots$ & 1 & • & . & 19 & 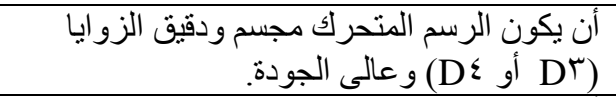 & Tร \\
\hline تُقُبل & $1 \ldots$ & 1 & - & · & 19 & أنتخدمج مع الرسم المتحرك تعليق صوتى بدلا من & ro \\
\hline
\end{tabular}




\begin{tabular}{|c|c|c|c|c|c|c|c|}
\hline \multirow{2}{*}{ ملاحظات } & \multirow{2}{*}{ 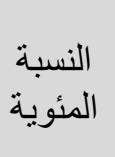 } & \multirow{2}{*}{ 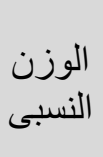 } & \multicolumn{3}{|c|}{ الأهمبــــة } & \multirow{2}{*}{ 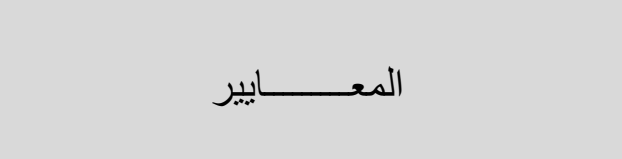 } & \multirow[b]{2}{*}{ r } \\
\hline & & & 转衣 & 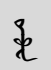 & de & & \\
\hline 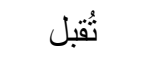 & $1 \cdots$ & 1 & • & $\cdot$ & 19 & أن يتز امن سر عة الرسم المتحرك مع التعليق الصوتى. & ד \\
\hline تُقُبل & $1 \cdots$ & 1 & . & $\cdot$ & 19 & و أن يحقق المبالغة في استخدام الرسو الردف التدريبي فقط. & re \\
\hline وتُعبل & 94.91 & $\cdot 9 \mu$. & 1 & r & 17 & أن يتحكم المندرب في اعادة تشغيل الرسم المتحرك. & rᄉ \\
\hline وتُعْبل & $91 . r \mathrm{r}$ & $\cdot .91 r$ & r & 1 & 17 & تخزينية قلبلة. & rq \\
\hline تُقبل & $1 \cdots$ & 1 & $\cdot$ & $\cdot$ & 19 & أن يتتاسب الرسم المتحرك الفئة المستهدفة من التدريب. & $\varepsilon$. \\
\hline \multirow[t]{2}{*}{ و تُنُعدل } & 91. Yo $^{\circ}$ & $\cdot .9 \wedge r$ & • & 1 & 11 & 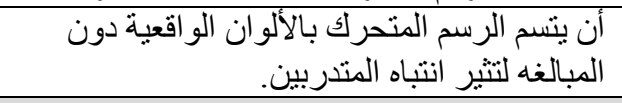 & «) \\
\hline & $1 \cdots$ & 1 & · & $\cdot$ & 19 & \multicolumn{2}{|l|}{ المعيار الرابع : جودة الفيديو فى المحتوى المعزز: } \\
\hline 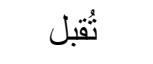 & $1 \cdots$ & 1 & • & $\cdot$ & 19 & أن يتتاسب استخدام الفيديو الأهداف والمحتوى التدرييى. & $\varepsilon r$ \\
\hline 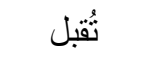 & $1 \cdots$ & 1 & • & $\cdot$ & 19 & أن ير اعى التز امن بين الصوت و الصورة في الفيديو. & $\varepsilon r$ \\
\hline تُقُبل & $1 \cdots$ & 1 & • & $\cdot$ & 19 & 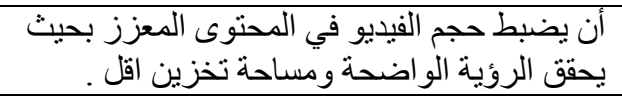 & $\varepsilon \varepsilon$ \\
\hline 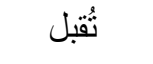 & $1 \cdots$ & 1 & · & $\cdot$ & 19 & أن ير اعى دقة الألوان في عرض ملفات الفيديو . & $\leqslant 0$ \\
\hline 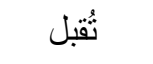 & $1 \cdots$ & 1 & • & $\cdot$ & 19 & أن ير اعى المساحة التخزينية لملفات الفيديو . & $\leqslant 7$ \\
\hline وَتُعدل & $9 \wedge . Y_{0}$ & $\cdot 9 \wedge r$ & • & 1 & 11 & خلال شريط اللتحكم الفيديو. في عرض الفيديو من & $\varepsilon V$ \\
\hline وتُُْبَل & $9 \wedge . r_{0}$ & $\cdot .9 \wedge r$ & • & 1 & 11 & أن يستخدم السر عة الطبيعية في عرض لقطات الفيديو. & $\varepsilon \wedge$ \\
\hline و تُعُعَل & $91 . \mathrm{ro}_{0}$ & $\cdot .9 \wedge r$ & • & 1 & 11 & 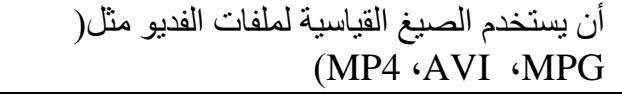 & $\varepsilon 9$ \\
\hline وتُعْلِل & $97 . \leqslant 9$ & .970 & • & r & iv & أن يتم تحميل بر امج تشغيل ملفات الفيديو ذاتيا & 0. \\
\hline \multirow[t]{2}{*}{ تُقُبل } & $1 \cdots$ & 1 & • & $\cdot$ & 19 & أن ير اعى إمكانية العرض أكثر من مرة لملف فيديو معين . & 01 \\
\hline & $9 \wedge . Y_{0}$ & $.9 \wedge r$ & · & 1 & 11 & \multicolumn{2}{|l|}{ المعيار الخامس: جودة النصوص فى المحتوى المعزز: } \\
\hline تُقبل & $1 \cdots$ & 1 & • & $\cdot$ & 19 & أن بستخدم نمط واحد لخط المحتوى التدريبى المعزز. & or \\
\hline تُقُبل & $1 \cdots$ & 1 & $\cdot$ & $\cdot$ & 19 & أن يستخدم نمطو احد لعناوين المحتوى التنريبى المعزز. & or \\
\hline تُقُبل & $1 \cdots$ & 1 & - & . & 19 & أنت يتناسب حجم الخط المستخدم مع أهمية المحتوى & $0 \leqslant$ \\
\hline وتُقُقدل & $97 . \leqslant 9$ & .970 & 1 & . & 11 & أن بستخبة للصور المتحركة داكنة و وعريضة الفيديوهات. في الكتابة & 00 \\
\hline تُعدل & 91.10 & $\cdot .9 \wedge r$ & $\cdot$ & 1 & 11 & أن يستخدم أساليب تميز النص داخل المحتوى & 07 \\
\hline
\end{tabular}




\begin{tabular}{|c|c|c|c|c|c|c|c|}
\hline \multirow{2}{*}{ ملاحظات } & \multirow{2}{*}{ المئوية - النة } & \multirow{2}{*}{ 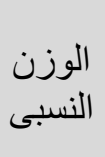 } & \multicolumn{3}{|c|}{ الأهميــــة } & \multirow{2}{*}{ 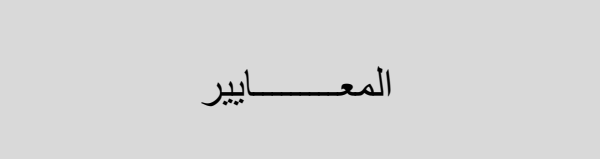 } & \multirow[b]{2}{*}{5} \\
\hline & & & 电: & $\notin$ & $\notin d$ & & \\
\hline و وتُقبل & & & & & & ال المعزز. & \\
\hline وتُعُعدل & $q \wedge . \varphi_{0}$ & $\cdot .9 \wedge r$ & - & 1 & 11 & أن يكون المسافات بين السطور و الفقر ات المكتوبة (مفرد). & or \\
\hline 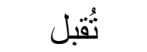 & $1 \cdots$ & 1 & . & . & 19 & أن يميز نقاط الإبحار و الوصلات داخل النص المعزز. & o^ \\
\hline \multirow[t]{2}{*}{ وتُعُعدل } & $97 . \leqslant 9$ & .970 & . & r & IV & أن يستخدم الحركة مع النص لجذب الانتباه. & 09 \\
\hline & $\Sigma V . r v$ & $\cdot . \leqslant \vee \leqslant$ & $1 \leq$ & r & r & أن يعبر المعنى بأقل عدد من الكلمات. & 7. \\
\hline و تُقُعبل & 94.91 & $\cdot .9 \mu \cdot$ & 1 & r & 17 & أن يستخدم رموز (Symbols ،Icons) لتدل على المعنى. & 71 \\
\hline وتُعبل & 94.91 & $\cdot .9 \mu \cdot$ & 1 & r & 17 & أن يحتوى شاثشة المحتوى المعزز على قدر أقل من النصوص & Tr \\
\hline تُحذف & $07.1 \varepsilon$ & .071 & 1. & 0 & $\varepsilon$ & المعيار السادس : المساعدة و التوجيه: & \\
\hline تُحذف & $0 \leqslant .49$ & $\because 0 \leqslant \leqslant$ & 1. & 7 & r & 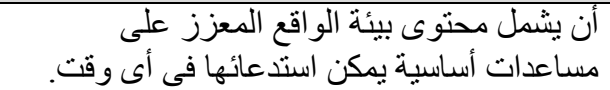 & זיד \\
\hline تُحذف & $07.1 \leq$ & .071 & 1. & 0 & $\varepsilon$ & أن يحتوى المحتوى المكى التدريبي على النير فليل يوضية التدريب & $T \varepsilon$ \\
\hline تُحذف & OY.T & $\because 0 Y 7$ & 11 & 0 & $r$ & 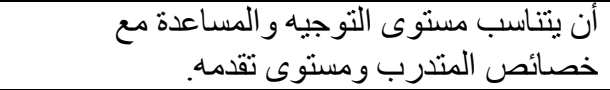 & 70 \\
\hline تُحذف & 09.70 & $\because .097$ & 9 & 0 & 0 & 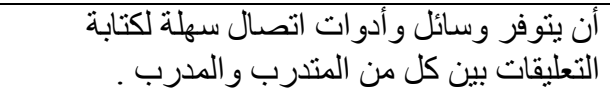 & 77 \\
\hline تُحذف & or.tr & $\because .0 Y 7$ & 11 & 0 & $r$ & 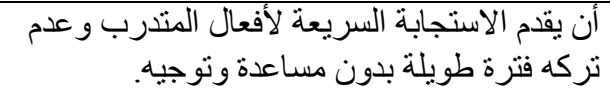 & $T V$ \\
\hline \multirow[t]{2}{*}{ تُحذف } & ०V.^9 & $.0 \vee 9$ & 11 & r & 7 & أن يحصل المتدرب على التوجيه و المساعدة من & 71 \\
\hline & $1 \cdots$ & 1 & - & . & 19 & المعيار السابع : القابلية للاستخدام: & \\
\hline 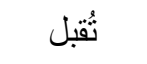 & $1 \cdots$ & 1 & • & . & 19 & أن يعرض محتوى بيئة الو اقع المعزز بشكل سهل وو اضح. & 79 \\
\hline 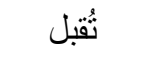 & $1 \cdots$ & 1 & - & . & 19 & أن يُحمل بيئة الو اقع المعزز فى وقت قصير. & $v$. \\
\hline وتُتُعدل & $9 \wedge . Y_{0}$ & $\cdot .9 \wedge$ & - & 1 & 11 & داخل يُنفذ الأنشطة التدريبية المختلفة بسهولة ويسر & V) \\
\hline و تُُعْلِ & $9 \leq . \vee \leq$ & $\cdot .9 \leq V$ & 1 & 1 & IV & 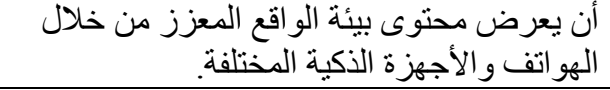 & $V Y$ \\
\hline وتُُْْبل & $97 . \leqslant 9$ & .970 & - & r & IV & أن لا يظهر نو افذ أو رسائل مزعجة غير مطلوبة. & $V r$ \\
\hline تُحذف & or.tr & $.0 Y 7$ & ir & r & $\varepsilon$ & أن يكون محتوى بيئة الو اقع المعزز جذابًا ومثيرًا للانتباه. & $\vee \varepsilon$ \\
\hline و ت تُقُعبل & $9 \varepsilon . \vee \varepsilon$ & $\cdot .9 \leq V$ & - & r & 17 & 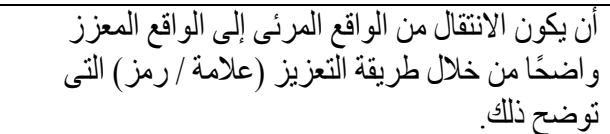 & vo \\
\hline
\end{tabular}




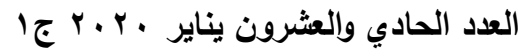

المجلة العلمية لكلية التربية النوعية

\begin{tabular}{|c|c|c|c|c|c|c|c|}
\hline \multirow{2}{*}{ ملاحظات } & \multirow{2}{*}{ 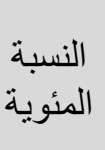 } & \multirow{2}{*}{ 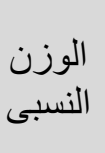 } & \multicolumn{3}{|c|}{ الأهمبـــــة } & \multirow{2}{*}{ 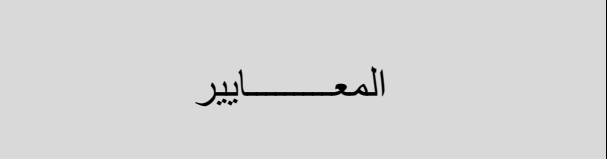 } & \multirow[b]{2}{*}{ s } \\
\hline & & & 里: & $\$$ & de & & \\
\hline تُقبل & $1 \cdots$ & 1 & • & $\cdot$ & 19 & 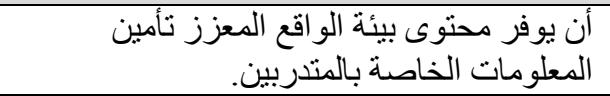 & $\vee 7$ \\
\hline \multirow[t]{2}{*}{ تُقُبل } & $1 \ldots$ & 1 & • & . & 19 & وأن يتم الوصول محاولات عديدة. محتوى الو اقع المعزز بسر عة & $\checkmark V$ \\
\hline & $9 \varepsilon . \vee \leqslant$ & $\cdot 9 \leqslant V$ & - & r & 17 & \multicolumn{2}{|l|}{ متوسط نسبة اتفاق السادة المحكمين على المجال الثانى } \\
\hline
\end{tabular}

يتضح من الجدول السابق أن النسبة المئوية لاتفاق المحكمين حول أهمية كل مؤثر

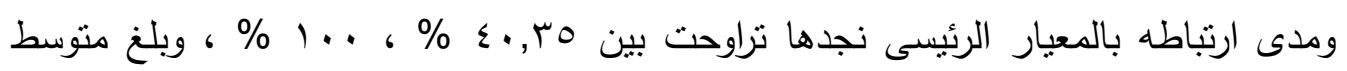

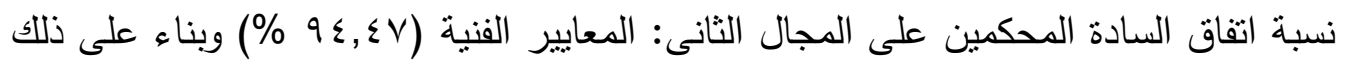
تم استبعاد مجموعة من المؤشرات التى تقل نسبة اتفاق السادة المحكمين عليها عن ، م \% ، ونلاحظ ايضاً بانه تم استبعاد معيار كاملاً بمؤشراته (المساعده والتوجيه) حيث بلغت نسبة الاتفاق عليه ـ ا, اه \% ونظرا لعدم ارتباطه بالناحية الفنية لتصميم المحتوى التدريبي ببيئة الواقع المعزز، وتم اجراء التعديلات اللازمة على قائمة المجال الثانى: المعايير الفنية لتصميم وانتاج المحتوى التدريبي ببيئة الواقع المعزز •

المرحلة السابعة: قائمة المعاييز النهائية:

في ضوء الإجراءات السابقة، تكونت قائمة المعايير في صورتها النهائية، حيث شملت

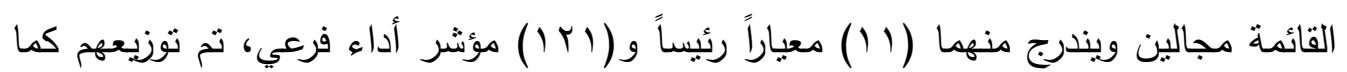

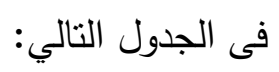

جدول (ع) قائمة المعايير التربوية والفنية لتصميم وإنتاج المحتوى التدربي ببيئة الواقع المعزز

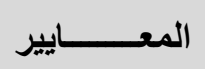

r

المجال الأول : المعايير التربوية لانتاج المحتوى التدريبي ببيئة الواقع المعزز

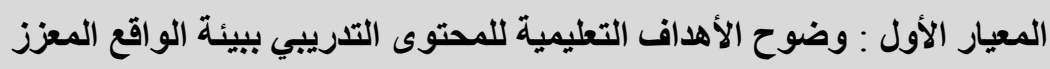

|

أن يتناسب الأهداف التدريبية طبيعة التدريب. r م أن تُصساغ الأهداف صياغة سلوكية صحيحة ودقيقة . ع أن تُعرض الأهداف التدريبية بشكل متسلسل وو اضح. 


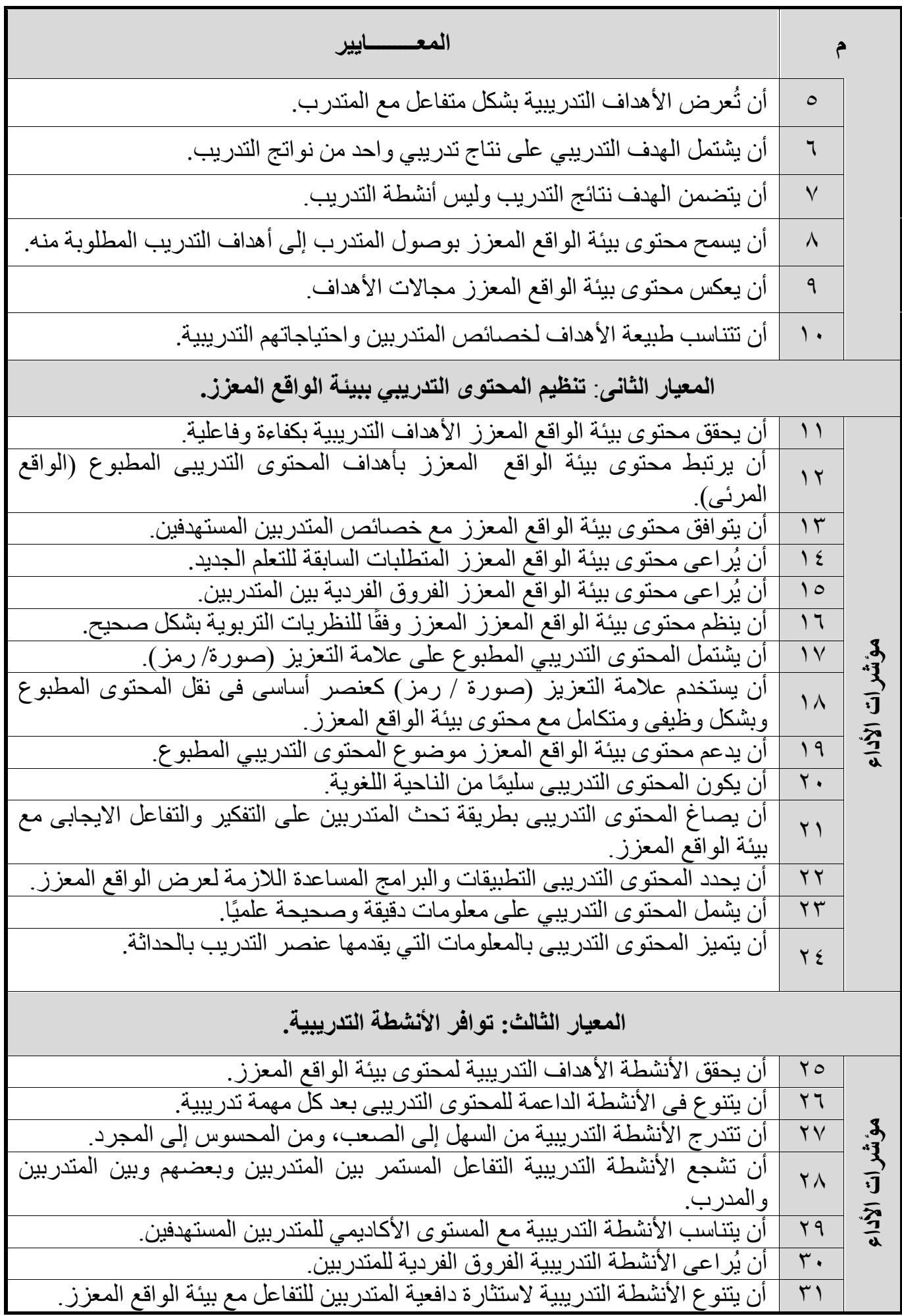




\section{المعــــــير}

أن يتضمن محتوى بيئة الو اقع المعزز على أنشطة علاجية و إثرائية.

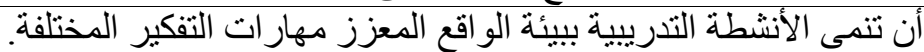

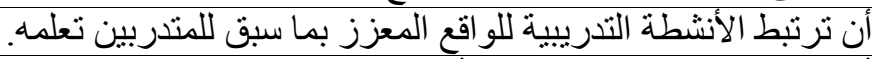

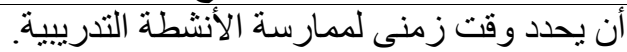

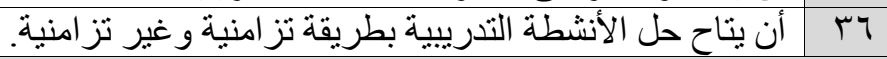

\section{المعيار الرابع: اثارة الدافعية.}

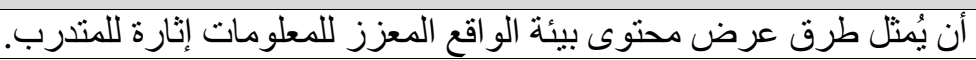

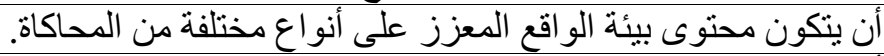

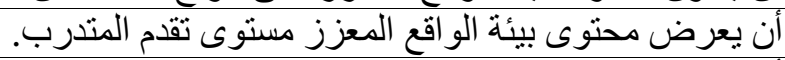

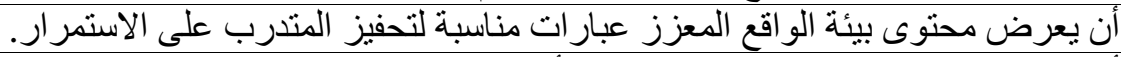

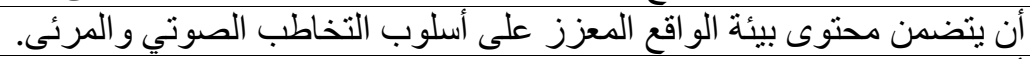

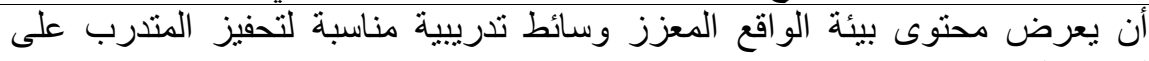

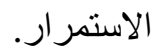

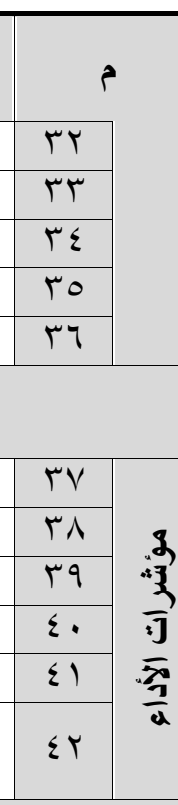

\section{المعيار الخامس : التغذية الراجعة.}

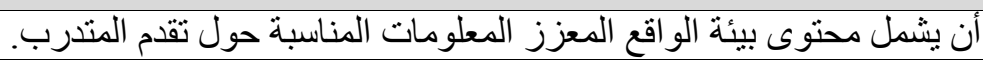

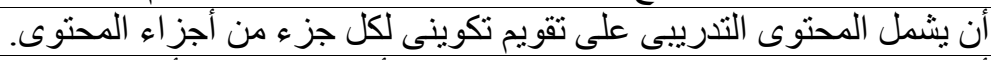

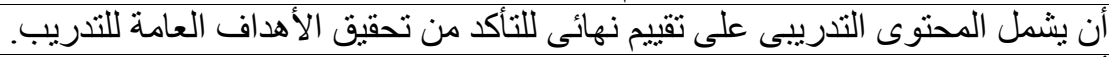

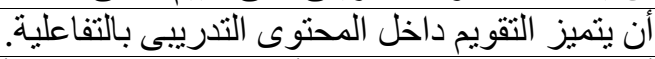

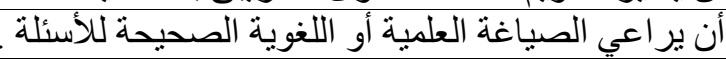

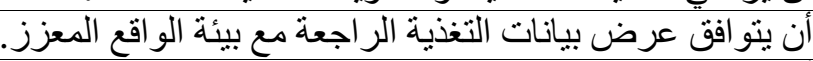

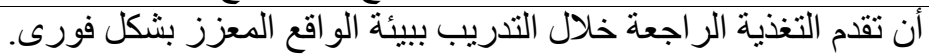

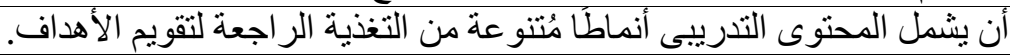

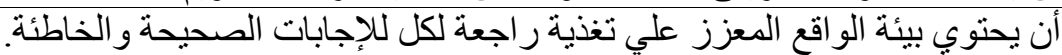

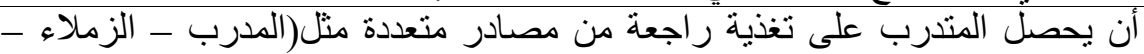

المجال الثانى : المعايير الفنية لتصميم وانتاج المحتوى التدريبي بييئة الواقع المعزز.

\section{المعيار الأول: تصميم المحتوى المطبوع (الواقع المرئى).}

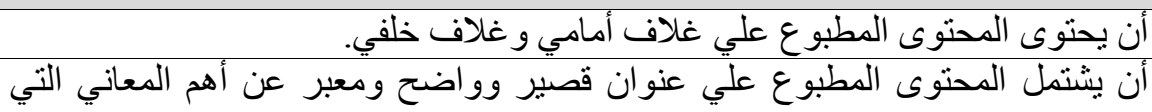
أن يكون الغلاف مناسبًا للفئة المستهدفة من التندريب. أن يشتمل المحتوى المطبو ع علي صفحه للعنو النوان. أن تثمل صفحة عنو ان المحتوى المطبوع علئو البيانات الوصفية مثل المؤلف و النانشر وتاريخ 


\section{المعــــــير}

أن يشتمل المحتوى المطبوع على قائمة محتويات للعناوين الرئيسية و الفرعية. أن بتضمن المحتوى المطبوع علي صفحة التعليمات توضح كيفية استخدام المحتوى.

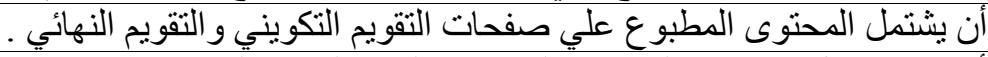

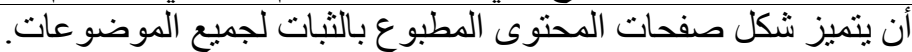

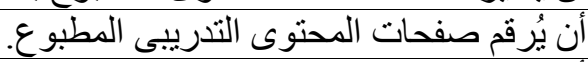

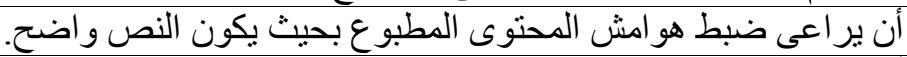

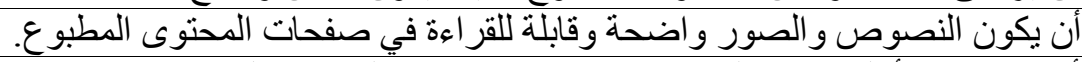

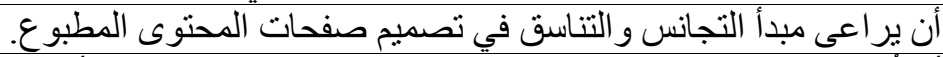

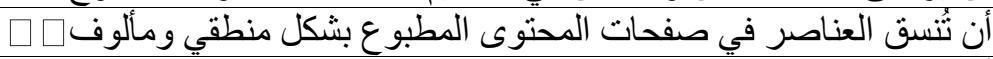

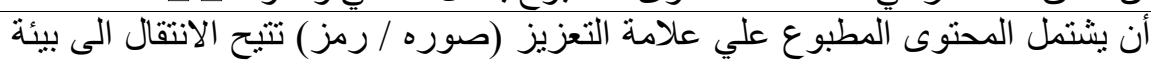
الواقع المعزز.

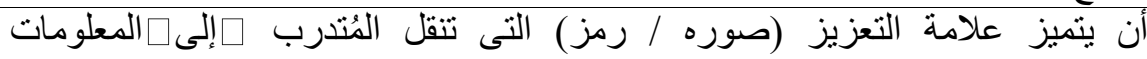

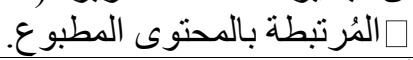

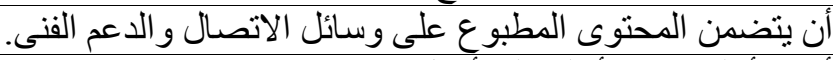

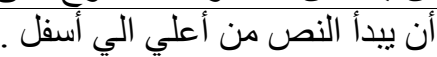
أن يبدأ النص من اليمين الي اليسار في حالة اللغة العربية والعكس في الأجنبية.

\section{المعيار الثانى: تصميم المحتوى المعزز (الواقع المعزز).}

أن يشتمل المحتوى المعزز على وسائط متعددة مرتبطة بأهداف التدريب.

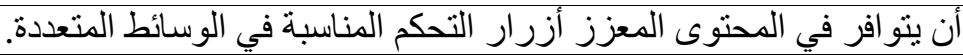

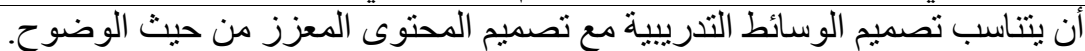
19

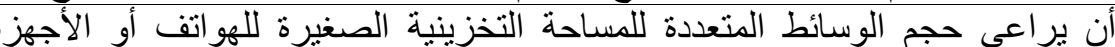

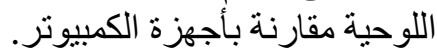

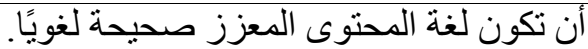

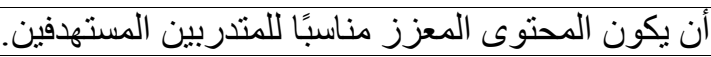

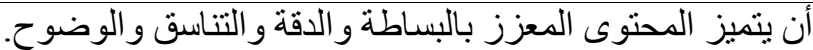

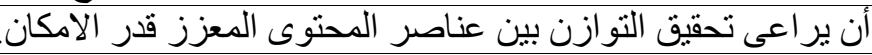

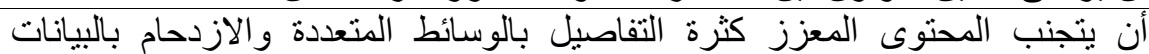
و المعلومات.

أن يكون المحتوى المعزز مناسبًا لطبيعة مهام التدريب المر اد تعلمها.

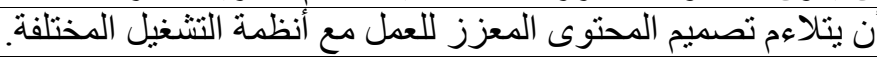
r. YI rr r

المعيار الثالث: جودة الرسوم المتحركة فى المحتوى المعزز.

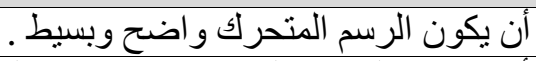

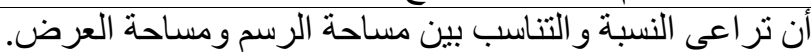

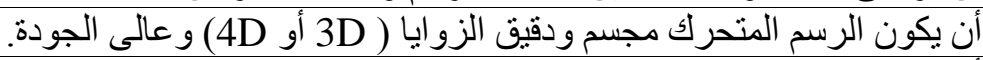

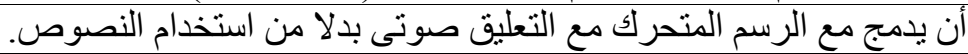

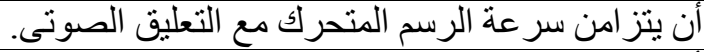

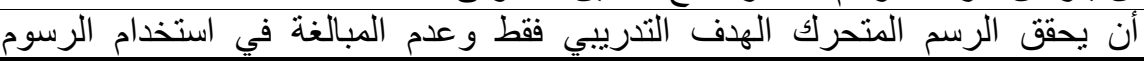

\begin{tabular}{|c|c|}
\hline 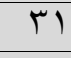 & \\
\hline rT & \\
\hline אד & \\
\hline$\Gamma \varepsilon$ & \\
\hline ro & \\
\hline צr & \\
\hline
\end{tabular}




\begin{tabular}{|c|c|c|}
\hline المعـــــــيير & $\hat{\imath}$ & \\
\hline \multicolumn{3}{|l|}{ 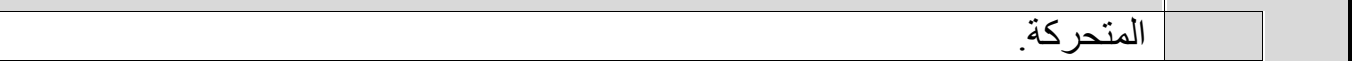 } \\
\hline أن يتحكم المتدرب في اعادة نشغيل الرسم المتحرك. & re & \\
\hline أن يكون الرسم المتحرك و اضحًا. & rᄉ & \\
\hline أن يكون الرسم المتحرك ذا مساحة تخزينية قليلة. & rq & \\
\hline أن يتناسب الرسم المتحرك الفئة المستهدفة من التدريب. & $\varepsilon$ & \\
\hline أن بتسم الرسم المتحرك بالألو ان الو اقعية دون المبالغه لتثير انتباه المتدربين. & $\leqslant 1$ & \\
\hline \multicolumn{3}{|l|}{ المعيار الرابع: جودة الفيديو فى المحتوى المعزز. } \\
\hline أن يعكس الفيديو الأهداف و المحتوى التدريبى. & $\sum r$ & \multirow{10}{*}{$\frac{3}{3}$} \\
\hline أن ير اعى التز امن بين الصوت و الصورة في الفيديو. & $\varepsilon r$ & \\
\hline تخزين أنبط . تجم الفيديو في المحتوى المعزز بحيث يحقق الرؤية الواضحة ومساحة & $\varepsilon \varepsilon$ & \\
\hline أن ير اعى دقة الألو ان في عرض ملفات الفيديو. & $\leqslant 0$ & \\
\hline أن ير اعى المساحة التخزينية لملفات الفيديو. & $\leqslant 7$ & \\
\hline أن يتاح للمتدرب التحكم في عرض الفيديو من خلال شريط تحكم الفيديو. & $\varepsilon V$ & \\
\hline أن بستخدم السر عة الطبيعية في عرض لقطات الفيديو. & $\varepsilon \wedge$ & \\
\hline أن يستخدم الصيغ القياسية لملفات الفديو مثل(MP4 ، AVI ، MPG) & $\leqslant 9$ & \\
\hline أن يتم تحميل بر امج نشغيل ملفات الفيديو ذاتيا. & 0. & \\
\hline أن ير اعى إمكانية العرض أكثر من مرة لملف فيديو معين. & 01 & \\
\hline \multicolumn{3}{|l|}{ المعيار الخامس: جودة النصوص فى المحتوى المعزز. } \\
\hline أن يستخدم نمط واحد لخط المحتوى التدريبى المعزز. & or & \multirow{10}{*}{$\frac{3}{\sqrt[3]{3}}$} \\
\hline أن بستخدم نمط واحد لعناوين المحتوى التدريبى المعزز. & or & \\
\hline أن يتتاسب حجم الخط المستخدم مع أهمية المحتوى التدريبى المعزز. & os & \\
\hline أن يستخدم خطوط داكنة وعريضة في الكتابة المصاحبة للصور المتحركة أو & 00 & \\
\hline أن يستخدم أساليب تميز النص داخل المحتوى المعزز. & 07 & \\
\hline أن يكون المسافات بين السطور و الفقر ات المكتوبة (مفرد). & ov & \\
\hline أن يميز نقاط الإبحار و الوصلات داخل النص المعزز. & $0 \wedge$ & \\
\hline أن يستخدم الحركة مع النص لجذب الانتباه. & 09 & \\
\hline أن يستخدم رموز (Icons, Symbols) لتدل على المعنى. & 7. & \\
\hline أن يحتوى شاشة المحتوى المعزز على قدر أقل من النصوص . & 71 & \\
\hline \multicolumn{3}{|l|}{ المعيار السادس: القابلية للاستخدام. } \\
\hline أن يعرض محتوى بيئة الواقع المعزز بشكل سهل وو اضح. & $7 r$ & \multirow{4}{*}{$\frac{3}{\sqrt[3]{3}} \frac{\overline{7}}{4}$} \\
\hline أن تُحمل بيئة الو اقع المعزز فى وقت قصير. & $7 \pi$ & \\
\hline أبن تُنف الأنشطة التدريبية المختلفة بسهولة ويسر داخل محتوى بيئة الو اقع المعزز. & $7 \leq$ & \\
\hline أن يعرض محتوى بيئة الو اقع المعزز من خلال الهواتف بأنماطها المختلفة أوالأجهزة & 70 & \\
\hline
\end{tabular}




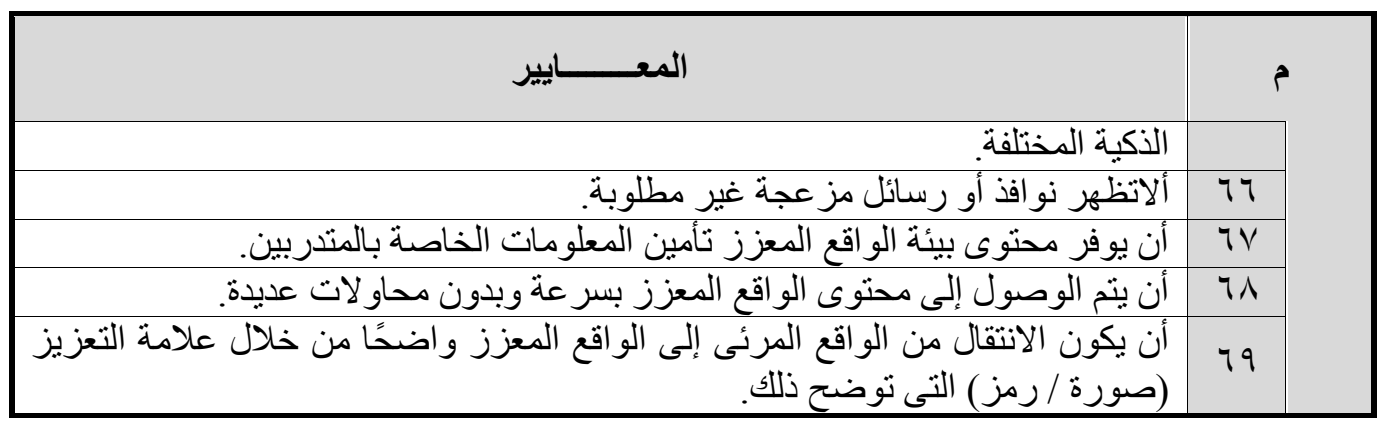

تمثلت نتائج البحث الحالي في بناء قائمة معايير تتكون من (1) (1) معيار رئيسيًا

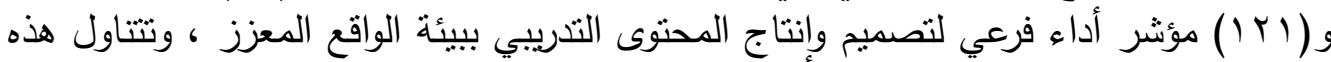

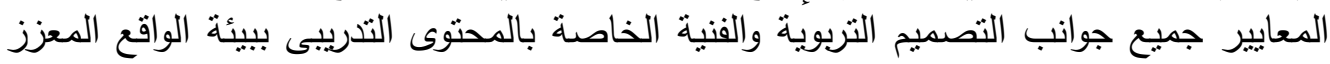

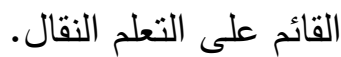
وبذلك قد قام الباحثون بالإجابة على سؤال البحث: ما المعايير التربوية والفنية لتصميم

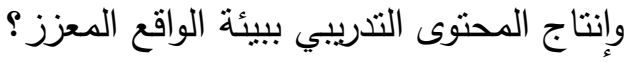

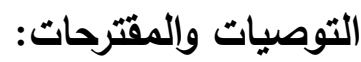

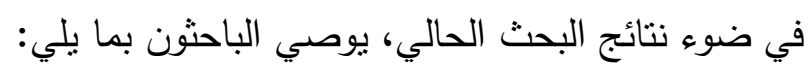

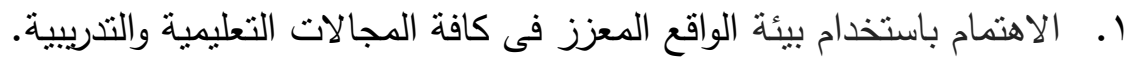

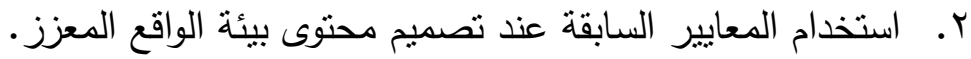

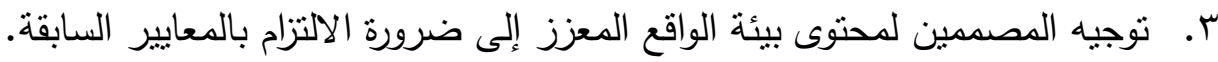

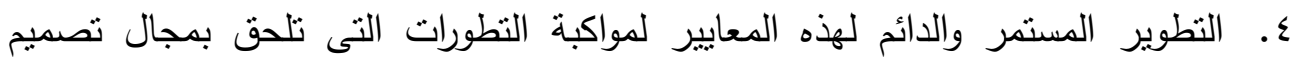
وانتاج بيئة الواقع المعزز التعليمي.

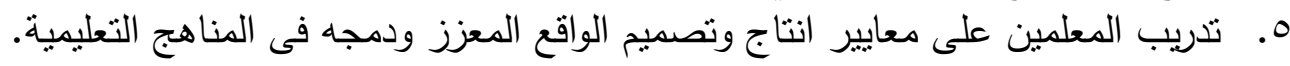

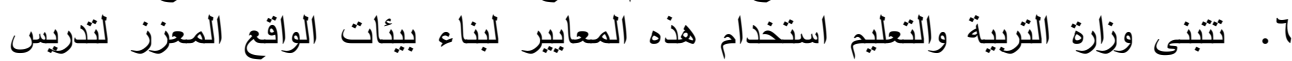

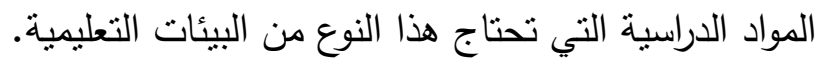

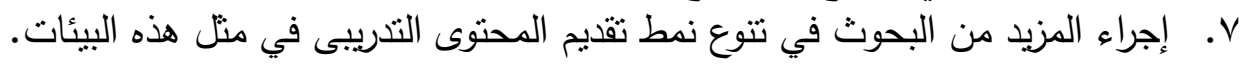




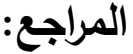

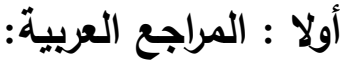

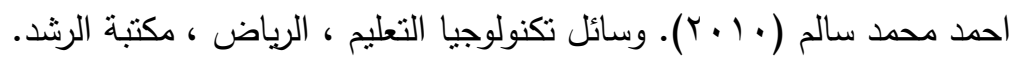
توفيق مرعي، محمد محمود الحيلة (Y . . ץ) طرائق التدريس العامة، القاهرة : دار ميسرة.

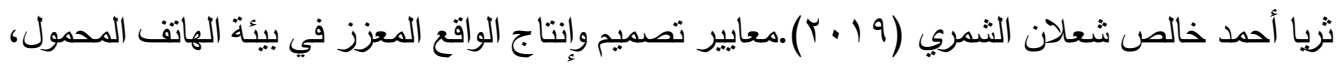

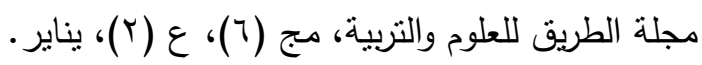

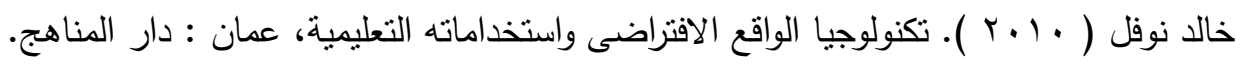

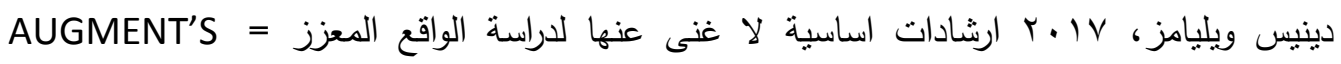
REALITY ESSENTIAL GUIDE TO AUGMENTED

$$
\text { القاهرة : دار الفكر العربى. }
$$

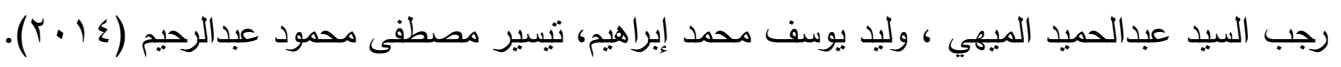
التفاعل بين نمط عرض الرسومات ثلاثية الأبعاد وأسلوب التحكم فيها في برامج التبد الكمبيوتر

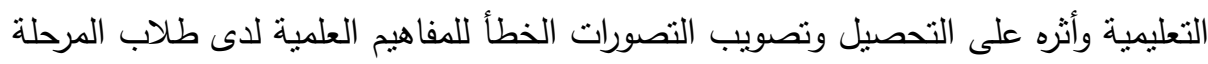

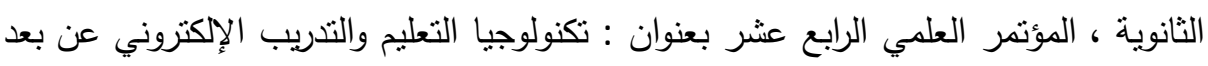

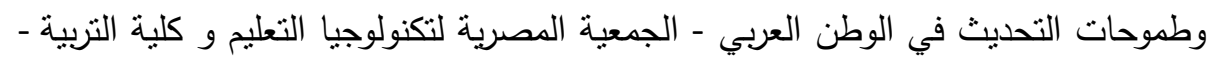

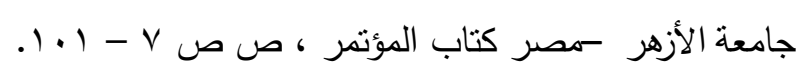

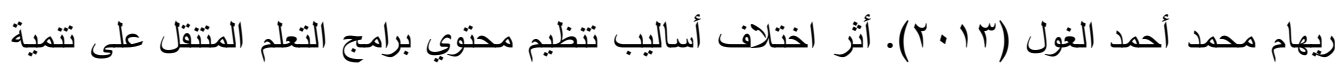

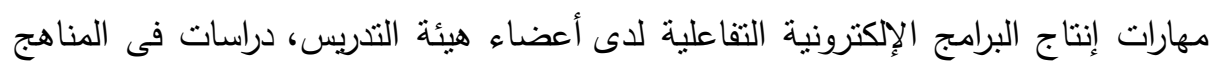

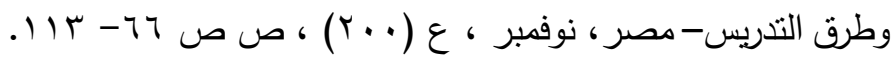

$$
\begin{aligned}
& \text { زاهر أحمد محمد (1997) (197) تكنولوجيا التعليم، القاهرة : المكتبة الأكاديمية. }
\end{aligned}
$$

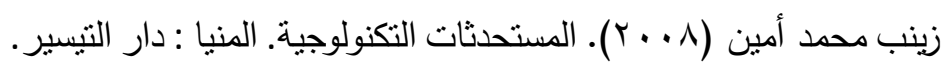

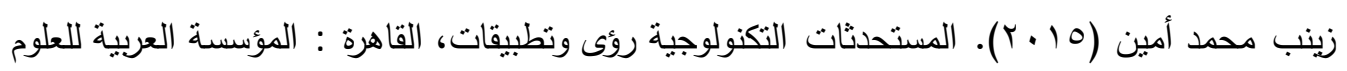
والثقافة.

سوزان محمد الثحات (ع ( ب ץ). نموذج مقترح لتوظيف التعلم المتتقل في المواقف التعليمية وفعاليته علي

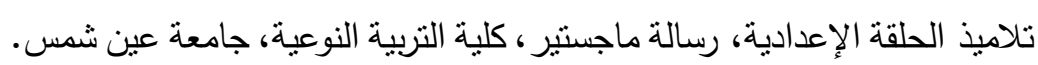

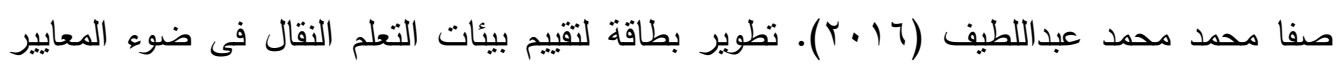

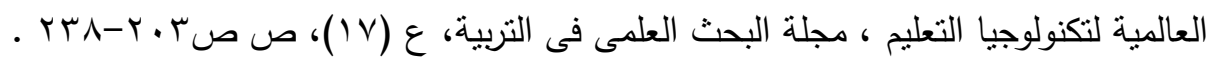

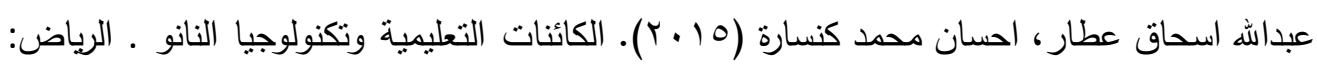
مكتبة الملك فهد الوطنية. 
غادة عبد العاطى على (9 ( • (Y).معايير تصميم بيئات التعلم النقال القائمة على الواقع المعزز ، مجلة دراسات وبحوث التربية النوعية، المؤتمر العلىى الثالث( الدولى الثانى )الدراسات النوعية فى

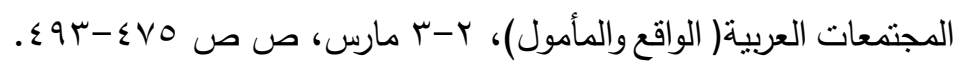

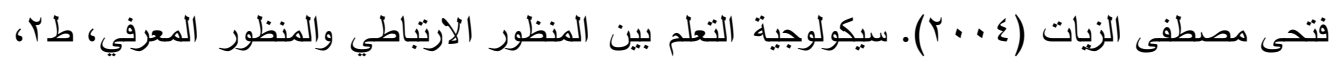

$$
\text { القاهرة : دار النشرللجامعات. }
$$

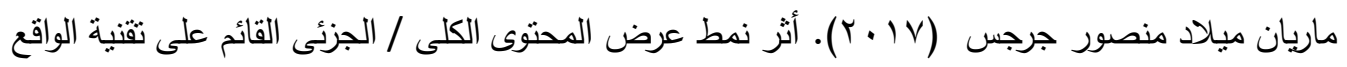
المعزز على تتمية التتظيم الذاتى وكفاءة التعلم لدى طلاب الصف الأول الإعدادى، تكنولوجيا

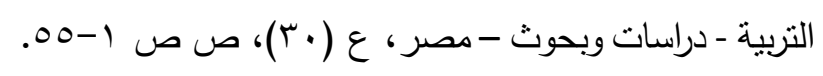

محمد عطية خميس (ץ. . Y). عمليات تكنولوجيا التعليم .القاهرة: دار الكلمة.

محمد عطية خميس (V. . . . . الكمبيوتز التعليميى وتكنولوجيا الوسائط المتعددة، طا، القاهرة ، دار

$$
\text { سحاب }
$$

محمد عطية خميس (V. . . r). عمليات نشر المستحدثات التكنولوجية وتننيها وتتفيذها ، مجلة كلية

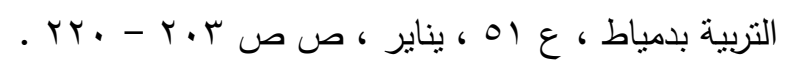

محمد عطية خميس (10 • r) ـ تكنولوجيا الواقع الافتراضي وتتكنولوجيا الواقع المعزز وتكنولوجيا الواقع المخلوط ، تكنولوجيا التعليم ، دراسات وبحوث محكمة ، مج هب ، ع ا

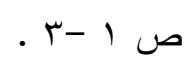

محمد عطية خميس (0 1 •r). مصادر التعلم الالكترونى، ج (1): الأفراد والوسائط، ط (، القاهرة ، دار

$$
\text { سحاب }
$$

محمد عطية خميس، فوزية أبا الخيل (ع . . ץ). معايير تصميم برامج الوسائل المتعددة التفاعلية لتلاميذ مدارس التربية الفكرية، مؤتمر المستحدثات التكنولوجية وتطوير التعليم فى الوطن العربى، كلية التربية، جامعة المنصور والجمعية المصرية لتكنولوجيا التعليم، من 9- ـ أمايو • مصطفى أبوالنور مصطفى سالم (YV (Y). أثز التفاعل بين أنماط التعلم داخل بيئة الواقع المعزز المعروض بواسطة الأجهزة الذكية : الحواسيب اللوحية والهواتف الذكية والأسلوب المعرفي، على التحصيل المعرفي لدي طلاب التربية الخاصة المعلمين بكلية التربية واتجاهاتهم نحو استخدام تقنيات التعلم الإكتروني لذوي الاحتياجات الخاصة، نكنولوجيا التربية - دراسات عربية فى

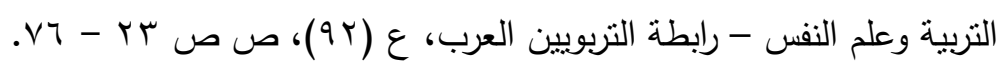

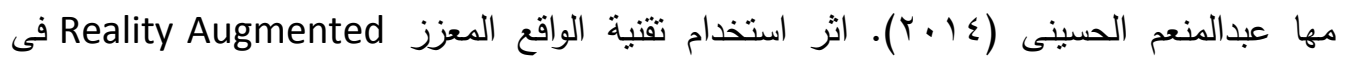
وحدة من مقرر الحاسب الآلي في تحصيل و اتجاه طالبات المرحلة الثانوية ، رسالة ماجستير ، جامعة أم القرى ، مكة المكرمة. 


\section{نبيل جاد عزمى، سهام عبدالحافظ مجاهد ، مروة حسن حامد (؟ ا •Y). بيئات التعلم الافتراضية · فى : نبيل جاد عزمى ( محرر)، بيئات التعلم التفاعلية ، القاهرة ، دار الفكر.

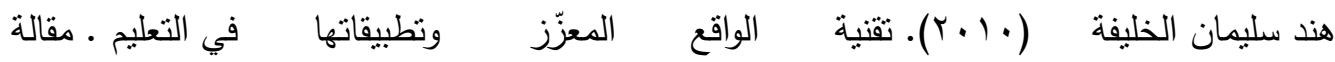

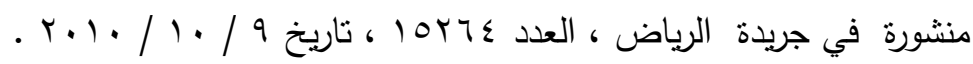 \\ وزارة التربية والتعليم المصرية (r . . ץ). المعايير القومية للتعليم، مطابع الأهرام، مج ( ()، ع (r). ثانيًا : المراجع الأجنبية: وانية}

Anderson, E. \& Liarokapis, F.(2014). Using augmented reality as medium to assist teaching in higher education. Coventry University, UK.

Botden, S. M., \& Jakimowicz, J, J.(2009). What is going on in Augmented reality simulation in laparoscopic surgery? Surgical endoscopy, 23 (8), 1693 - 1700.

Chiang, T.-H.-C., Yang, S.-J.-H., \& Hwang, G.-J. (2014). An Augmented Realitybased Mobile Learning System to Improve Students' Learning Achievements and Motivations in Natural Science Inquiry Activities. Educational Technology \& Society, 17 (4), 352-365.

Dabbagh, N. (2005). Pedagogical models for Elearning: A theory-based design framework. International Journal of Technology in Teaching and Learning, $1(1), 25-44$.

Dunleavy, M \& ‘.Dede, C. (2006). Augmented Reality Teaching and Learning.Augmented reality, USA: Harvard Education Press.

El Sayed. M. Neven. ( 2011),Applying Augmented Reality Technique in the Field of Education, ACM Digital Library, LAP Lambert Academic Publishing : Germany Retrieved on 211312016, from: http://dl.acm.org/citation.cfm?id=2161849.

Fatma, B.(2007). Guidelines for Developing Adaptive Mobile Learning. Conference IMCL., Amman, Jordan, 18 -20.

Fraih, E. (2009). design And Implementation Of Mobile Learning Content Model, A Thesis Presented to the Faculty Of Information Systems and Technology, Middle East University, Oman, for Graduate Studies in Partial Fulfillment of the Requirements for the Master Degree.

Glockner, H., Jannek, K., Mahn, J., \& Theis, B. (2014). Augmented Reality in Logistics. Online: http://www. dhl. com/content/dam/dow nloads/g0/about_us/logistics_insights/csi_augmented_reality_report_290414. pdf .

Hou, L., Wang, X., Bernold, L., \& Love, P. (2013).Using Animated Augmented Reality to Cognitively Guide Assembly, Journal of Computing in Civil Engineering Vol. 27, No. 5, pp. 439-451. 
Ivanova, M., \& Ivanov ,G. ( 2011). Enhancement of Learning and Teaching in Computer Graphics Through Marker Augmented Reality Technology,International Journal on New Computer Architectures and Their Applications , (IJNCAA), Vol.1 No. 1, pp. 176-184.

Larsen, Y. C., Buchholz, H., Brosda, C., \& Bogner, F. X. (2011). Evaluation of a portable and interactive augmented reality learning system by teachers and students. open classroom conference Augmented Reality in Education, Ellinogermaniki Agogi, Athens, Greece 2011, 47-56.

Lee, K. (2012). Augmented Reality in education and training, Tech Trends: Linking Research \& Practice to Improve Learning, Vol. 56, No. 2, pp. 13-21.

Patkar, R. S., Singh, S. P., \& Birje, S. V. (2013). Marker based augmented reality using Android os. International Journal, 3(5), 46-69.

Vincent, T. \& Others (2013). Classifying handheld augmented reality, Three categories linked by spatial happings. Retrieved 12-6-2016, 3pm, from: http://goo.gl/6YKEXA

Wang, S. (2014). Making the Invisible Visible in Science Museums through Augmented Reality Devices, Unpublished Thesis, University of Pennsylvania.

Wang, X. (2012). Augmented Reality: A new way of augmented learning. eLearn Magazine, (10), 1.

Yang, J. C., Chen, C. H., \& Jeng, M. C.(2010). Integrating video - capture virtual reality technology into a physically interactive learning environment for English learning. Computers \& Education. 55(3), pp. 1346-1356.

Yen, J. C., Tsai, C. H., \& Wu, M. (2013). Augmented reality in the higher education: Students' science concept learning and academic achievement in astronomy. Procedia-social and behavioral sciences, 103, 165-173.

Yuen, S., Yaoyune, G., \& Johnson, E. (2011), Augmented reality: An overview and five directions for AR in education. Journal of Educational Technology Development and Exchange, Vol. 4, No. 1, pp. 119-140. 